\title{
Chip-Based Sensing of the Intercellular Transfer of Cell Surface Proteins: Regulation by the Metabolic State
}

\author{
Günter A. Müller 1,2,3,* , Matthias H. Tschöp ${ }^{2,4,5}$ and Timo D. Müller 1,2 (D) \\ 1 Institute for Diabetes and Obesity, Helmholtz Diabetes Center at Helmholtz Zentrum München, German \\ Research Center for Environmental Health, Ingolstädter Landstraße 1, 85764 Oberschleissheim, Germany; \\ timo.mueller@helmholtz-muenchen.de \\ 2 German Center for Diabetes Research, 85764 Oberschleissheim, Germany; \\ matthias.tschoep@helmholtz-muenchen.de \\ 3 Department Biology I, Genetics, Ludwig-Maximilians-Universität München, \\ 82152 Planegg-Martinsried, Germany \\ 4 Division of Metabolic Diseases, Department of Medicine, Technische Universität München, \\ 81675 München, Germany \\ 5 Helmholtz Zentrum München, German Research Center for Environmental Health, \\ 85764 Oberschleissheim, Germany \\ * Correspondence: guenter.mueller@helmholtz-muenchen.de
}

Citation: Müller, G.A.; Tschöp, M.H.; Müller, T.D. Chip-Based Sensing of the Intercellular Transfer of Cell Surface Proteins: Regulation by the Metabolic State. Biomedicines 2021, 9 , 1452. https://doi.org/10.3390/ biomedicines 9101452

Academic Editor: Dariusz Zakrzewicz

Received: 2 September 2021

Accepted: 7 October 2021

Published: 13 October 2021

Publisher's Note: MDPI stays neutral with regard to jurisdictional claims in published maps and institutional affiliations.

Copyright: (c) 2021 by the authors. Licensee MDPI, Basel, Switzerland. This article is an open access article distributed under the terms and conditions of the Creative Commons Attribution (CC BY) license (https:/ / creativecommons.org/licenses/by/ $4.0 /)$.
Abstract: Glycosylphosphatidylinositol (GPI)-anchored proteins (GPI-APs) are anchored at the surface of mammalian blood and tissue cells through a carboxy-terminal GPI glycolipid. Eventually, they are released into incubation medium in vitro and blood in vivo and subsequently inserted into neighboring cells, potentially leading to inappropriate surface expression or lysis. To obtain first insight into the potential (patho)physiological relevance of intercellular GPI-AP transfer and its biochemical characterization, a cell-free chip- and microfluidic channel-based sensing system was introduced. For this, rat or human adipocyte or erythrocyte plasma membranes (PM) were covalently captured by the $\mathrm{TiO}_{2}$ chip surface operating as the acceptor PM. To measure transfer between PM, donor erythrocyte or adipocyte PM were injected into the channels of a flow chamber, incubated, and washed out, and the type and amount of proteins which had been transferred to acceptor PM evaluated with specific antibodies. Antibody binding was detected as phase shift of horizontal surface acoustic waves propagating over the chip surface. Time- and temperaturedependent transfer, which did not rely on fusion of donor and acceptor PM, was detected for GPI-APs, but not typical transmembrane proteins. Transfer of GPI-APs was found to be prevented by $\alpha$-toxin, which binds to the glycan core of GPI anchors, and serum proteins in concentration-dependent fashion. Blockade of transfer, which was restored by synthetic phosphoinositolglycans mimicking the glycan core of GPI anchors, led to accumulation in the chip channels of full-length GPI-APs in association with phospholipids and cholesterol in non-membrane structures. Strikingly, efficacy of transfer between adipocytes and erythrocytes was determined by the metabolic state (genotype and feeding state) of the rats, which were used as source for the PM and sera, with upregulation in obese and diabetic rats and counterbalance by serum proteins. The novel chip-based sensing system for GPI-AP transfer may be useful for the prediction and stratification of metabolic diseases as well as elucidation of the putative role of intercellular transfer of cell surface proteins, such as GPI-APs, in (patho)physiological mechanisms.

Keywords: cell-free chip-based assay; cell surface protein expression; glycosylphosphatidylinositol (GPI)-anchored proteins (GPI-APs); GPI-specific phospholipase D (GPLD1); insulin resistance; protein transfer

\section{Introduction}

The expression of a specific set of cell surface proteins contributes to separation as well as exchange of substances and information between neighboring cells and between 
cells and surrounding milieu. Thereby, it plays tremendous roles in a multitude of cell biological processes, such as cell growth, differentiation and development, tissue and organ morphogenesis, as well as responsiveness of cells and tissues towards hormonal and environmental cues. In general, the tissue- and time-specific exposure of surface proteins is under cell-endogenous control and based on differential gene expression. The possibility of exogenous control, i.e., acquisition of cell surface proteins produced in contacting cells within the same tissue depot or in distinct cells of remote tissues or the blood compartment and transferred via the interstitial space or surrounding medium (e.g., body fluids, blood), respectively, has attracted less attention so far. The fusion of microvesicles budding from plasma membranes (PM) of donor cells [1-3] or of exosomes secreted from donor cells [4-6] and harboring a specific subset of membrane proteins with the PM of acceptor cells has been regarded as the typical molecular mechanism for the intercellular transfer of cell surface proteins.

Glycosylphosphatidylinositol-anchored proteins (GPI-APs) represent a specific class of cell surface proteins, which lack proteinaceous transmembrane domains and in humans encompass about 150 members ([7], Uniprot database). They are constituted by a hydrophilic protein moiety of variable size (1.5-200 kDa) and a glycosylphosphatidylinositol (GPI) moiety [8-10]. This amphiphilic GPI moiety consists of phosphatidylinositol and the core glycan, which is conserved from yeast to man and modified by additional glycan side chains [11]. It becomes post-translationally coupled via a phosphoethanolamine bridge and an amide bond to the carboxy-terminus of the protein moiety and mediates anchorage of GPI-APs at the PM by insertion of their fatty acyl chains into the outer leaflet of the lipid bilayer $[12,13]$. Cell surface anchorage by GPI confers some unique features to the protein moiety. Of particular relevance is the possibility of intercellular transfer (i.e., from the PM of donor cells to the PM of acceptor cells), which relies on the presence of the full-length GPI anchor (i.e., including its diacylglycerol/phosphatidate moiety) and the resulting biophysical consequences.

In fact, considerably less tight binding to and the more facile extraction from supported phospholipid/cholesterol mono- and bilayers of GPI-APs compared to transmembrane proteins has been demonstrated recently by a multitude of biophysical studies [14-18]. Moreover, two independent groups demonstrated less stable residence at PM of fulllength GPI-APs compared to transmembrane proteins at a time point (more than 40 years ago) before the first identification of GPI anchors: Bouma and coworkers found that in course of incubation of cells and liposomes, certain membrane proteins, among them the GPI-AP acetylcholinesterase (AChE) are translocated from intact human erythrocytes to protein-free sealed liposomes in concert with the exchange of phospholipids, the original study object [19]. Medof and coworkers incubated purified human erythrocyte GPI-APs CD59 and CD55 or decay accelerating factor (DAF) in the detergent-solubilized state with sheep erythrocytes [20] and observed their tight association with erythrocyte membranes and in case of DAF maintenance of its biological activity [21]. These early findings have meanwhile been confirmed by other groups and extended to "empty" planar phospholipid bi- and monolayers and other cellular membranes [22-29]. In conclusion, full-length GPIAPs manage to translocate from detergent micelles into natural and artificial membranes and vice versa without loss of their biological function. In addition, more recent studies revealed (i) that a subset of full-length GPI-APs became released from the surface of rat adipocytes into incubation medium and into the blood of rats and humans in complex with (lyso)phosphatidylcholine and cholesterol in micelle-like structures [30,31] and (ii) that fulllength GPI-APs become translocated from micelle-like complexes into rat adipocytes [32]. Remarkably, the efficacy of both release and translocation was strictly dependent on the metabolic state and age of the rats and humans [30,32,33]. This was reflected best in the correlation between both the serum level of full-length GPI-APs and the efficacy of their translocation into adipocytes and the blood glucose/plasma insulin levels in diabetic rats and human patients. 
Importantly, step (i), the release of full-length GPI-APs with the complete GPI anchor retained from cellular donor membranes, has to be discriminated from the so-called shedding of GPI-APs which involves the proteolytic or lipolytic cleavage of their carboxyterminus or GPI anchor, respectively. The resulting removal of the complete anchor moiety or diacylglycerol/phosphatidate portions causes liberation of a truncated soluble version, i.e., of the protein moiety only or the protein moiety with the glycan attached, of the GPIAPs from the PM [11-13]. Furthermore, step (ii), the translocation of full-length GPI-APs into cellular acceptor membranes, has to be discriminated from their intercellular transfer, as analyzed in the present study, which involves the simultaneous presence of donor and acceptor PM. Consequently, release of GPI-APs is prerequisite for their subsequent translocation which in combination exert the overall process, the intercellular transfer of full-length GPI-APs from mammalian "donor" cells to "acceptor" cells at the same or distant tissue $\operatorname{depot}(\mathrm{s})$ involving a paracrine and endocrine route, respectively. By nature, intercellular transfer of GPI-APs is prevented by shedding.

However, so far investigations have not addressed the potential (patho)physiological relevance of intercellular GPI-AP transfer and the following related issues: (i) transfer mechanism (spontaneous vs. regulated), (ii) components involved (GPI-APs, phospholipids, catalysts), (iii) factors determining transfer efficacy at the molecular (viscoelasticity and stiffness of PM) and physiological level (cell type, disease state). The limited interest in and knowledge about intercellular transfer of cell surface proteins, in general, and GPI-APs, in particular, as a putative mode for controlling their cell surface expression in multicellular organisms, in particular in disease states, presumably rely on the experimental expenditure for its analysis both in vitro and in vivo.

Here, a cell-free system for sensing of GPI-AP transfer under defined conditions of the donor and acceptor PM, including the surrounding incubation medium, is presented: PM derived from rat and human adipocytes or erythrocytes as donors of full-length GPI-APs were injected into the microfluidic channels of sensor chips, to which PM from rat and human adipocytes or erythrocytes had been immobilized as acceptors. After incubation with serum or factors putatively controlling the transfer and removal of the donor PM by washing, transfer of GPI-APs to acceptor PM was monitored by consecutive injection of antibodies against typical adipocyte and erythrocyte PM proteins. Incremental mass loading onto the chip caused by transferred proteins and bound antibodies triggered stepwise right-ward phase shifts of horizontal surface acoustic waves (SAW) propagating across the chip surface. Strikingly, mass loading was detected for GPI-APs but not for transmembrane proteins.

Taking cells and serum samples from genetically and diet-induced obese and diabetic rats, it was found that (i) both the donor and the acceptor PM are critical for the upregulation of GPI-AP transfer provoked by metabolic derangement in the obese and diabetic state, (ii) serum proteins interfere with GPI-AP transfer with those from metabolically deranged rats displaying higher potency compared to normal rats and (iii) the transfer involves nonmembrane complexes of GPI-APs and lipids rather than membrane fusion. This sensing system may be useful for future delineation of the (patho)physiological roles of GPI-AP transfer as well as of the potential of GPI-AP transfer for the prediction and stratification of diseases. Together, the findings indicate that GPI-AP transfer may represent a mechanism for the extrinsic, i.e., not cell-autonomous, control of cell surface expression of proteins, and the coordination of the functional state of cells within the same or between different tissue depots. This (paracrine or endocrine) mechanism should be understood as transfer of biologically relevant matter, e.g., enzymes, binding proteins, rather than of information, e.g., signaling proteins, hormones, since the structure of the former but not of the latter is related to their function. 


\section{Materials and Methods}

\subsection{Materials}

Human adipose derived stem cells (hADSC) were delivered by iXCells Biotechnologies (San Diego, CA, USA, Cat. Nr. 10HU-001). Partially purified phosphatidylinositolspecific phospholipase C (PI-PLC) from Bacillus cereus (1 unit/mg protein) was obtained from Sigma-Aldrich Chemie GmbH (Munich, Germany). Recombinant (E. coli) human glycosylphosphatidylinositol-specific phospholipase D1 (GPLD1) (0.5 units/mg protein) was purchased from Creative BioMart Inc. (New York, NY, USA). Anti-hCD73 antibody (mouse monoclonal, prepared against CD73 purified from human placenta with no crossreactivity against mouse/rat CD73 [for sensing 1:1250; dot blotting 1:200]) was provided by Santa Cruz Biotechnology Inc., Heidelberg, Germany, (sc-32299). Anti-rCD73 antibody (rabbit polyclonal, affinity-purified, IgG isotype, prepared against recombinant full-size human CD73 with cross-reactivity against rat CD73 [for sensing 1:1500; for dot blotting 1:400]) was obtained from Genetex/Biozol (Eching, Germany). Antibodies against CD55 (ab231061, rabbit polyclonal, affinity-purified, IgG isotype, prepared against unconjugated His-tagged recombinant peptide corresponding to rat CD55 aa 254-372 and produced in E. coli [for sensing 1:2500] and ab253284, mouse monoclonal, protein G-purified from tissue culture supernatant, IgG2a, prepared against a recombinant fragment corresponding to the extracellular domain of human CD55 [for sensing 1:1000]), tissue-nonspecific alkaline phosphatase (TNAP) (ab95462, rabbit polyclonal, affinity-purified, IgG isotype, prepared against an unconjugated synthetic peptide corresponding to TNAP [for sensing 1:750; for dot blotting 1:250]), CD59 (ab248625, rabbit monoclonal, protein A-purified, IgG isotype, prepared against a synthetic peptide corresponding to human CD59 [for sensing 1:2500; for dot blotting 1:500], AChE (ab34533, goat polyclonal, multi-step purified, IgG isotype, biotinylated, prepared against purified AChE from bovine erythrocytes [for sensing 1:1500; for dot blotting 1:300]), annexin-V (ab54775, mouse monoclonal, tissue culture supernatant, IgG1, prepared against a recombinant full-length protein corresponding to human annexin- $\mathrm{V}$ aa 1-321 [for sensing 1:1800] and ab140068, rabbit polyclonal, immunogen affinity-purified, IgG, prepared against a recombinant protein corresponding to full-length annexin- $V$ [for sensing 1:2500; for dot blotting 1:500]), anti-insulin receptor $\alpha$-subunit (ab203037, rabbit polyclonal, protein A-purified, IgG, prepared against a synthetic peptide corresponding to human insulin receptor $\alpha$ aa $700-800$ conjugated to keyhole limpet haemocyanin [for sensing 1:500] and ab283717, rabbit monoclonal, protein A-purified, IgG, prepared against a recombinant fragment from the rat insulin receptor $\alpha$-subunit [for sensing 1:1500; for dot blotting 1:200]), Glycophorin-A (ab129024, rabbit monoclonal, protein A-purified, IgG, prepared against a synthetic peptide corresponding to a fragment of human glycophorin-A 100 aa distant from the carboxy-terminus [for sensing 1:750), Band-3 (ab108414, rabbit monoclonal, protein A-purified, IgG, prepared against a synthetic peptide corresponding to a fragment of rat Band-3 [for sensing 1:2000]), Glut4 (ab216661, rabbit polyclonal, protein A-purified, IgG, prepared against a synthetic peptide corresponding to aa 467-509 of mouse Glut4 [for sensing 1:2500; for dot blotting 1:500]), Glut1 (ab128033, rabbit polyclonal, immunogen affinity-purified, IgG, prepared against a synthetic peptide corresponding to aa 300-400 of mouse Glut1; ab14683, rabbit polyclonal, immunogen affinity-purified, IgG, prepared against a synthetic peptide corresponding to aa 481-492 of human Glut1 [for sensing 1:400; for dot blotting 1:150]), and Apo-AI (ab52945, rabbit monoclonal, protein A-purified, IgG, prepared against a synthetic peptide corresponding to aa 1-100 of human Apo-AI [for sensing 1:2000] and ab20453, rabbit polyclonal, immunogen affinity-purified, IgG, prepared against purified mouse Apo-AI from pooled mouse plasma high density lipoprotein [for sensing 1:2500]) were delivered by Abcam (Cambridge, UK). 1-ethyl-3-[3-dimethylaminopropyl]carbodiimide (EDC) and N-hydroxysulfosuccinimide (Sulfo-NHS, premium grade) were bought from Pierce/Thermo Scientific (Rockford, IL, USA). Protein A- and protein G-Sepharose (Cl4B) were from Calbiochem/Merck (Darmstadt, Germany). Polystyrene Bio-Beads SM-2 (20-50 mesh) were bought from Bio-Rad Laboratories (Munich, Germany). NSB Reducer 
was obtained from GE Healthcare. Ortho-phenanthroline (Pha) was delivered by Sigma (Deisenhofen, Germany). Human blood and serum samples derived from the control probands of a previously approved, performed, and published study [32]. Other materials (highest purity available) were obtained as described previously [30-33].

\subsection{Animal Handling}

Male Wistar rats (Crl:WI(WU)) were obtained from Charles River (Sulzfeld, Germany). Rats were housed two per cage in an environmentally controlled room with a 12:12-h light-dark circle (light on at 06:00) and ad libitum access to water and standard rat chow (17.7 kJ/g, Ssniff diet R/M-H, V1535 with 18\% (w/v) crude protein, $4.7 \%$ sugar, and 3.5\% crude fat) (Ssniff, Soest, Germany). The rats, including their metabolic characterization, were made available by Sanofi Pharma Deutschland GmbH (Frankfurt am Main, Germany). Blood and serum samples were collected as reported previously [33].

\subsection{Preparation of Rat Adipocytes from Epididymal Fat Pads}

Primary rat adipocytes were prepared from epididymal fat pads of male Wistar rats (140-160 g, fed ad libitum) as described previously [30]. Finally, portions were suspended in $2.5 \mathrm{~mL}$ of adipocyte buffer (20 mM Hepes/KOH, pH 7.4, $140 \mathrm{mM} \mathrm{NaCl}, 4.7 \mathrm{mM} \mathrm{KCl}$, $2.5 \mathrm{mM} \mathrm{CaCl}_{2}, 1.2 \mathrm{mM} \mathrm{MgSO}_{4}, 1.2 \mathrm{mM} \mathrm{KH}_{2} \mathrm{PO}_{4}, 2 \%$ [w/v] BSA, $100 \mu \mathrm{g} / \mathrm{mL}$ gentamycin, $1 \mathrm{mM}$ sodium pyruvate, $5.5 \mathrm{mM}$ glucose) at $3.5 \times 10^{6}$ cells $/ \mathrm{mL}$.

\subsection{Differentiation and Culture of Human Adipocytes}

Human adipose-derived stem cells (hADSCs) were isolated from lipoaspirate tissue from single normal donors collected during elective surgical liposuction procedures and cryopreserved at passage 1 (1.0 million cells/vial) by iXCells Inc., San Diego, CA, USA, Control hADSCs were demonstrated to be positive for CD29, CD44, CD73, CD90, and CD105 and to be negative for CD14, CD31, and CD45 and reported to differentiate into many different lineages including chondrogenic, osteogenic, neuronal, and adipogenic [34,35]. ADSCs were differentiated in vitro and further expanded for 3-4 passages as follows: The frozen cells were thawed by putting the vial in a $37^{\circ} \mathrm{C}$-water bath with gentle agitation for 1-2 min. The cells were transferred in a $15 \mathrm{~mL}$ conical tube with $5 \mathrm{~mL}$ of fresh ADSCs Growth Medium (iXCells Biotechnologies USA Inc., Cat. Nr. MD-0003) and then centrifuged $\left(220 \times g, 5 \mathrm{~min}, 25^{\circ} \mathrm{C}\right)$. After removal of the supernatant, the cells were resuspended in fresh ADSCs Growth Medium and then cultured in one T75 flask with medium change every $2-3$ days until the cells had reached $70-80 \%$ confluence. After removal of the medium, the cells were washed once with PBS ( $5 \mathrm{~mL}$ per flask). Following addition of $3-5 \mathrm{~mL}$ of $0.25 \%$ of trypsin-EDTA to the flask, the cells were incubated (5 min, $37^{\circ} \mathrm{C}$ ). Subsequent to neutralization of typsin-EDTA by adding 2-3 volumes of ADSCs Growth Medium, the cells were collected by centrifugation $\left(220 \times g, 5 \mathrm{~min}, 25^{\circ} \mathrm{C}\right)$ and then resuspended in the desired volume of medium. New culture flasks were seeded at $5 \times 10^{3}$ cells $/ \mathrm{cm}^{2}$ with medium change every 2-3 days until the cells had reached $70-80 \%$ confluence.

For adipocyte differentiation (12-well plate formate), hADSCs were grown in ADSCs Growth Medium to $>95 \%$ confluence. After gentle aspiration of the medium using a pipet and replacement with $1.5 \mathrm{~mL}$ of fresh medium/well (at very slow rate to avoid cell detachment), the cells were grown for 2-3 days. The medium was aspirated and $1.5 \mathrm{~mL}$ of Adipocytes Differentiation Medium (iXCells Biotechnologies USA Inc., Cat. Nr. MD0005) were added to the cells. The Adipocytes Differentiation Medium was changed every 3 days. The hADSC s were cultured in this medium for 10-14 days and then analyzed for the percentage of cells undergoing lipid droplet formation by Oil Red O-staining. Lipid droplets were observed in 7-10 days after adipogenic induction. hADSCs were regarded as differentiated human adipocytes when Oil Red-stained lipid droplets were detectable in more than $85 \%$ of the cells. After trypsinization, neutralization, and collection (see above), the human adipocytes were used for preparation of PM. 


\subsection{Preparation of Rat/Human Erythrocyte PM}

Stripped erythrocyte membrane ghosts, which were mainly constituted of PM vesicles, were prepared from rat or human blood (acid-citrate-dextrose) as described previously [36]. Briefly, after centrifugation of the blood (outdated bank blood) and aspiration of the plasma and buffy layer, the packed cells were resuspended in PBS and then filtered through a column with a $5 \mathrm{~cm}$ bed prepared by mixing equal amounts of microcrystalline cellulose and $\alpha$-cellulose for the removal of leukocytes and platelets. Thereafter, the erythrocytes were washed with PBS through the cellulose, then washed three times with ten volumes of PBS each, suspended in an equal volume of PBS and finally hemolysed, extracted, and washed by addition of ten volumes of $10 \mathrm{mM}$ Tris $/ \mathrm{HCl}$ ( $\mathrm{pH}$ 7.6), $1 \mathrm{mM}$ EGTA (TE). The suspension was centrifuged $\left(12,000 \times g, 5 \mathrm{~min}, 22^{\circ} \mathrm{C}\right)$. The pellet was resuspended in the same volume of TE. This washing cycle was repeated until complete elution of all hemoglobin (typically 4 times). The final pellet was suspended in $5 \mathrm{mM}$ sodium phosphate buffer (pH 7.4) at $0.2 \mathrm{mg}$ protein $/ \mathrm{mL}$ and stored at $-80^{\circ} \mathrm{C}$.

\subsection{Preparation of Rat Adipocyte PM}

PM were prepared from isolated rat adipocytes as described by Kiechle and coworkers [37], with minor modifications introduced previously [38]. Briefly, primary rat adipocytes $\left(5 \times 10^{7}\right.$ cells) were washed and immediately homogenized in $2 \mathrm{~mL}$ of lysis buffer $(25 \mathrm{mM}$ Tris/HCl, pH 7.4, 0.5 mM EDTA, 0.25 mM EGTA, and 0.25 M sucrose, supplemented with $10 \mu \mathrm{g} / \mathrm{mL}$ leupeptin, $2 \mu \mathrm{M}$ pepstatin, $10 \mu \mathrm{g} / \mathrm{mL}$ aprotinin, $5 \mu \mathrm{M}$ antipain, and $200 \mu \mathrm{M}$ PMSF) using a motor-driven Teflon-in-glass homogenizer (10 strokes with a loosely fitting pestle) at $22{ }^{\circ} \mathrm{C}$. The defatted postnuclear infranatant obtained after centrifugation $(1500 \times g, 5 \mathrm{~min})$ was centrifuged $(12,000 \times g, 15 \mathrm{~min})$. The resulting pellet containing PM and mitochondria was resuspended in $10 \mathrm{~mL}$ of lysis buffer by hand homogenization and then fractionated on a discontinuous $25 \mathrm{~mL}$ sucrose gradient of $0.8 \mathrm{M}, 1.06 \mathrm{M}$, and $2.02 \mathrm{M}$ sucrose in $10 \mathrm{mM}$ Mops/KOH (pH 7.4), $1 \mathrm{mM}$ EDTA supplemented with protease inhibitor cocktail (see above). The gradient was centrifuged ( $24,000 \mathrm{rpm}, 3 \mathrm{~h}, 4^{\circ} \mathrm{C}$, Beckman 25.1 rotor). The milky PM fraction at the interface between $0.8 \mathrm{M}$ and $1.06 \mathrm{M}$ sucrose was collected by suction and then diluted with 6 to 10 volumes of $10 \mathrm{mM}$ Mops/KOH (pH 7.5), 1 mM EDTA, and then centrifuged $\left(30,000 \times \mathrm{g}, 20 \mathrm{~min}, 4^{\circ} \mathrm{C}\right)$. The pellet was washed by suspending in $10 \mathrm{~mL}$ of lysis buffer by hand homogenization and again centrifuged. The pelleted PM were suspended in $10 \mathrm{mM}$ Mops/KOH (pH 7.4), $0.25 \mathrm{M}$ sucrose, $150 \mathrm{mM} \mathrm{NaCl}, 1 \mathrm{mM}$ EDTA at $0.2 \mathrm{mg}$ protein $/ \mathrm{mL}$, frozen in liquid $\mathrm{N}_{2}$, and stored until use at $-80^{\circ} \mathrm{C}$.

\subsection{Preparation of Human Adipocyte PM}

Washed human adipocytes $\left(5 \times 10^{7}\right.$ cells $)$ differentiated from hADSCs were centrifuged $\left(500 \times g, 5 \mathrm{~min}, 4^{\circ} \mathrm{C}\right)$. The pelleted cells were suspended in cold PBS, again centrifuged, and after complete removal of the supernatant resuspended in $1 \mathrm{~mL}$ of buffer A (Invent Biotechnologies Inc., Plymouth, UK; Minute ${ }^{\mathrm{TM}}$ Plasma Membrane Protein Isolation and Cell Fractionation Kit, Cat. Nr. SM-005). The adipocyte suspension was incubated (on ice, $10 \mathrm{~min}$ ), vortexed vigorously (45 s), and then transferred to the filter cartridge. The cartridge was closed and centrifuged $\left(16,000 \times g, 30 \mathrm{~s}, 4^{\circ} \mathrm{C}\right.$, Eppendorf $5415 \mathrm{C}$ table top microcentrifuge). The pelleted adipocyte ghosts (in the course of having lost their lipid droplets during the centrifugation/filtration procedures) in the collection tube were resuspended with buffer $\mathrm{A}$, then transferred to the same filter and centrifuged again (see above). The filter was discarded, and the adipocyte ghosts were resuspended in $0.5 \mathrm{~mL}$ of buffer A by vigorously vortexing $(10 \mathrm{~s})$. The adipocyte ghosts were centrifuged $(700 \times g$, $1 \mathrm{~min}, 4^{\circ} \mathrm{C}$ ). The supernatant was transferred to a fresh $1.5 \mathrm{~mL}$ microcentrifuge tube and then centrifuged $\left(16,000 \times \mathrm{g}, 30 \mathrm{~min}, 4^{\circ} \mathrm{C}\right)$. After removal of the supernatant, the total PM fraction (typically 300-500 $\mu$ g protein) was suspended in $250 \mu \mathrm{L}$ of buffer B (Invent Biotechnologies Inc., Eden Prairie, MN, USA) by repeatedly pipetting up and down and vortexing and then centrifuged $\left(7800 \times g, 10 \mathrm{~min}, 4^{\circ} \mathrm{C}\right)$. The supernatant was transferred to a fresh 2-mL microfuge tube and supplemented with $1.6 \mathrm{~mL}$ of ice-cold PBS. After vigorous 
mixing, the suspension was centrifuged $\left(16,000 \times g, 30 \mathrm{~min}, 4^{\circ} \mathrm{C}\right)$. After removal of the supernatant, the pelleted PM (typically 150-200 $\mu \mathrm{g}$ protein) were suspended in $1 \mathrm{~mL}$ of $10 \mathrm{mM}$ Mops/KOH (pH 7.5), $150 \mathrm{mM} \mathrm{NaCl}, 0.2 \mathrm{mM}$ EGTA containing protease inhibitor cocktail (see above), and stored in liquid $\mathrm{N}_{2}$ until use.

\subsection{Immobilization of PM at SAW Chip Surface by Ionic and Subsequent Covalent Capture}

For ionic capture, uncoated negatively charged and highly hydrophilic $\mathrm{TiO}_{2}$ chips were used. Immobilization of erythrocyte/adipocyte PM containing positively charged, negatively charged, or zwitterionic phospholipids or combinations thereof with high efficacy was performed in the presence of $2 \mathrm{mM} \mathrm{Ca}^{2+}$ in $10 \mathrm{mM}$ Hepes/NaOH (pH 7.5), $100 \mathrm{mM} \mathrm{NaCl}$ to enable salt bridges between the chip surface and the PM phospholipids [39]. $\mathrm{PM}\left(0.2 \mathrm{mg}\right.$ protein $/ \mathrm{mL}$ ) were injected at a flow rate of $25 \mu \mathrm{L} / \mathrm{min}$ for $4 \mathrm{~min}$ at $30{ }^{\circ} \mathrm{C}$. After termination of the flow for $20 \mathrm{~min}$ at $30^{\circ} \mathrm{C}$, the chip was washed with $10 \mathrm{mM}$ Hepes $/ \mathrm{NaOH}$ (pH 7.5), $100 \mathrm{mM} \mathrm{NaCl}$, and $2 \mathrm{mM}$ EGTA at a flow rate of $150 \mu \mathrm{L} / \mathrm{min}$ for $20 \mathrm{~min}$ at $30^{\circ} \mathrm{C}$.

The measured phase shift elicited by binding of adipocyte PM was found to be considerably higher for $\mathrm{TiO}_{2}-\mathrm{Ca}^{2+}$ compared to $\mathrm{Au}$ and $\mathrm{SiO}_{2}$ chip surfaces (data not shown). $\mathrm{Ca}^{2+}$ easily covers the $\mathrm{TiO}_{2}$ surface forming a complete interactive layer. Thus, the PM phospholipids can bind to many sites on the surface at high density. In fact, high amounts of PM were found to be bound to the $\mathrm{TiO}_{2}$ surface indicating that close to complete coverage had been achieved. In contrast, $\mathrm{Au}$ and $\mathrm{SiO}_{2}$ surfaces were only partially covered, presumably due to repulsive forces between the bound PM, while other parts of the chip surface remained free of phospholipids (thereby forming a "mosaic"; data not shown). In addition, the presence of $\mathrm{Ca}^{2+}$ during the injection may prevent the repulsion between individual PM vesicles and trigger their fusion. Thus, capture of $\mathrm{PM}$ by the $\mathrm{TiO}_{2}$ chip surface possibly led to their transformation into flat supported membrane bilayers.

For subsequent covalent capture via the protein moieties of GPI-APs as well as the extracellular protein domains of adipocyte and erythrocyte membrane proteins, which resists $\mathrm{Ca}^{2+}$-removal during assaying GPI-AP transfer, the microfluidic channels of uncoated chips were primed by three injections of $250 \mu \mathrm{L}$, each, of immobilization buffer at a flow rate of $50 \mu \mathrm{L} / \mathrm{min}$. Next, the chip surface was activated by a $250 \mu \mathrm{L}$ injection of $0.2 \mathrm{M}$ EDC and $0.05 \mathrm{M}$ Sulfo-NHS (mixed from $2 \times$ stock solutions right before injection) at a flow rate of $50 \mu \mathrm{L} / \mathrm{min}$. After a waiting period of $3 \mathrm{~min}$ (flow rate 0 ) and subsequent washing of the channels with two $300 \mu \mathrm{L}$ portions of PBS containing $0.5 \mathrm{mM}$ EGTA (PBSE) at a flow rate of $180 \mu \mathrm{L} / \mathrm{min}$, the residual activated groups on the chip surface were capped by injecting $200 \mu \mathrm{L}$ of $1 \mathrm{M}$ ethanolamine ( $\mathrm{pH} 8.5$ ) at a flow rate of $60 \mu \mathrm{L} / \mathrm{min}$. Thereafter, the chips were washed two times with $125 \mu \mathrm{L}$ of PBSE each at a flow rate of $150 \mu \mathrm{L} / \mathrm{min}$ and then two times with $160 \mu \mathrm{L}$ of $10 \mathrm{mM}$ Hepes $/ \mathrm{NaOH}(\mathrm{pH} 7.5)$ each at the same flow rate.

\subsection{Determination of Transfer of GPI-APs from Donor to Acceptor PM by SAW Sensing}

$400 \mu \mathrm{L}$ of rat or human adipocyte or erythrocyte donor PM $(0.2 \mathrm{mg}$ protein $/ \mathrm{mL})$ were injected (at 800-1200 s) at a flow rate of $60 \mu \mathrm{L} / \mathrm{min}$ into chips with rat or human erythrocyte or adipocyte acceptor PM consecutively immobilized by ionic and covalent capture. For initiation of transfer of GPI-APs from the donor PM presented in the chip microchannels as vesicles in solution to the acceptor $\mathrm{PM}$ immobilized at the chip $\mathrm{TiO}_{2}$ surface, the chips were incubated $\left(1 \mathrm{~h}\right.$, from 1200 to $4800 \mathrm{~s}, 37^{\circ} \mathrm{C}$ ) at flow rate 0 (double hatched lines) in the absence or presence of certain agents for putative interference with transfer as indicated. For removal of the donor PM and any soluble or complex-bound GPI-APs from the microchannels, the chips were washed two times with $150 \mu \mathrm{L}$ of PBSE each at a flow rate of $180 \mu \mathrm{L} / \mathrm{min}$ and then two times with $150 \mu \mathrm{L}$ of $10 \mathrm{mM}$ Hepes $/ \mathrm{NaOH}$, $150 \mathrm{mM} \mathrm{NaCl}$ (pH 7.5) (washing buffer) each at the same flow rate. Subsequently, for monitoring of the proteins transferred from the donor to the acceptor PM during the incubation, the protein composition of the captured acceptor PM was assayed by sequential injection of $75 \mu \mathrm{L}$ of antibody against appropriate GPI-APs and transmembrane proteins (diluted as indicated in the Materials section) at a flow rate of $15 \mu \mathrm{L} / \mathrm{min}$ according to the 
order indicated in the figures (green and black arrows with hatched lines for initiation and termination of fluid flow, respectively). Finally, for demonstration of the nature of the transferred GPI-APs and their incorporation into the phospholipid bilayer of the acceptor PM, $75 \mu \mathrm{L}$ of PI-PLC (Bacillus cereus, $5 \mathrm{ng}$ ) at a flow rate of $15 \mu \mathrm{L} / \mathrm{min}$ and then three portions of $220 \mu \mathrm{L}$ of $0.1 \%(w / v)$ Triton X-100, $10 \mathrm{mM}$ glycine $(\mathrm{pH} 12)$ at a flow rate of $200 \mu \mathrm{L} / \mathrm{min}$, respectively, were injected.

For elucidation of the nature and amount of the GPI-APs and transmembrane proteins which became transferred to the acceptor PM in course of injection of the donor PM into the chip and incubation, the chip-integrated homogenous sensor system was used. It relies on the propagation of horizontal SAW along the chip surface which is affected by binding of any entities to the chip. This may happen either directly and unspecifically or via specific interaction partners immobilized onto the chip with the aid of ionic or covalent capturing procedures. The resulting right-ward phase shift of the SAW represents a measure for the loaded mass (i.e., presence and amount) brought about by entities of the sample analytes. Thus, both the initial capture of the acceptor $\mathrm{PM}$ by the $\mathrm{TiO}_{2}$ surface and the subsequent transfer of proteins from the injected donor PM to the captured acceptor PM was monitored in real-time as increases in phase shift. For this, the difference $(\Delta)$ between the total phase shift provoked by all antibodies as a summation signal following injection of the last of the relevant antibodies and the phase shift left at the end of injection of PI-PLC (to correct for unspecific association of proteins, such as soluble GPI-APs or transmembrane proteins) was calculated as measure for the transfer of full-length GPI-APs for each donor-acceptor PM combination. The phase shift $\Delta$ is given upon correction for unspecific interaction (no acceptor PM) and normalization for varying capturing efficacy (of different chips for identical amounts of acceptor PM [32]).

\subsection{Digestion with PI-PLC}

For digestion of PM and proteins eluted from the chips according to ref. [40], $30 \mu \mathrm{L}$ of PM $(0.1 \mathrm{mg} / \mathrm{mL})$, and $150 \mu \mathrm{L}$ portions of eluate were supplemented with $50 \mu \mathrm{L}$ and $10 \mu \mathrm{L}$, respectively, of 4 -fold PIPLC buffer $(80 \mathrm{mM}$ Tris $/ \mathrm{HCl}$, pH 7.8, containing $0.4 \%(w / v)$ BSA, $600 \mathrm{mM} \mathrm{NaCl}, 2 \mathrm{mM}$ EDTA, $4 \mathrm{mM}$ DTT, and $0.4 \mathrm{mM}$ PMSF) and then incubated (30 min, $30^{\circ} \mathrm{C}$ ) with partially purified PI-PLC from Bacillus cereus $(0.25 \mathrm{mU}$ and $0.1 \mathrm{mU}$, respectively).

\subsection{Reconstitution of $A C h E$ and $C D 73$ Detergent Micelles}

bAChE and hCD73 prepared according to refs. [30,31] were lyophilized and then reconstituted into detergent micelles by suspending in $50 \mathrm{mM}$ Tris/ $\mathrm{HCl}(\mathrm{pH} 7.4), 150 \mathrm{mM}$ $\mathrm{NaCl}, 0.02 \%(w / v) \mathrm{NaN}_{3}$ containing $15 \mathrm{mM}$ octyl glucoside, and $0.1 \%(w / v) \mathrm{TX}-100$ at a final concentration of $10 \mu \mathrm{M}$, subsequent gentle vortexing, and final incubation $\left(20^{\circ} \mathrm{C}\right.$, $10 \mathrm{~min})$. bAChE and hCD73 detergent micelles were immediately used.

\subsection{Reconstitution of AChE/Band-3 and CD73/Glut4 Proteoliposomes}

Proteoliposomes constituted of lysoPC, PC, cholesterol and bAChE, or hCD73 were prepared by mixing of these components in the detergent-solubilized state and subsequent removal of the detergent by adsorption onto polystyrene Bio-Beads according to previously published protocols [41-43] with modifications. This caused the spontaneous reconstitution of the components into unilamellar proteoliposomes. In detail, lysoPC $(5 \mu \mathrm{mol})$, PC $(0.25 \mu \mathrm{mol})$, PS $(0.1 \mu \mathrm{mol})$, and cholesterol $(0.5 \mu \mathrm{mol})$ in chloroform $(10 \mathrm{mg} / \mathrm{mL}$ each $)$ were dispersed together into a glass test tube in a total volume of $1 \mathrm{~mL}$. After evaporation of the chloroform under a stream of $\mathrm{N}_{2}$ under atmospheric pressure, and then in a SpeedVac under high vacuum (60 min), the dried phospholipids (lipid films) were dispersed in $250 \mu \mathrm{L}$ HSA $(2 \mathrm{mg} / \mathrm{mL})$ and subsequently completely dissolved by gentle vortexing and incubation $\left(20^{\circ} \mathrm{C}, 30 \mathrm{~min}\right)$. The hydrated lipid dispersion was subjected to six freezing-thawing cycles $\left(-180^{\circ} \mathrm{C} /+25^{\circ} \mathrm{C}\right)$ and then passed 40 times through a polycarbonate membrane $(0.2 \mu \mathrm{m})$ of a mini-extruder (Avanti Polar Lipids Inc., Alabaster, AL, USA). Reconstitution 
of bAChE was initiated by addition of $750 \mu \mathrm{L}$ of $20 \mathrm{mM}$ octyl glucoside and incubation (15 min, $25^{\circ} \mathrm{C}$; just for destabilization of the lipid bilayer). Subsequently, $100 \mu \mathrm{L}$ of bAChE $(0.3 \mathrm{nmol}$, freshly prepared from the lyophilized materials) or hCD73 $(0.15 \mathrm{nmol})$ or $100 \mu \mathrm{L}$ of rat adipocyte PM (solubilized by $0.1 \%(w / v)$ TX-100 as source for Glut4) or $100 \mu \mathrm{L}$ of human erythrocyte PM (solubilized by $0.4 \%$ TX-100 as source for Band-3) were added to the mixture in a 1.5-mL microcentrifuge tube (Eppendorf Inc., Hamburg, Germany). Reconstitution was initiated by the addition of $50 \mathrm{mg}$ damp Bio-Beads SM-2 to the tube and rotation on a tube rotator $\left(20 \mathrm{rpm}, 90 \mathrm{~min}, 20^{\circ} \mathrm{C}\right)$. After addition of another $350 \mathrm{mg}$ (damp weight) of Bio-Beads and rotation (180 $\mathrm{min}$ ), the Bio-Beads were allowed to settle (5 min). The supernatant harboring $300 \mathrm{nM} \mathrm{bAChE}$ and $2.6 \mathrm{mM}$ lipids in HSA (molar ratio $=8700: 1$ ) was carefully removed. For recovery, 200- $\mu \mathrm{L}$ portions of the supernatant were centrifuged $\left(400,000 \times g, 1 \mathrm{~h}, 4^{\circ} \mathrm{C}\right.$; Beckman TL-100 ultracentrifuge, TLA-100 rotor, $95,000 \mathrm{rpm}$ ). The pellets containing the proteoliposomes with reconstituted bAChE, hCD73, Glut 4 or Band-3 were suspended in $100 \mu \mathrm{L}$ of HSA $(2 \mathrm{mg} / \mathrm{mL})$. The proteoliposomes were sequentially sized through 0.4 - and $0.2-\mu \mathrm{m}$ polycarbonate membranes to select for large unilamellar ones (100-200 nm). Control liposomes were prepared by reconstitution of the lipids together with anchor-less bAChE or hCD73 (prepared by treatment of the purified GPI-APs with PI-PLC and subsequent recovery of the lipolytically cleaved versions from the detergent-depleted phase upon TX-114 partitioning) at the same ratios and using the same procedures as above.

\subsection{TX-114 Partitioning}

The sample (max. vol. $50 \mu \mathrm{L}$ ) was diluted to $150 \mu \mathrm{L}$ with $10 \mathrm{mM}$ Tris $/ \mathrm{HCl}(\mathrm{pH} 7.4)$, $150 \mathrm{mM} \mathrm{NaCl}$, left on ice ( $5 \mathrm{~min}$ ), then added to $600 \mu \mathrm{L}$ of ice-cold $2.5 \% \mathrm{TX}-114$ (prepared by dissolving $37.5 \mathrm{~g}$ of TX-114 in $1 \mathrm{~L}$ of $10 \mathrm{mM}$ Tris/HCl, $\mathrm{pH} 7.5,150 \mathrm{mM} \mathrm{NaCl}$ on ice, precondensation at $37^{\circ} \mathrm{C}$, centrifugation, and use of the TX-114-enriched lower phase), mixed thoroughly and incubated $\left(37^{\circ} \mathrm{C}, 5 \mathrm{~min}\right)$ for induction of clouding according to ref. [44]. The detergent-enriched and depleted phases were separated by centrifugation $\left(15,000 \times g, 2 \mathrm{~min}, 25^{\circ} \mathrm{C}\right)$. The upper TX-114-depleted phase $(100 \mu \mathrm{L})$ was removed without any disturbance of the interface, transferred to a new tube, and supplemented with TX-114 to a final concentration of $2.0 \%(v / v)$ for a second cycle of partitioning. After mixing and sequential incubation $\left(0{ }^{\circ} \mathrm{C}, 5 \mathrm{~min} ; 30^{\circ} \mathrm{C}, 3 \mathrm{~min}\right)$, the solution was centrifuged $(3000 \times g$, $3 \mathrm{~min}$ ). Thereafter, $100 \mu \mathrm{L}$ of the supernatant were carefully transferred to a new tube avoiding any disturbance of the interface. This represented the final TX-114-depleted phase and was analyzed for the presence of the protein moieties of GPI-APs.

\subsection{Adsorption of Eluate Materials to $\alpha$-Toxin-Beads and Analysis by Dot Blotting}

$100 \mu \mathrm{L}$ of chip eluate were added to $50 \mu \mathrm{L}$ of PBS containing microspheres coupled to $\alpha$-toxin in a $1.5-\mathrm{mL}$ microcentrifuge tube. After vortexing, the mixtures were incubated $\left(30 \mathrm{~min}, 22{ }^{\circ} \mathrm{C}\right.$ ) under head-over rotation. Subsequently, the tubes were placed into a magnetic separator and separation was allowed to occur for 30 to $60 \mathrm{~s}$. The supernatants were removed and then the tube from the separator. The coupled microspheres were resuspended in $50 \mu \mathrm{L}$ of PBS/TBN by vortexing and sonication for $20 \mathrm{~s}$. The washing step with magnetic separation and resuspension was repeated three times with $100 \mu \mathrm{L}$ of PBS each. Thereafter, the beads were suspended in $50 \mu \mathrm{L}$ of PBS/TBN containing $2 \%(w / v)$ SDS, $20 \mathrm{mM}$ DTT, and then incubated $\left(95^{\circ} \mathrm{C}, 5 \mathrm{~min}\right)$. The microspheres were again subjected to magnetic separation. The supernatant was removed and then immediately used for dot blotting.

For this, $10 \mu \mathrm{L}$ portions (up to 8 replicates) of eluate, recombinant protein of interest (if available) and the corresponding primary antibodies were blotted onto PVDF membranes (Immuno-Blot PVDF Membrane, precut for minigels, Cat. Nr. 1620174; BIORAD, Munich, Germany). The membranes were incubated $\left(25^{\circ} \mathrm{C}, 2 \mathrm{~h}\right)$. Thereafter, the completely dry membranes were blocked with $5 \%(w / v)$ dry milk and $0.1 \%(w / v)$ BSA (fraction V, defatted) in $50 \mathrm{mM}$ Tris $/ \mathrm{HCl}(\mathrm{pH} 7.4), 0.5 \mathrm{M} \mathrm{NaCl}, 0.05 \%(w / v)$ Tween-20 (TTBS) by incubation 
$\left(25^{\circ} \mathrm{C}, 2 \mathrm{~h}\right)$. The blocking buffer was poured off and the membranes were kept wet for the remainder of the procedure. The membranes were incubated $\left(25^{\circ} \mathrm{C}, 1 \mathrm{~h}\right)$ with appropriate antibodies in TTBS (diluted as indicated in the Materials section). Following washing of the membranes three times for 10 min each with sufficient volume of TTBS on a rocking water bath $\left(25^{\circ} \mathrm{C}\right)$, the membranes were incubated $\left(25^{\circ} \mathrm{C}, 2 \mathrm{~h}\right)$ with secondary antibodies coupled to horseradish peroxidase in TTBS. Following washing of the membranes three times for 10 min each with sufficient volume of TTBS on a rocking water bath $\left(25^{\circ} \mathrm{C}\right)$, the membranes were developed with ECL chemiluminescent detection kit (GE Healthcare, Braunschweig, Germany) according to the instructions of the manufacturer. Chemiluminescence of the dotted spots was quantitatively evaluated by phosphorimaging (Storm 840, Molecular Devices Inc., San Jose, CA, USA).

\subsection{Statistical Analysis}

All numerical data were presented as means \pm standard deviations (SD). Statistical significance was calculated using GraphPad Prism6 software (version 6.0.2, GraphPad Software, San Diego, CA, USA) on the basis of either the two-tailed unpaired Student's t-test between two experimental groups or the one-way ANOVA performed with Tukey's post test for multiple comparisons. $p \leq 0.05$ was considered to be significant.

\subsection{Miscellaneous}

Blood and serum samples were collected according to published procedures [30]. Preparation of Band-3 protein, bAChE, and hCD73, as well as recHDL and their reconstitution into liposomes, hCD73-recHDL, bAChE-recHDL, and micelle-like GPI-AP complexes, respectively, were described previously [32]. Pretreatment of serum (proteinase K digestion, PEG6000 precipitation, heat inactivation) was performed as described previously [32]. Chemical synthesis of PIG41, protein determination, preparation of $\alpha$-toxin from the culture supernatant of Clostridium septicum and bAChE from bovine erythrocytes, coupling of $\alpha$-toxin to Sepharose beads using conventional EDC/NHS-based protocol, SAW sensing with long-chain 3D CM-dextran sam ${ }^{\circledR} 5$ chips using a samX instrument (SAW/Nanotemper, Bonn/Munich, Germany) (Supplementary File S1) and evaluation were performed as has been described in detail previously [30-33,45]. Before injection of serum samples into CM-dextran chips, 0.1 vol. of $10 \mathrm{mg} / \mathrm{mL}$ carboxymethyl dextran (sodium salt, $0.15 \mathrm{M} \mathrm{NaCl}$, $0.02 \%(w / v) \mathrm{NaN}_{3}$ (NSB Reducer) was injected in order to reduce non-specific binding of sample components to the chip surface, and total cholesterol was determined with a colorimetric assay kit (Abcam, ab282928, Cambridge, UK).

\section{Results}

3.1. Chip-Based SAW Sensing Monitors the Transfer of Full-Length GPI-APs from Donor to Acceptor PM at Various Combinations, which Does Not Involve Membrane Fusion

For set-up of an assay system reflecting the transfer of full-length GPI-APs between PM under defined conditions with regard to the type of the donor and acceptor cells, the incubation medium and any molecular entities affecting the transfer, a chip-based microfluidic sensor was established based on SAW. For this, the acceptor PM, derived either from primary rat adipocytes, human adipocytes differentiated from human adipose-derived stem cells (hADSC), or human erythrocytes, and harboring the GPI-APs acetylcholinesterase (AChE), tissue non-specific alkaline phosphatase (TNAP), 5'-nucleotidase (CD73), decay accelerating factor (CD55, DAF), and the complement membrane attack complex inhibitor (CD59), respectively, and in addition the transmembrane proteins, glucose transporter 4 and 1 (Glut4/1), insulin receptor (IR), Band-3, Glycophorin and Glut1, respectively in cell type-specific manner, were immobilized on the surface of $\mathrm{TiO}_{2}$ chips in course of a two-step capturing procedure (Figure 1a).

In the first step, acceptor PM (middle panel) were captured by negatively charged $\mathrm{TiO}_{2}$ chips in the presence of excess of $\mathrm{Ca}^{2+}$ through a combination of ionic (negatively-, and to a lower extent, positively charged phospholipids) and hydrophobic (zwitterionic 
phospholipids) interactions, yielding an almost complete coverage of the chip surface at high density and thereby increasing the efficacy of the subsequent covalent capture (right panel). In this second step, the acceptor PM were crosslinked to the activated $\mathrm{TiO}_{2}$ surface via the protein moieties of their constituent GPI-APs and transmembrane proteins using conventional EDC/NHS-based coupling chemistry with subsequent blocking of the reaction by ethanolamine. This resulted in chip channels with covalently captured and presumably enlarged and flattened PM vesicles (due to fusion in course of $\mathrm{Ca}^{2+}$-mediated absence of repulsive forces). Following removal of $\mathrm{Ca}^{2+}$ by EGTA and injection of $\mathrm{NaCl}$ to avoid fusion of the subsequently injected donor PM with the acceptor PM as well as their unspecific binding to the chip surface, respectively, the chips were ready for use as acceptor for GPI-APs in case of their putative transfer (right panel).

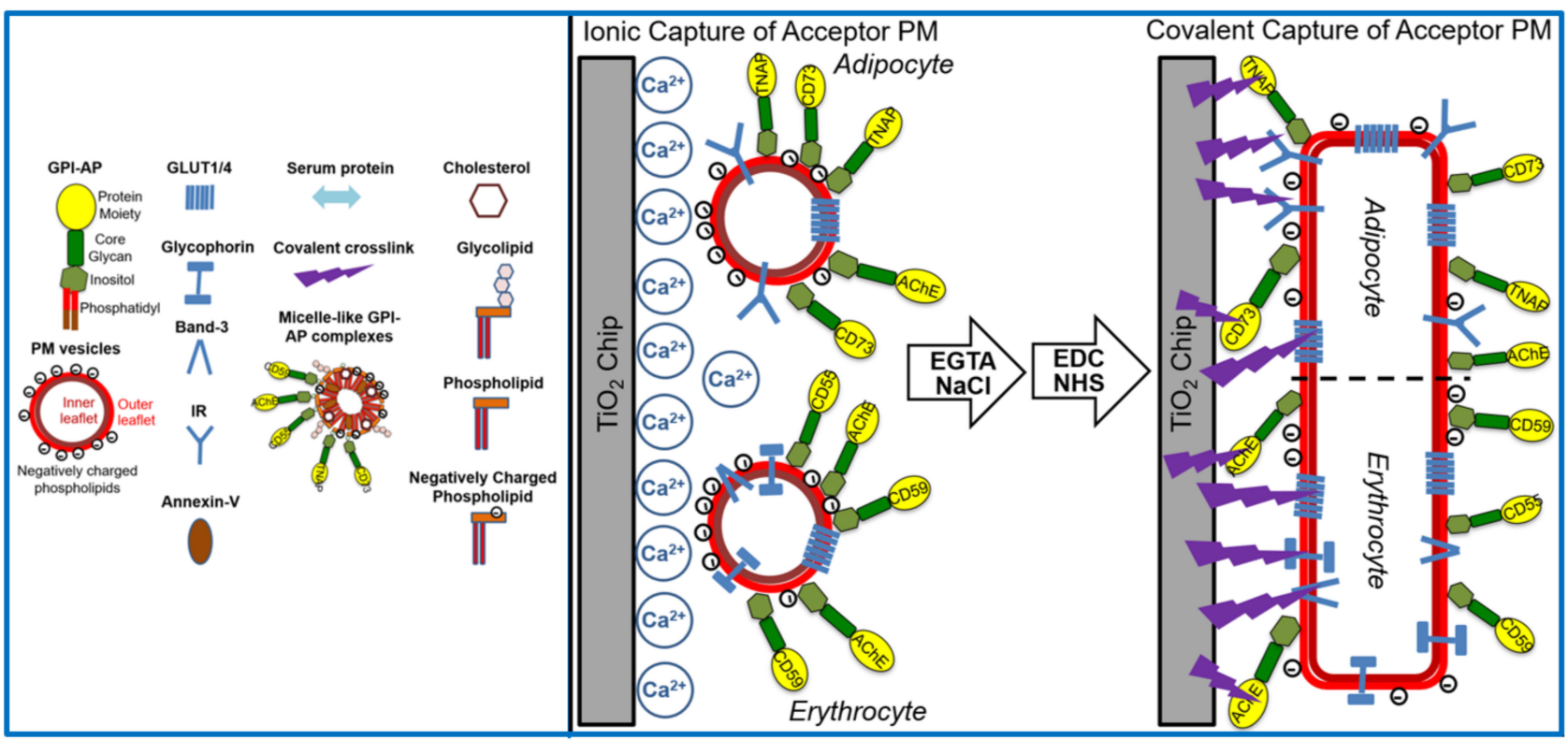

(a)

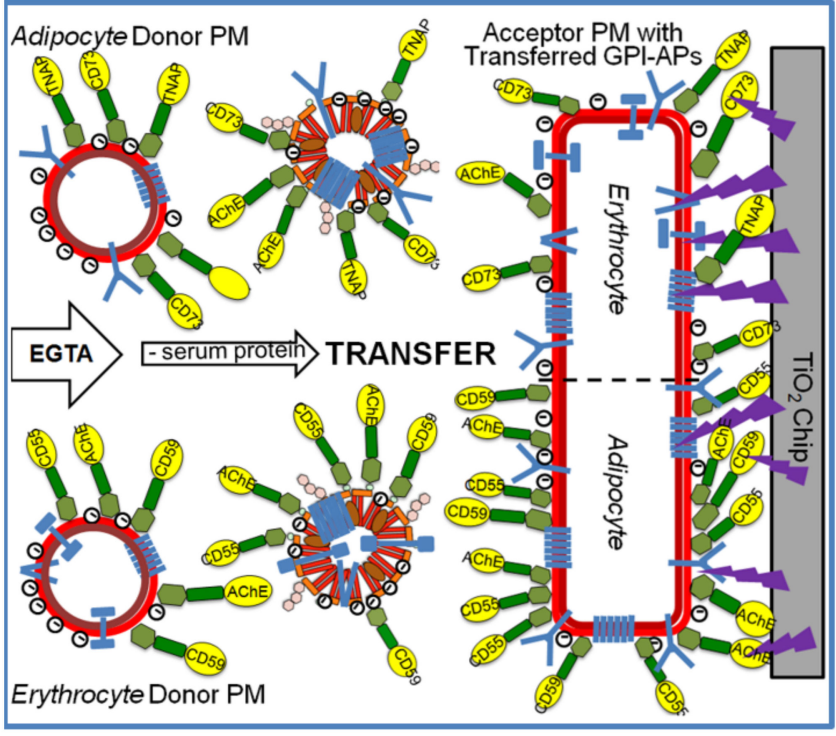

(b)

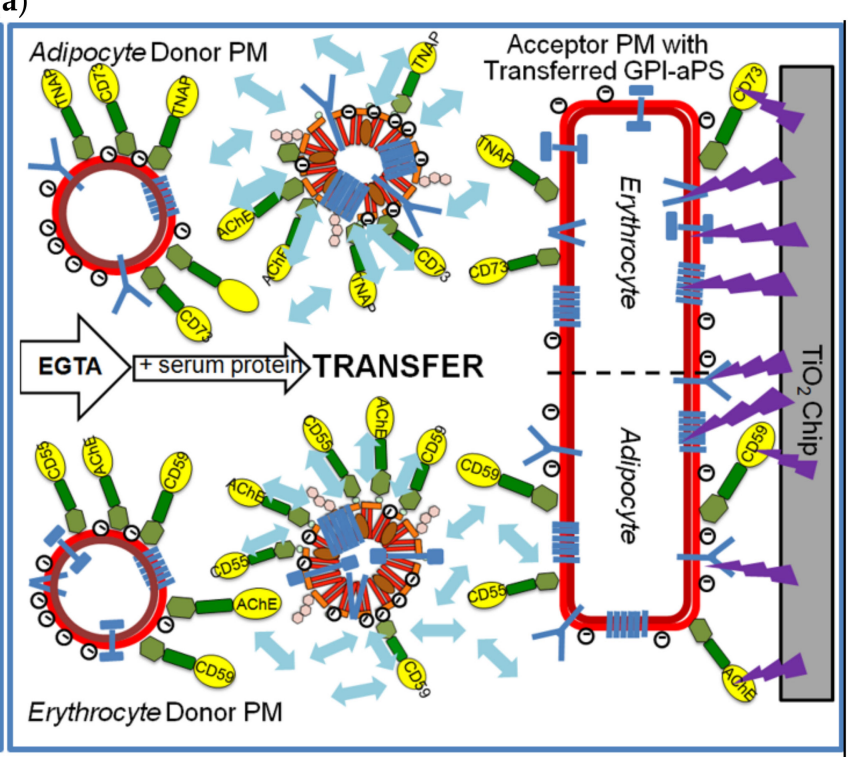

(c)

Figure 1. Cont. 


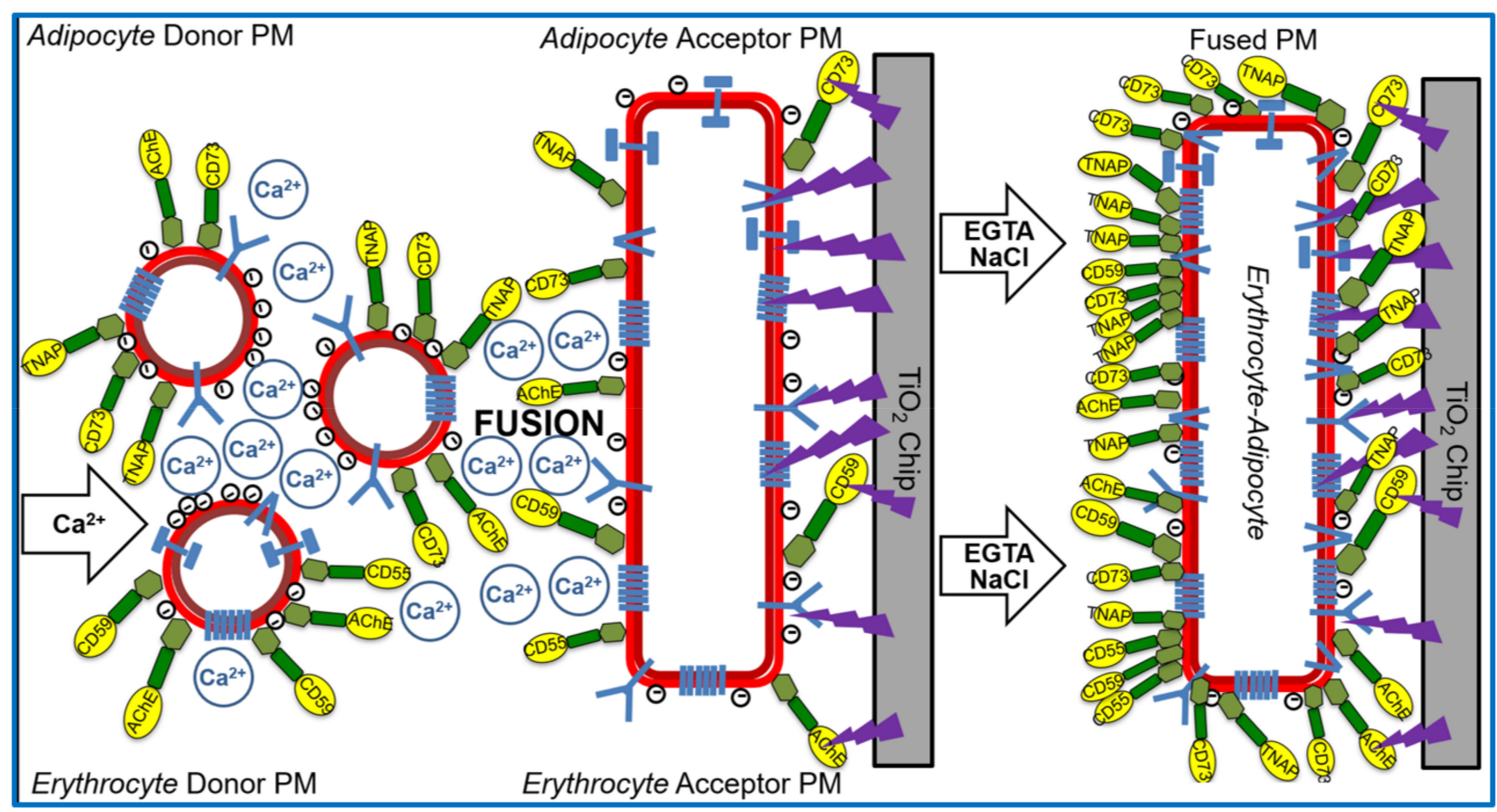

(d)

Figure 1. Model of the cell-free chip-based sensing system for analysis of transfer of GPI-APs between adipocyte and erythrocyte PM and the effect of serum proteins. (a) Ionic (middle panel) and covalent (right panel) capture of acceptor adipocyte and erythrocyte PM with legend for symbols (left panel). The possibility of formation of extended flat vesicular structures of PM at the chip surface in course of covalent capture is indicated. $(\mathbf{b}, \mathbf{c})$ Injection of adipocyte and erythrocyte donor PM together with EGTA in the absence $(\mathbf{b})$ or presence (c) of serum proteins for analysis of transfer of GPI-APs to covalently captured adipocyte and erythrocyte acceptor PM via micelle-like GPI-AP complexes resulting in acceptor PM with transferred GPI-APs in the absence (b), but not in the presence (c), of serum proteins. The two combinations of donor and acceptor PM exhibiting the highest and lowest transfer efficacy for GPI-APs in the absence of serum proteins (b), $\mathrm{hE} \rightarrow \mathrm{rE} / \mathrm{hA}$ (lower half) and $\mathrm{h} / \mathrm{rA} \rightarrow \mathrm{h} / \mathrm{rE}$ (upper half), respectively, are depicted (see also Table 1). (d) Injection of adipocyte and erythrocyte donor PM together with $\mathrm{Ca}^{2+}$ (left panel) for analysis of the fusion of adipocyte and erythrocyte donor and acceptor PM (middle panel). In all cases the $\mathrm{TiO}_{2}$ chips were sensed for GPI-APs and transmembrane proteins and the corresponding antibodies loaded onto the chip by measurement of SAW phase shift.

The efficacies of covalent capture of rat adipocyte and rat and human erythrocyte PM were monitored by an increase in right-ward phase shift (i.e., decrease in frequency) of the horizontal SAW propagating along the plane of the chip surface as measure for the mass of the loaded PM (Figure $2 \mathrm{a}-\mathrm{c}$ ). In each case, about 40 to $50 \%$ of the ionically captured PM (at 600 s) resisted injection of $\mathrm{NaCl} /$ EGTA and buffer, indicating covalent capture of a considerable portion of the PM (at $800 \mathrm{~s}$ ). The nature of the captured PM was characterized by sequential injection (at 800 to $2700 \mathrm{~s}$ ) of antibodies against typical GPI-APs and transmembrane proteins. The stepwise increases in phase shift reflecting antibody binding to the PM in sandwich demonstrated the differential expression of membrane proteins. Only a portion of the total phase shift increases (as summation signals) was due to GPI-APs. This was revealed by injection of bacterial PI-PLC (Figure 2a, 2400-2700 s; Figure 2b, 2700-2900 s), which specifically removed the diacylglycerol moiety from the GPI anchor. The resulting loss of the GPI-AP protein moieties, as well as of those PM vesicles captured through their GPI-APs from the chip, led to reduction in phase shift (Figure 2a-c). The remaining PI-PLC resistant component of the total phase shift increase (50 to $70 \%$ ) was completely abrogated in course of injection of TX-100 (Figure 2a, at 2800-3000 s; Figure 2b, 3000-3200 s). This was compatible with disintegration of the structural integrity of the PM captured through their transmembrane proteins and/or those GPI-APs which escape cleavage by bacterial PI-PLC (possibly due to steric hindrance of PI-PLC access by the bound antibodies). For differentiation between the possibilities, the experiment with 
captured rat adipocyte and erythrocyte PM (Figure 2a,b) was modified with injection of PI-PLC prior to, rather than following, the injections of antibodies against GPI-APs and transmembrane proteins. Compatible with transmembrane anchorage, the phase shift increase in response to anti-Glut4, anti-Glut1, anti-IR, anti-Band-3, and anti-Glycophorin antibodies (data not shown) were very similar to those generated in the absence of PI-PLC injection (see Figure 2a,b). In contrast, the phase shift increases induced by anti-GPI-APs antibodies were considerably lower when injected following (data not shown) rather than prior to injection of PI-PLC (see Figure 2a,b). Remarkably, the GPI-APs analyzed differed in their susceptibility towards lipolytic cleavage, with the PI-PLC-induced phase shift decrease being most pronounced for TNAP and CD59, followed by CD73 and CD55, and lowest for AChE. Remarkably, PI-PLC exerted considerably less phase shift decrease with erythrocyte compared to adipocyte GPI-APs. Partial or complete resistance towards bacterial PI-PLC activity has been amply documented for a number of GPI anchors in the past and attributed to covalent modification of their core glycan (e.g., acylation of the 2-position of myo-inositol, which seems to be prevalent in erythrocyte GPI-APs [46-48]) or steric hindrance due to high packaging density of those GPI-APs (e.g., nanoclustering and oligomerization at PM microdomains or lipid rafts [49-51]) or tight interaction with other cell surface components [52]. Nevertheless, on basis of the moderate overall noncleavability of the GPI-APs at the adipocyte and erythrocyte PM, which accounts for only 11 to $14 \%$ and 48 to $53 \%$, respectively, based on the phase shift left upon correction for the transmembrane proteins, consecutive injections of PI-PLC and TX-100 were routinely performed to delineate the nature of the GPI-APs and transmembrane proteins, respectively, in the following transfer experiments.

The amount of PM amenable to capture by ionic and covalent bonds was saturatable, as revealed (Figure 2d) by the concentration-dependent increases in phase shift (at 0-300 s) and confirmed by subsequent anti-Glut4 and anti-TNAP injections (at 1300-1900 s) to up to a maximal value (shown only for rat adipocyte PM). Furthermore, only chips harboring submaximal amounts of covalently captured rat adipocyte PM $(0.25 \times, 0.5 \times$ rel. concentration) displayed additional phase shift increases upon subsequent injection of rat adipocyte PM (at 800-1200 s) at submaximal ( $0.25 \times$ rel. concentration) to up to saturating $(1 \times$ rel. concentration) amounts and subsequent anti-Glycophorin, anti-CD59, and anti-AChE injections (at 1900-2800 s).

Saturation was apparently due to complete coverage of the surface area with PM, i.e., exhaustion of the maximal capturing capacity, rather than to overriding of the measuring range of the sensing element of the chip. This has been revealed during previous titration experiments based on the capture of (increasing amounts of) purified GPI-APs by $\alpha$-toxincoated chips. The maximal phase shift increases obtained thereby were considerably higher than those elicited upon injection of (increasing amounts of) PM for ionic/covalent capture (Müller, G.A.; Ussar, S.; Müller, T.D.; unpublished data). This can be explained best by mutual steric hindrance of the PM vesicles during capturing, in combination with lower mass loading provoked by the PM (as assembly of lipids and proteins) compared to proteins exclusively. Under conditions of subsaturating capture of acceptor PM, the unspecific binding of full-length GPI-APs embedded in micelle-like complexes as prevalent in rat and human serum samples [32] was reduced to less than 8 and 5\%, respectively, of the acceptor PM-induced phase shift by injection of NSB reducer plus $2 \mathrm{M} \mathrm{NaCl}$ prior to sample injection (according to manufacturers' instructions) as outlined in the Materials and Methods section. Apparently, the conditions for the initial (prior to covalent) capture of acceptor PM did not support unspecific binding of full-length GPI-APs to chip. This presumably relied on ionic rather than hydrophobic interaction of the vesicular phospholipids with the $\mathrm{TiO}_{2}$ surface in combination with prevention of both ionic and hydrophobic interactions of the fatty acids of the GPI anchor and GPI-AP protein moiety by $\mathrm{NaCl}$ plus NSB, respectively. 
(a)

(b)

(c)

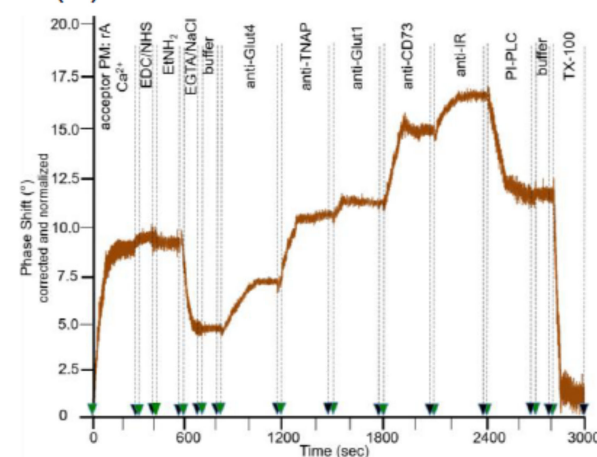

(d)

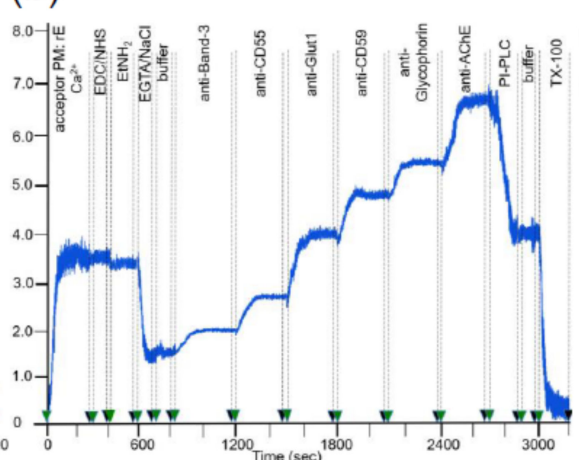

(e)

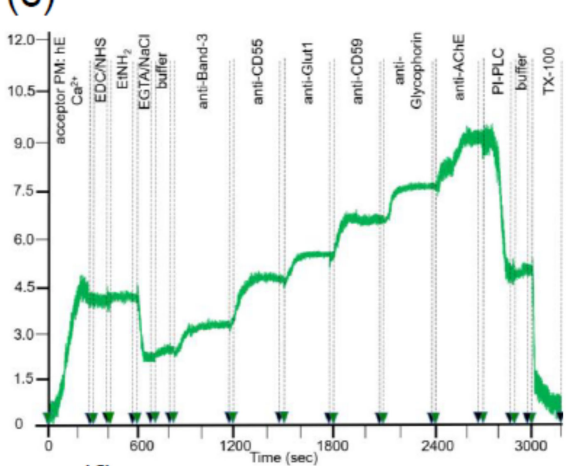

(f)

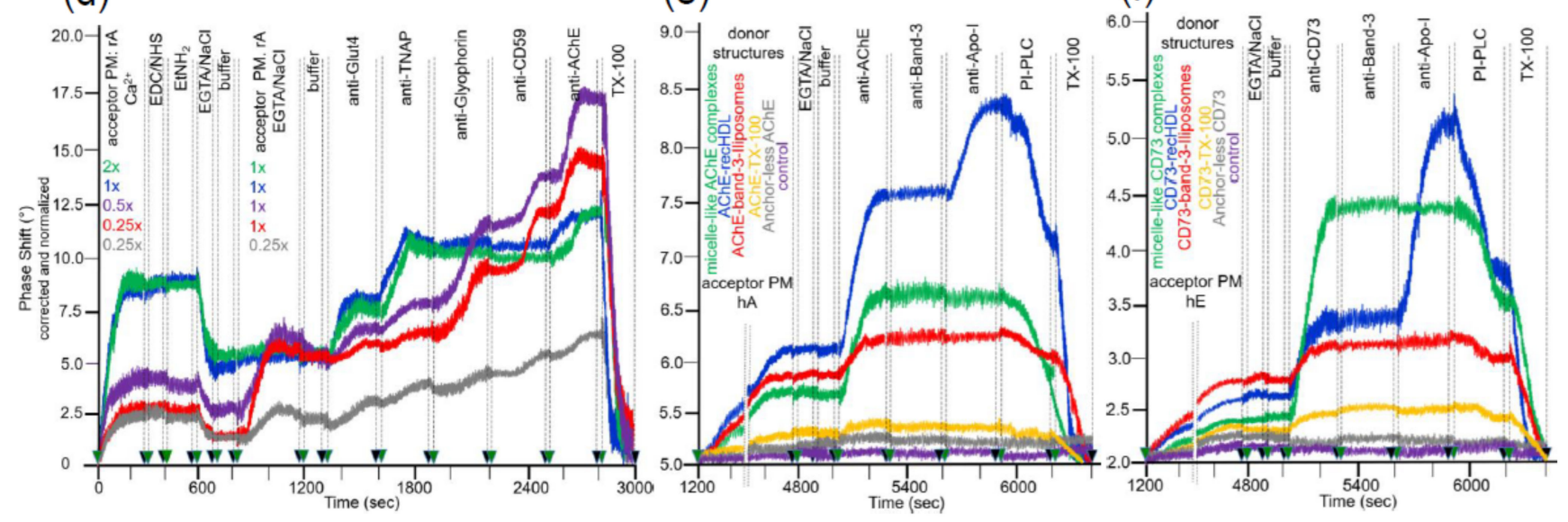

Figure 2. Capture of acceptor PM by SAW chip. PM from rat adipocytes (a,d), rat erythrocytes (b), human erythrocytes $(\mathbf{c}, \mathbf{f})$, and human adipocytes (e) were consecutively captured by chips via ionic $\left(\mathrm{Ca}^{2+}\right)$ and covalent bonds (EDC/NHS, $\mathrm{EtNH}_{2}$; shown only for $(\mathbf{a}-\mathbf{d})$. (a-c) Characterization of the protein composition of the captured acceptor PM. Following consecutive injection of $150 \mu \mathrm{L}$ of acceptor PM $(0.15-0.20 \mathrm{mg}$ protein $/ \mathrm{mL}), 50 \mu \mathrm{L}$ of EDC/NHS, $100 \mu \mathrm{L}$ of $1 \mathrm{mM}$ EGTA/2 M $\mathrm{NaCl}$, and then $50 \mu \mathrm{L}$ of buffer each at a flow rate of $30 \mu \mathrm{L} / \mathrm{min}, 75 \mu \mathrm{L}$ of antibodies against GPI-APs and transmembrane proteins, then $75 \mu \mathrm{L}$ of PI-PLC (Bacillus cereus, $7.5 \mathrm{mU} / \mathrm{mL}$ ), subsequently $25 \mu \mathrm{L}$ of washing buffer and finally $50 \mu \mathrm{L}$ of TX-100 (0.1\%) each at a flow rate of $15 \mu \mathrm{L} / \mathrm{min}$ were injected as indicated. (d) Demonstration of saturation of the chips with acceptor PM. After consecutive ionic and covalent capture of rat adipocyte PM $(150 \mu \mathrm{L})$ at varying concentration $(1 \times$ rel. concentration corresponded to $0.15-0.20 \mathrm{mg}$ protein $/ \mathrm{mL}$ ) and then washing with EGTA/ $\mathrm{NaCl}$ and subsequently washing buffer as performed for $(\mathbf{a}-\mathbf{c}), 200 \mu \mathrm{L}$ of fresh rat adipocyte acceptor PM were injected at the concentration (see above) indicated in the presence of $1 \mathrm{mM}$ EGTA/2 M NaCl, followed by antibodies against GPI-APs and transmembrane proteins and finally TX-100 (0.1\%) as performed for $(\mathbf{a}-\mathbf{c})$. (e,f) Translocation of GPI-APs from sources other than PM into acceptor PM. $100 \mu \mathrm{L}$ of micelle-like bAChE complexes, AChE-recHDL, liposomes reconstituted with bAChE and Band-3, AChE reconstituted into TX-100 detergent micelles, anchorless AChE or buffer (control) were injected into chips with captured human adipocyte (e) or erythrocyte (f) PM (at 800-1200 s) at a flow rate of $15 \mu \mathrm{L} / \mathrm{min}$. Thereafter at $1200 \mathrm{~s}$, the flow rate was set at 0 for $1 \mathrm{~h}$ (hatched double line). Following injection of $200 \mu \mathrm{L}$ of $1 \mathrm{mM}$ EGTA/2 M NaCl and then $200 \mu \mathrm{L}$ of washing buffer each at a flow rate of $120 \mu \mathrm{L} / \mathrm{min}$, antibodies against GPI-APs and transmembrane proteins, subsequently PI-PLC and finally TX-100 (0.1\%) were injected (see (a-c); but omission of final buffer injection) as indicated. (a-f) The measured phase shift is given upon correction for unspecific interaction (no acceptor PM) and normalization for variable capturing efficacy of different chips (i.e., for identical amounts of captured acceptor PM). The experiment was repeated once with similar results. Hatched lines with green and black arrows indicate start and termination, respectively, of cycles of fluid injection as indicated.

Next, the suitability of the covalently captured acceptor PM for the translocation of GPI-APs released from sources other than PM, such as lipoproteins [53], was tested. Injection of micelle-like complexes, recombinant HDL particles (recHDL), or liposomes reconstituted with AChE (Figure 2e) or CD73 (Figure 2f) or Band-3 (Figure 2e,f; liposomes only) into chips with covalently captured human adipocyte (Figure 2e) or human erythro- 
cyte (Figure 2f) PM caused considerable phase shift increases during prolonged incubation (termination of buffer flow at $1200-4800$ s). In contrast, AChE or CD73 reconstituted into TX-100 micelles as well as anchorless AChE or CD73, produced by PI-PLC digestion, exhibited only marginal phase shift increases and/or no increase at all, respectively, compared to control. This argued for the release of GPI-APs from micelle-like complexes, recHDL, and proteoliposomes, and their translocation into acceptor PM at varying efficacy, which was confirmed by subsequent injection (at 5000-5300 s) of anti-AChE (Figure 2e) and anti-CD73 (Figure 2f). Under these conditions, Band-3 was found to resist release from AChE/CD73-Band-3 liposomes (red lines) and/or translocation into human adipocyte (Figure 2e) or erythrocyte (Figure 2f) acceptor PM. At variance, the atypical membrane protein apolipoprotein A-I (Apo-I) was translocated together with AChE and CD73 from AChE/CD73-recHDL, respectively, (blue lines) into both acceptor PM as revealed by antiApo-I injection (at 5600-5900 s). This confirmed previous findings [19] about the specificity of intermembrane protein transfer for GPI-APs.

After having established the conditions for capture of acceptor $\mathrm{PM}$ by the $\mathrm{TiO}_{2}$ surface of SAW sensing chips and compatible with translocation of GPI-APs upon release from micelle-like complexes, recHDL and proteoliposomes, the possibility of their transfer from donor to acceptor PM was evaluated (Figure $1 \mathrm{~b}$ ). For this, donor PM of various origins were injected into chips with captured acceptor PM of various origin in buffer containing EGTA to avoid $\mathrm{Ca}^{2+}$-induced fusion of donor and acceptor PM (Figure 3) and incubated (60 min, $37^{\circ} \mathrm{C}$ ) by transient termination of the buffer flow (at 1200-4800 s). Following washing of the chip channels with EGTA and $\mathrm{NaCl}$ and then buffer to get rid of the donor PM from the microfluidic channels, the captured acceptor PM were assayed for mass loading per se and after sequential injection of antibodies against GPI-APs and transmembrane proteins expressed in the donor PM by real-time measurement of phase shift increases. Incubation of donor PM with acceptor PM at the various combinations (Figure 3, blue and green lines) alone and subsequent injection of anti-CD73 and anti-TNAP, but not anti-Glut4 and anti-IR antibodies (Figure 3a) and anti-AChE, anti-CD59, and anti-CD55, but not anti-Band-3 and anti-Glycophorin antibodies (Figure $3 b, c)$, led to considerable phase shift increases (until $5000 \mathrm{~s}$ ). Both the donor PM- and antibody-induced phase shift increases were diminished by 65 to $85 \%$ in course of subsequent injection of PI-PLC (at 6500-6800 s). This indicated that the corresponding mass loadings onto acceptor PM were mediated by GPI anchorage amenable to cleavage by PI-PLC. The total phase shift increases (i.e., including those induced by capture of the acceptor PM alone) were abrogated by final injection of TX-100 (at 6800-7000 s). This demonstrated dependence of the phase shift increase on the presence of phospholipid layers at the $\mathrm{TiO}_{2}$ chip surface and excluded unspecific adsorption of the GPI-APs.

Together, the SAW sensing data are explained best (Figure 1b) by transfer of the GPI-APs CD73 and TNAP from human adipocyte donor PM to rat and human erythrocyte acceptor PM (Figure 3a) and of the GPI-APs AChE, CD59, and CD55 from rat (Figure 3b) and human erythrocyte donor PM (Figure 3c) to rat and human adipocyte and erythrocyte acceptor PM. The specificity of the transfer for GPI-APs was demonstrated (Figure 3a-c) by (i) failure of typical transmembrane proteins to elicit corresponding phase shift increases and (ii) complete blockade and considerable reduction, respectively, of phase shift increase in the presence of PI-PLC or $\alpha$-toxin during incubation of donor and acceptor PM (at 1200-4800 s). (ii) was most likely caused by lipolytic cleavage of the GPI-APs to be transferred and inhibition of transfer due to binding of $\alpha$-toxin to the GPI core glycan, respectively [54,55]. 
(a)

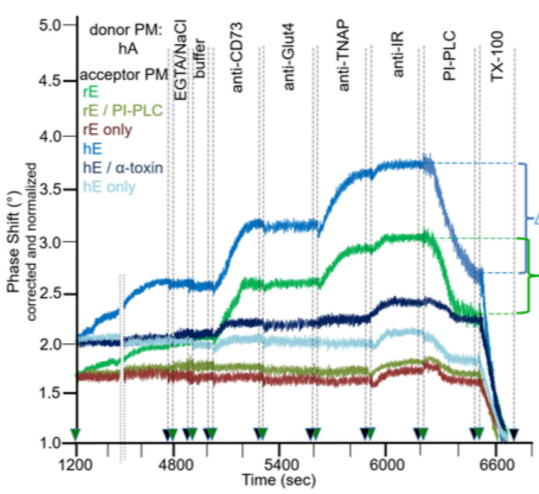

(b)

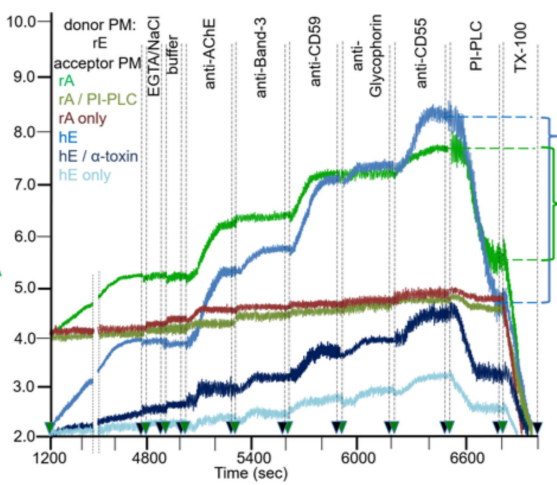

(c)

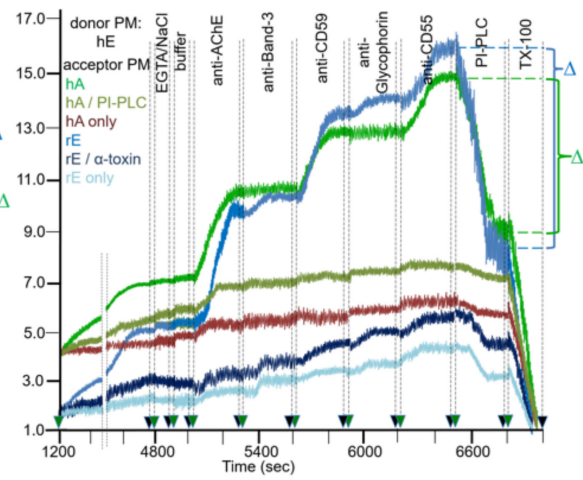

Figure 3. Set-up of chip-based sensing system for transfer of GPI-APs and transmembrane proteins from donor to acceptor PM at various combinations. Human adipocyte (a), rat erythrocyte (b), and human erythrocyte (c) donor PM or washing buffer (acceptor PM only) were injected (at 800-1200 s) into chips with rat erythrocyte (a,c), human erythrocyte (a,b), rat adipocyte (b), or human adipocyte (c) acceptor PM consecutively captured via ionic $\left(\mathrm{Ca}^{2+}\right)$ and covalent bonds as described for Figure 2. The chips were then incubated $\left(1 \mathrm{~h}, 37^{\circ} \mathrm{C}\right)$ at flow rate 0 (double hatched lines) until $4800 \mathrm{~s}$ in the absence or presence of PI-PLC or $\alpha$-toxin, as indicated. Following injection of EGTA/ $\mathrm{NaCl}$ and then washing buffer, the protein composition of the acceptor PM was assayed by sequential injection of antibodies against GPI-APs and transmembrane proteins, then of PI-PLC, and finally of TX-100 (0.1\%) as indicated. The measured phase shift is given upon correction for unspecific interaction (chips lacking acceptor PM) and normalization for variable capturing efficacy. The differences $(\Delta)$ between total phase shift upon injection of the last antibody and the phase shift left at the end of injection of PI-PLC are indicated by horizontal hatched lines and brackets as a measure for GPI-AP transfer for each donor-acceptor PM combination. The experiment was repeated two times with similar results.

The omission of donor PM during the incubation revealed the endogenous expression of the relevant GPI-APs and transmembrane proteins at the acceptor PM determined by their differential species- and tissue-specific expression as well as the differential speciesspecific cross-reactivity of the antibodies used (Table 1). Rat and human erythrocyte PM harbored a low amount of IR (Figure 3a; at 5900-6200 s), rat adipocyte PM of AChE (Figure 3b,c; at 5000-5300 s). Human and rat erythrocyte PM expressed low amounts of AChE, Band-3, CD59, Glycophorin, and CD55 (Figure 3b,c; at 5000-6500 s). For transmembrane proteins, the antibody-induced phase shift increases were very similar for incubations of acceptor PM only and of donor with acceptor PM, confirming failure of their transfer. For GPIAPs, the increases were considerably higher for incubations of donor with acceptor PM compared to incubation of acceptor PM only, which was compatible with their transfer from donor to acceptor PM. With regard to GPI-APs, the unequivocal demonstration of their transfer from donor to acceptor PM for the six combinations assayed was enabled by differential species-/tissue-specific GPI-AP expression and/or differential species-specific antibody reactivity (Table 1 ). The difference $\Delta$ between the maximal phase shift increase at $6500 \mathrm{~s}$ (in course of sequential injection of the donor PM and the set of antibodies as indicated) and the phase shift increase left upon injection of PI-PLC at $6800 \mathrm{~s}$ ( $\Delta$ phase shift) was calculated for each combination of donor and acceptor PM (see Figure 3) and used as a measure for the transfer efficacy in the following experiments.

Next, critical parameters for the efficacy of the transfer of GPI-APs using this experimental set-up were investigated, such as the amount of donor PM injected into the chip and then incubated with the acceptor PM (Figure 4a), the flow rate during the initial injection of the donor PM (Figure 4b), the time of incubation of donor and acceptor PM at flow rate 0 (Figure $4 \mathrm{c}$ ), and the incubation temperature (Figure $4 \mathrm{~d}$ ). Maximal transfer efficacy was observed at 300-500 $\mu \mathrm{L}$ of PM (corresponding to $60-100 \mu \mathrm{g}$ of protein) and 60-80 $\mu \mathrm{L} / \mathrm{min}$ flow rate, with approximate linear correlation with incubation time between 10 and $60 \mathrm{~min}$ and temperature between 20 and $37^{\circ} \mathrm{C}$. Only minor differences were found between the six donor-acceptor PM combinations (Figure 4). Therefore, injection of $400 \mu \mathrm{L}$ 
of PM at $60 \mu \mathrm{L} / \mathrm{min}$ flow rate and subsequent incubation $\left(60 \mathrm{~min}, 30^{\circ} \mathrm{C}\right)$ were used for the following experiments. Under these optimal conditions, the transfer of GPI-APs from donor to acceptor PM was most efficient for the combinations $\mathrm{hE} \rightarrow \mathrm{rE}$ and $\mathrm{hE} \rightarrow \mathrm{hA}$ and least for $\mathrm{hA} \rightarrow \mathrm{hE}$ and $\mathrm{rA} \rightarrow \mathrm{rE}$ (Table 1 ).

Table 1. Synopsis of the various combinations of donor and acceptor PM including the experimental basis enabling analysis of the transfer of GPI-APs, and the comparison of the relative transfer efficacy. Relative transfer efficacy is derived from Figure 4a (with $400 \mu \mathrm{L}$ of donor PM injected) and categorized as follows: +, 0.5-1.0 $\Delta$ phase shift; +++, 2.0-3.0; ++++, 3.0-4.0; ,$+++++ 5.0-6.0 ;++++++, 6.0-7.0$.

\begin{tabular}{|c|c|c|c|c|c|}
\hline \multicolumn{3}{|c|}{ Combination } & \multicolumn{2}{|c|}{ Experimental Basis } & \multirow[b]{2}{*}{$\begin{array}{c}\text { Relative Transfer } \\
\text { Efficacy }\end{array}$} \\
\hline Donor PM & Acceptor PM & Abbreviation & $\begin{array}{l}\text { Differential Species- } \\
\text { /Tissue-Specific } \\
\text { GPI-AP Expression }\end{array}$ & $\begin{array}{c}\text { Differential } \\
\text { Species-Specific } \\
\text { Antibody Reactivity }\end{array}$ & \\
\hline human adipocyte & human erythrocyte & $\mathrm{hA} \rightarrow \mathrm{hE}$ & yes & yes & + \\
\hline rat erythrocyte & human erythrocyte & $\mathrm{rE} \rightarrow \mathrm{hE}$ & no & yes & ++++ \\
\hline human erythrocyte & human adipocyte & $\mathrm{hE} \rightarrow \mathrm{hA}$ & yes & yes & +++++ \\
\hline human erythrocyte & rat erythrocyte & $\mathrm{hE} \rightarrow \mathrm{rE}$ & no & yes & ++++++ \\
\hline rat adipocyte & rat erythrocyte & $\mathrm{rA} \rightarrow \mathrm{rE}$ & yes & no & + \\
\hline rat erythrocyte & rat adipocyte & $\mathrm{rE} \rightarrow \mathrm{rA}$ & yes & no & +++ \\
\hline
\end{tabular}

The apparent specificity of the GPI-AP transfer, as reflected in the exclusion of transmembrane proteins from expression at the acceptor PM (see Figure 3), provided a first hint that the experimental set-up, in particular the absence of $\mathrm{Ca}^{2+}$ during injection and incubation of the donor and acceptor PM, did not support vesicle fusion. For clarification as to whether fusion of donor and acceptor PM can be provoked at the chip surface under special conditions and monitored as SAW phase shift, donor PM were injected together with $\mathrm{Ca}^{2+}$, known to trigger phospholipid bilayer fusion in vitro [56,57], into chips with covalently captured acceptor PM (Figure 1d, left panel). Following incubation, subsequent removal of $\mathrm{Ca}^{2+}$, and then washing with $\mathrm{NaCl}$ (Figure $1 \mathrm{~d}$, middle panel), the chip $\mathrm{TiO}_{2}$ surface was assayed for the presence of GPI-APs and transmembrane proteins by successive injection of corresponding antibodies (Figure 1d, right panel).

The covalently captured human/rat erythrocyte and adipocyte acceptor PM were found to be constituted of small amounts of CD73, TNAP, IR (Figure 5a; erythrocyte), and AChE, Band-3, CD59, Glycophorin, CD55 (Figure 5b,c; adipocyte), and of small amounts of AChE, CD59, CD55 (Figure 5b,c; adipocyte) as measured upon omission of donor PM injection ( $\mathrm{h} / \mathrm{rE} / \mathrm{A}$ only, light green and blue lines). Injection of human adipocyte (Figure 5a), rat erythrocyte (Figure 5b), or human erythrocyte (Figure 5c) donor PM together with $\mathrm{Ca}^{2+}$ (at 1200-4800 s) led to drastic increases in phase shift for each of the acceptor PM, about half of which resisted subsequent washing with EGTA/ $\mathrm{NaCl}$ (at 4800-4900 s). Strikingly, injection of antibodies against both GPI-APs and transmembrane proteins (at 5000-6200 s) led to pronounced phase shift increases (Figure $5 \mathrm{a}-\mathrm{c}$; dark green and blue lines). These findings were explained best by $\mathrm{Ca}^{2+}$-induced fusion of donor and acceptor PM vesicles. The 25-35\% phase shift lowering in response to PI-PLC injection (at 6200-6500 s) confirmed that the major portion of the donor PM-dependent mass loading is due to transmembrane proteins and a minor one to GPI-APs. Phase shift increases by both transmembrane proteins and GPI-APs were completely abrogated by injection of TX-100, which apparently caused disintegration of the fused donor-acceptor PM vesicles (Figure 5a-c).

Thus, fusion of donor and acceptor PM at the chip surface could be achieved for each combination (Figure 1d, right panel), but strictly depended on the presence of $\mathrm{Ca}^{2+}$ with optimum at $300 \mu \mathrm{M}$ (Figure 5d). This, together with the considerable deviations in the amount of donor PM (Figure 5e) and incubation time (Figure 5f) leading to maximal phase shift increases (60-80 $\mu \mathrm{L}$ vs. 300-500 $\mu \mathrm{L}$; 20-30 min vs. 60-180 min) with incubations of donor and acceptor PM in the presence (Figure 5) vs. absence (Figure 4) of $\mathrm{Ca}^{2+}$, strongly argued for fusion of PM vesicles under the former and transfer of GPI-APs under the 
latter conditions. Both was monitored and distinguished from one another by chip-based SAW sensing.

(a)
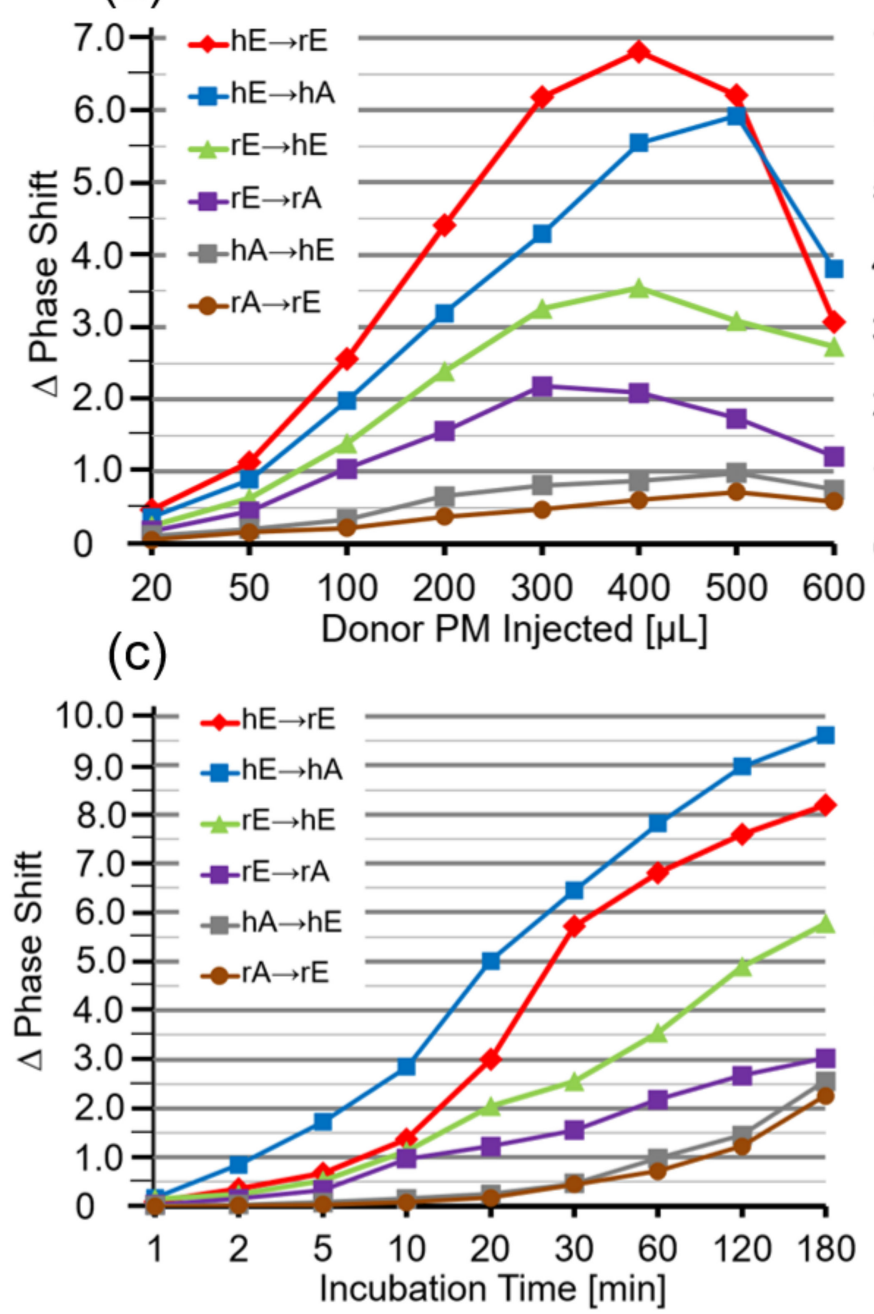

(b)

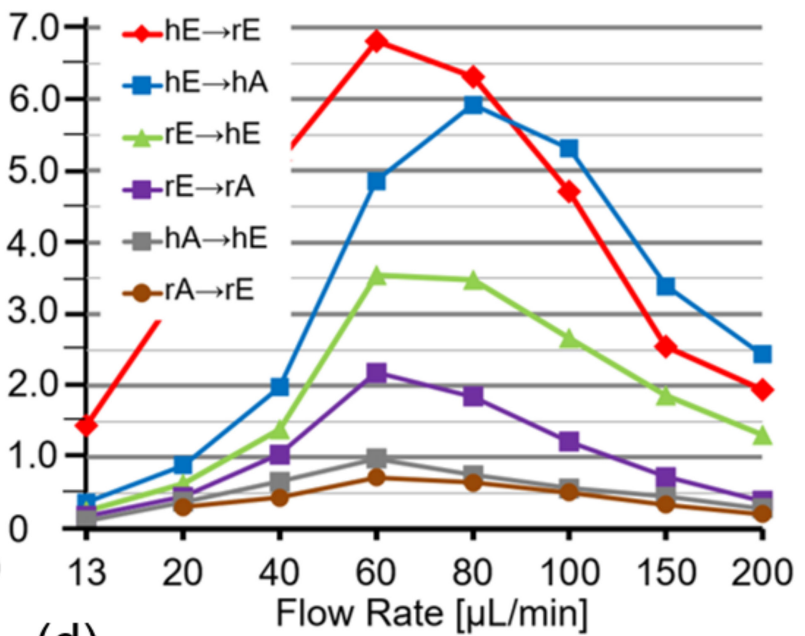

(d)

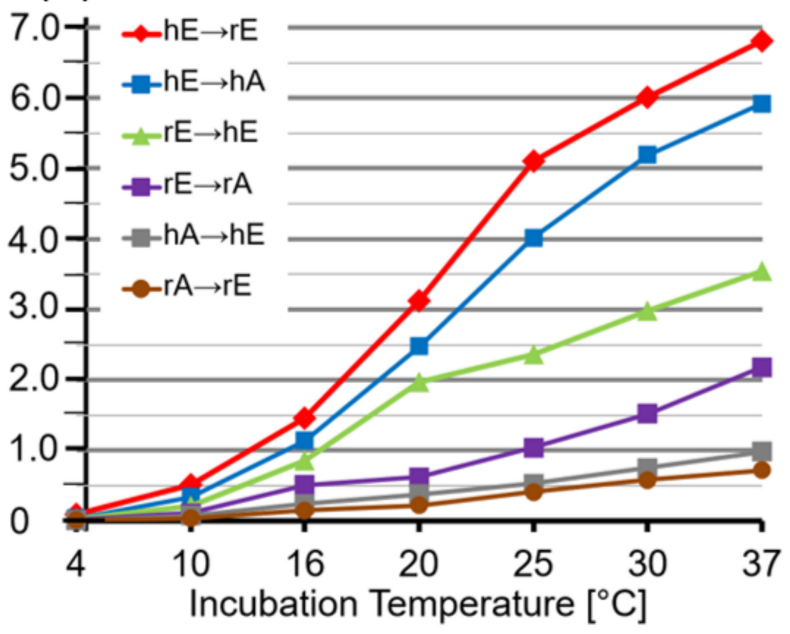

Figure 4. Optimization of chip-based sensing system for transfer of GPI-APs and membrane proteins from donor to acceptor PM. Dependence of transfer efficacy on the amount of donor PM (a), flow rate during donor PM injection (b), length of transfer period (c), temperature during transfer (d). The experiment was performed as described for Figure 3 with injection of donor PM at $800 \mathrm{~s}$, and start of incubation of the donor-acceptor PM combinations indicated at $1200 \mathrm{~s}$ in the absence or presence of PI-PLC (in the absence of $\alpha$-toxin) (a) with increasing volumes of the donor PM at a flow rate of $60 \mu \mathrm{L} / \mathrm{min}$ for $60 \mathrm{~min}$ at $37^{\circ} \mathrm{C},(\mathbf{b})$ at increasing flow rates with $400 \mu \mathrm{L}$ of donor PM for $60 \mathrm{~min}$ at $37^{\circ} \mathrm{C}$, (c) for increasing incubation periods with $400 \mu \mathrm{L}$ of donor PM at flow rate 0 at $37^{\circ} \mathrm{C}$ and (d) at increasing temperatures with $400 \mu \mathrm{L}$ of donor PM at a flow rate of $60 \mu \mathrm{L} / \mathrm{min}$ for $60 \mathrm{~min}$. $\Delta$ phase shifts as measure for GPI-AP transfer are calculated as described for Figure 3 . The experiments were repeated two times with similar results. Mean values are given for each donor-acceptor PM combination. 
(a)

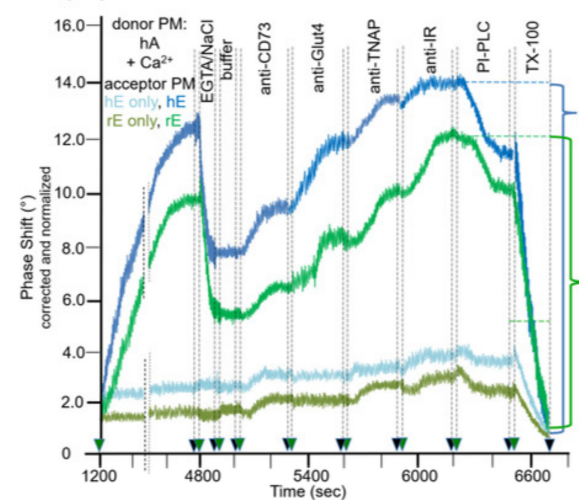

(d)

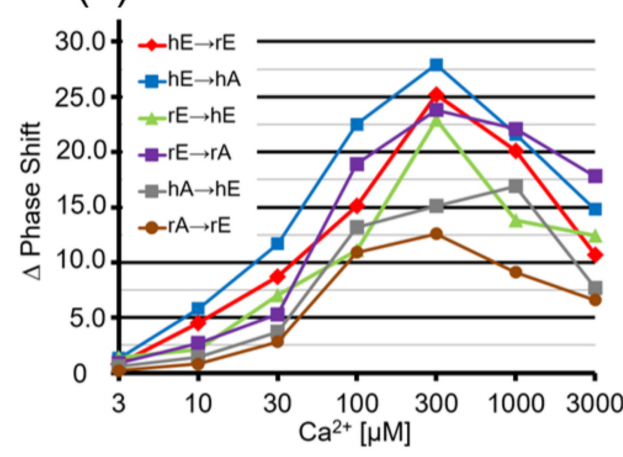

(b)

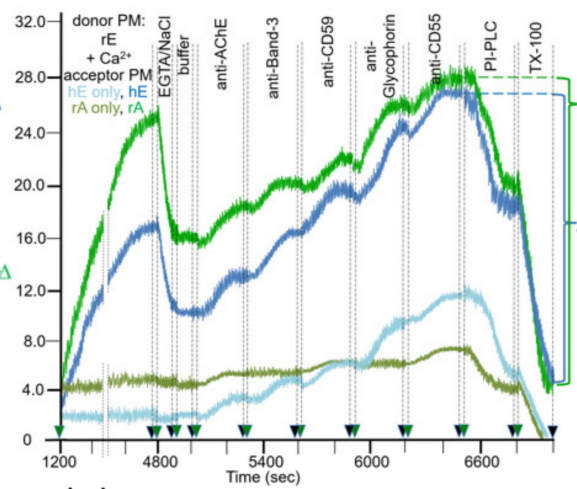

(e)

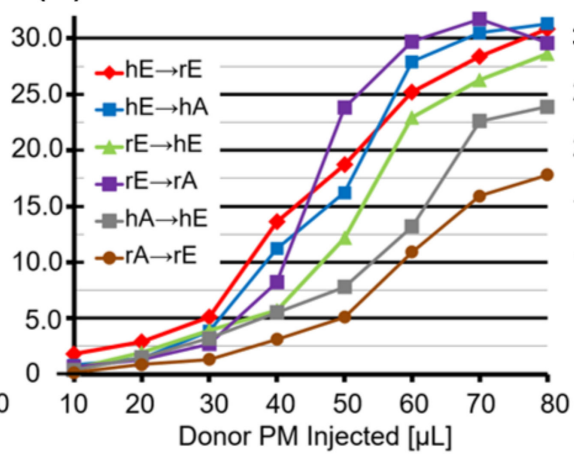

(c)

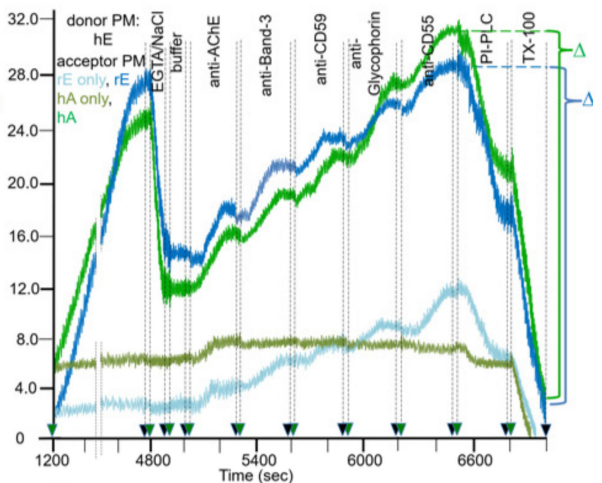

(f)

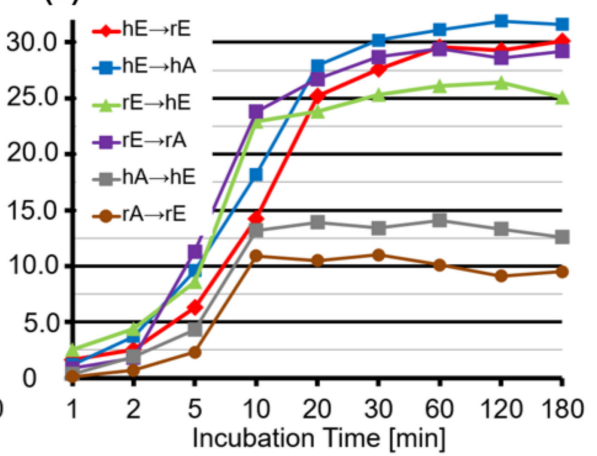

Figure 5. $\mathrm{Ca}^{2+}$-dependent fusion of donor and acceptor PM harboring GPI-APs and transmembrane proteins at various combinations (a-c) and its dependence on the amount of donor PM (d), length of the incubation period (e) and concentration of $\mathrm{Ca}^{2+}$ (f). The experiment was performed as described for Figure 3 with injection at 800-1200 s of $85 \mu \mathrm{L}(\mathbf{a}-\mathbf{d}, \mathbf{f})$ or increasing volumes (e) of donor PM at a flow rate of $13 \mu \mathrm{L} / \mathrm{min}$ and subsequent incubation $\left(37^{\circ} \mathrm{C}\right)$ of the donor-acceptor PM combinations or acceptor PM only as indicated (in the absence of PI-PLC and $\alpha$-toxin) in the presence of $100 \mu \mathrm{M} \mathrm{Ca}^{2+}$ $(\mathbf{a}-\mathbf{c}, \mathbf{e}, \mathbf{f})$ or increasing concentrations (d) for $60 \mathrm{~min}(1200-4800 \mathrm{~s},(\mathbf{a}-\mathbf{e}))$ or increasing periods of time (f). $\Delta$ phase shifts as measure for GPI-AP transfer are calculated as described for Figure 3. The experiments were repeated two times with similar results. Mean values are given for each donor-acceptor PM combination $(\mathbf{d}-\mathbf{f})$.

3.2. Transfer of Full-Length GPI-APs between Rat PM at Various Combinations Depends on the Metabolic State of the Rats

Previous studies have demonstrated that full-length GPI-APs, i.e., those harboring the complete GPI anchor with the fatty acid moieties remaining attached, can be released from the surface of tissue and blood cells into the blood stream of rats and humans [58-60]. Interestingly, the release was reported to be increased in obese and diabetic compared to normal rats and humans, albeit lower serum concentrations of full-length GPI-APs were measured for the former vs. the latter [30]. This inverse relationship between the rate of release of GPI-APs and their steady state concentration in serum was attributed to enhanced degradation of the released GPI-APs by lipolytic cleavage of their GPI anchor through serum GPI-specific phospholipase D (GPLD1). Its activity and amount were found to be elevated in obese and diabetic rats and humans [31]. Nevertheless, the measured upregulation of GPLD1 did not exclude the possibility that a portion of full-length GPIAPs released from donor tissue or blood cells manage to escape cleavage by GPLD1. Consequently, those may find their path to acceptor cells in the same or a neighboring tissue depot via a paracrine route or to distinct tissue or blood acceptor cells via an endocrine route, and finally become translocated in the outer phospholipid bilayer of their PM.

Next, the sensing system for transfer of full-length GPI-APs from donor to acceptor PM under conditions which do not support vesicle fusion was used to investigate whether there are differences in the transfer of GPI-APs dependent on the metabolic state of the rats which serve as source for the donor to acceptor PM. Putative correlations between transfer 
efficacy and metabolic state would argue for relevance in vivo of GPI-AP transfer. For this, PM were prepared from primary epididymal adipocytes and erythrocytes from six groups of rats, which differ in genotype, feeding state, and metabolic phenotype (Table 2) and were used as donors as well as acceptors for GPI-APs at various combinations. In addition, PM from human erythrocytes were used as "neutral" donors and acceptors, respectively, to check for the metabolic relevance of donor vs. acceptor PM. The acceptor PM were assayed for the presence of transferred GPI-APs by mass loading onto the chip of antibodies against GPI-APs and transmembrane proteins (Figure 6).

Table 2. Characteristics of the six rat groups. Mean values $\pm \mathrm{SD}(n=8)$ of weight, fasting blood glucose and fasting plasma insulin for each rat group (of given genotype and feeding state) are shown ( ${ }^{*} p \leq 0.01,{ }^{\S} p \leq 0.02,{ }^{\#} p \leq 0.05$ vs. lean Wistar).

\begin{tabular}{|c|c|c|c|c|c|c|}
\hline Genotype & $\begin{array}{l}\text { Feeding } \\
\text { State }\end{array}$ & $\begin{array}{l}\text { Weight } \\
\text { [g] }\end{array}$ & Age [week] & $\begin{array}{l}\text { Fasting Blood Glucose } \\
{[\mathrm{mM}]}\end{array}$ & $\begin{array}{l}\text { Fasting Plasma } \\
\text { Insulin }[\mu \mathrm{g} / \mathrm{L}]\end{array}$ & Metabolic Phenotype \\
\hline \multirow[t]{2}{*}{ Wistar } & lean & $328.3 \pm 40.2$ & 10 & $6.58 \pm 0.23$ & $0.95 \pm 0.19$ & $\begin{array}{l}\text { normoglycemic } \\
\text { normoinsulinemic } \\
\text { normoglycemic }\end{array}$ \\
\hline & obese & $519.6 \pm 59.2 *$ & 10 & $7.07 \pm 0.69$ & $2.17 \pm 0.38 *$ & $\begin{array}{c}\text { mildly } \\
\text { hyperinsulinemic }\end{array}$ \\
\hline \multirow[t]{2}{*}{$\mathrm{ZF}$} & lean & $481.5 \pm 51.3^{*}$ & 40 & $5.65 \pm 0.44^{\#}$ & $0.90 \pm 0.26$ & $\begin{array}{l}\text { normoglycemic } \\
\text { normoinsulinemic }\end{array}$ \\
\hline & obese & $682.0 \pm 74.9 *$ & 40 & $5.61 \pm 0.40^{\#}$ & $3.39 \pm 0.61 *$ & $\begin{array}{l}\text { normoglycemic } \\
\text { hyperinsulinemic } \\
\text { normoglycemic }\end{array}$ \\
\hline \multirow[t]{2}{*}{ ZDF } & lean & $377.2 \pm 43.8$ & 16 & $6.05 \pm 0.47$ & $1.28 \pm 0.29$ & $\begin{array}{l}\text { mildly } \\
\text { hyperinsulinemic }\end{array}$ \\
\hline & obese & $428.9 \pm 55.9 \S$ & 16 & $20.40 \pm 1.23 *$ & $2.35 \pm 0.55^{*}$ & $\begin{array}{l}\text { hyperglycemic } \\
\text { hyperinsulinemic }\end{array}$ \\
\hline
\end{tabular}

Considerable differences in transfer of GPI-APs (at 5000-6200 s) were monitored between the six rat groups with identical ranking for the six donor-acceptor PM combinations (Figure 6a-f). In all cases, transfer efficacy was considerably higher than that measured during omission of injection of the corresponding donor PM (PM only). This confirmed the species- and tissue-specific expression and detection of the GPI-APs and transmembrane proteins studied. In agreement, the phase shift increases caused by the acceptor PM only were more pronounced for erythrocytes "homologously" assayed for the transfer of erythrocyte proteins (Figure $6 \mathrm{~d}, \mathrm{f}$ ) compared to erythrocyte or adipocyte PM "heterologously" assayed for adipocyte and erythrocyte proteins, respectively (Figure 6a-c,e). This confirmed the species and tissue specificity of the antibodies used.

Transfer of adipocyte CD73 and TNAP (Figure 6a,b), as well as erythrocyte AChE and CD59 (Figure 6c-f), were highest for obese ZDF rats exhibiting elevated fasting blood glucose (hyperglyemia) and elevated fasting plasma insulin (hyperinsulinemia) levels, followed by obese ZF rats with normal fasting blood glucose (normoglycemia) and hyperinsulinemia and obese normoglycemic Wistar rats with mild hyperinsulinemia. Lean normoglycemic ZDF with mild hyperinsulinemia and lean normoglycemic ZF rats with normal fasting plasma insulin (normoinsulinemia) displayed intermediary GPI-AP transfer, which was slightly above that of lean normoglycemic normoinsulinemic Wistar rats. Importantly, in each donor-acceptor PM combination, no or only very minor transfer of adipocyte Glut4 and IR (Figure 6a,b), as well as erythrocyte Band-3 and Glycophorin (Figure 6c-f), was detectable. Again, this demonstrated the specificity of transfer for GPI-APs. 
(a)

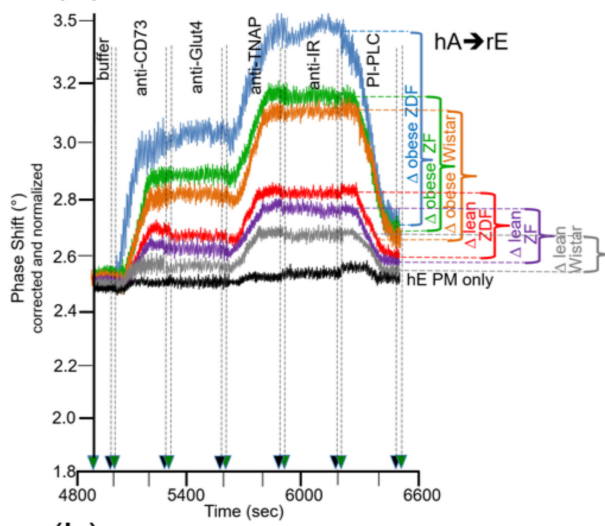

(b)

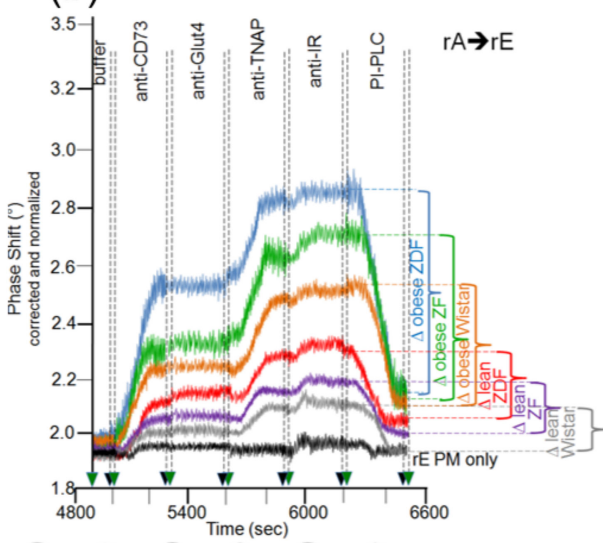

(c)

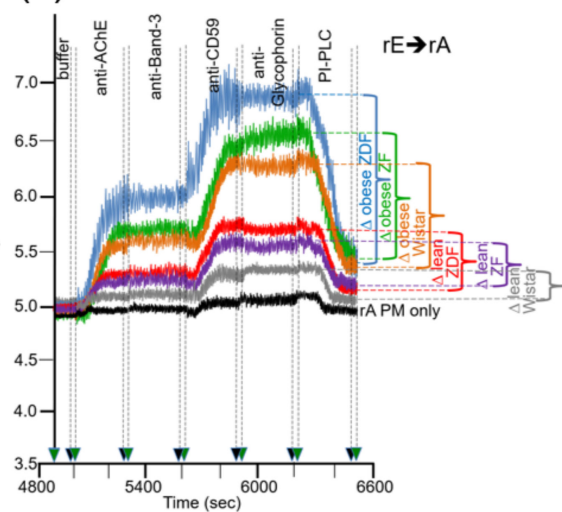

(d)

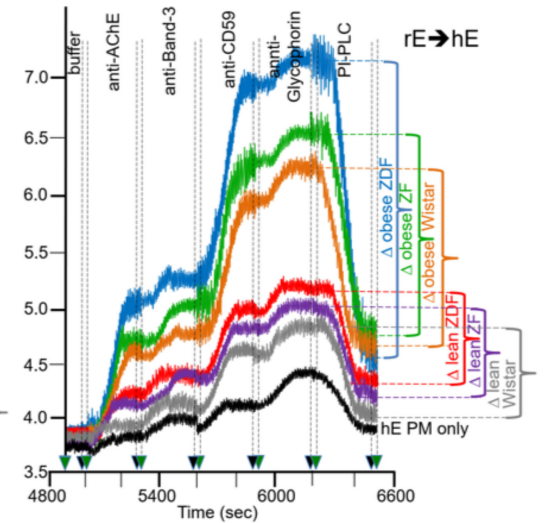

(e)

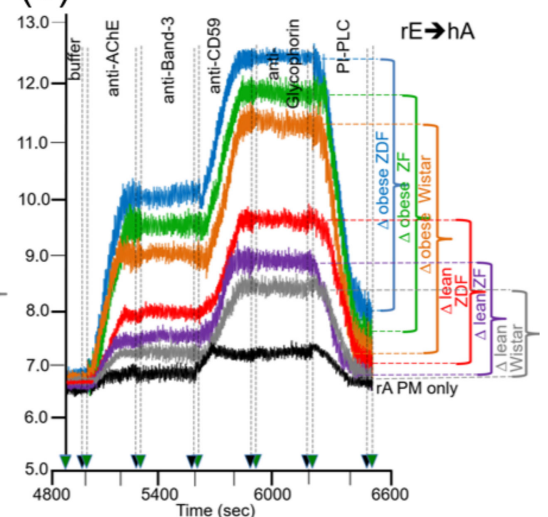

(f)

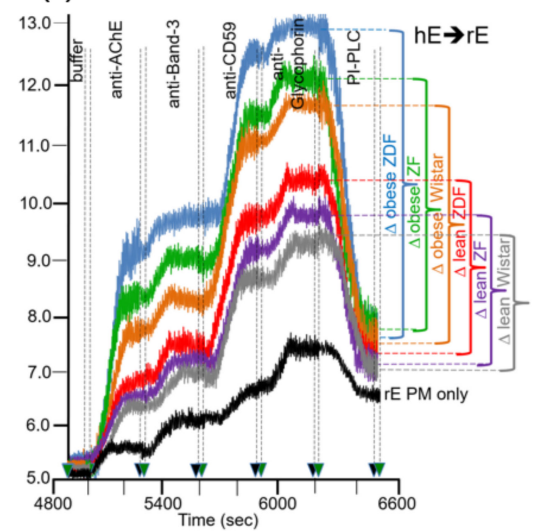

Figure 6. Chip-based sensing system for the transfer of full-length GPI-APs from donor to acceptor PM at various combinations of the six rat groups. (a-f) The experiment was performed as described for Figure 3 with injection of $400 \mu \mathrm{L}$ of donor PM (800-1200 s) at a flow rate of $60 \mu \mathrm{L} / \mathrm{min}$ and subsequent incubation (until $4800 \mathrm{~s}, 60 \mathrm{~min}, 37^{\circ} \mathrm{C}$ ) of the donor-acceptor PM combinations or acceptor PM only as indicated (donor PM $\rightarrow$ acceptor PM). At variance with Figure 3 , injection of anti-CD55 antibody was omitted for the combinations with donor erythrocytes (c-f). The rat (r) donor and acceptor PM were derived from adipocytes (A) and erythrocytes (E) which had been prepared from the six rat groups. Phase shifts are shown only after termination of the transfer period/start of buffer injection (4800 s) and termination of PI-PLC injection (6500 s). $\Delta$ phase shifts as measure for GPI-AP transfer are calculated as described for Figure 3.

Quantitative evaluation of the transfer efficacy for total GPI-APs (Figure 7a) revealed prominent differences (at 5000-6200 s) between the various donor-acceptor PM combinations with identical ranking for each rat group with decreasing efficacy in that order: $\mathrm{hE} \rightarrow \mathrm{rE}>\mathrm{r} / \mathrm{hE} \rightarrow \mathrm{hA}>\mathrm{rE} \rightarrow \mathrm{hE}>\mathrm{rE} \rightarrow \mathrm{rA}>\mathrm{rA} \rightarrow \mathrm{rE}=\mathrm{hA} \rightarrow \mathrm{h} / \mathrm{rE}$. Apparently, the transfer efficacy was determined by both donor and acceptor PM, since a given donor or acceptor PM led to different transfer efficacy when assayed with different acceptor or donor PM, respectively. Apparently, the release of GPI-APs from donor PM as well as their translocation into acceptor PM were critical for transfer of GPI-APs between PM. Both the differential transfer efficacy of GPI-APs as assayed for the various donor-acceptor PM combinations in vitro (Figure 5) and their varying potency to accomplish differentiation between the rats of the six different metabolic phenotypes (Figure 7a) may be explained by subtle differences in the biophysical and biochemical characteristics of the PM, such as stiffness, viscoelasticity, and fluidity, which determine the release and/or translocation of GPI-APs and thus their transfer between tissue and blood cells in vivo.

Consequently, maximal differentiation power was obtained by summation of the phase shift differences measured for all six donor-acceptor PM combinations for each of the six rat groups and calculation of the fold GPI-AP transfer (Figure 7b). This resulted in significant differences between each of the six rat groups in that ranking order of increasing transfer efficacy: lean Wistar $<$ ZF $<$ ZDF $<$ obese Wistar $<$ ZF $<$ ZDF. 

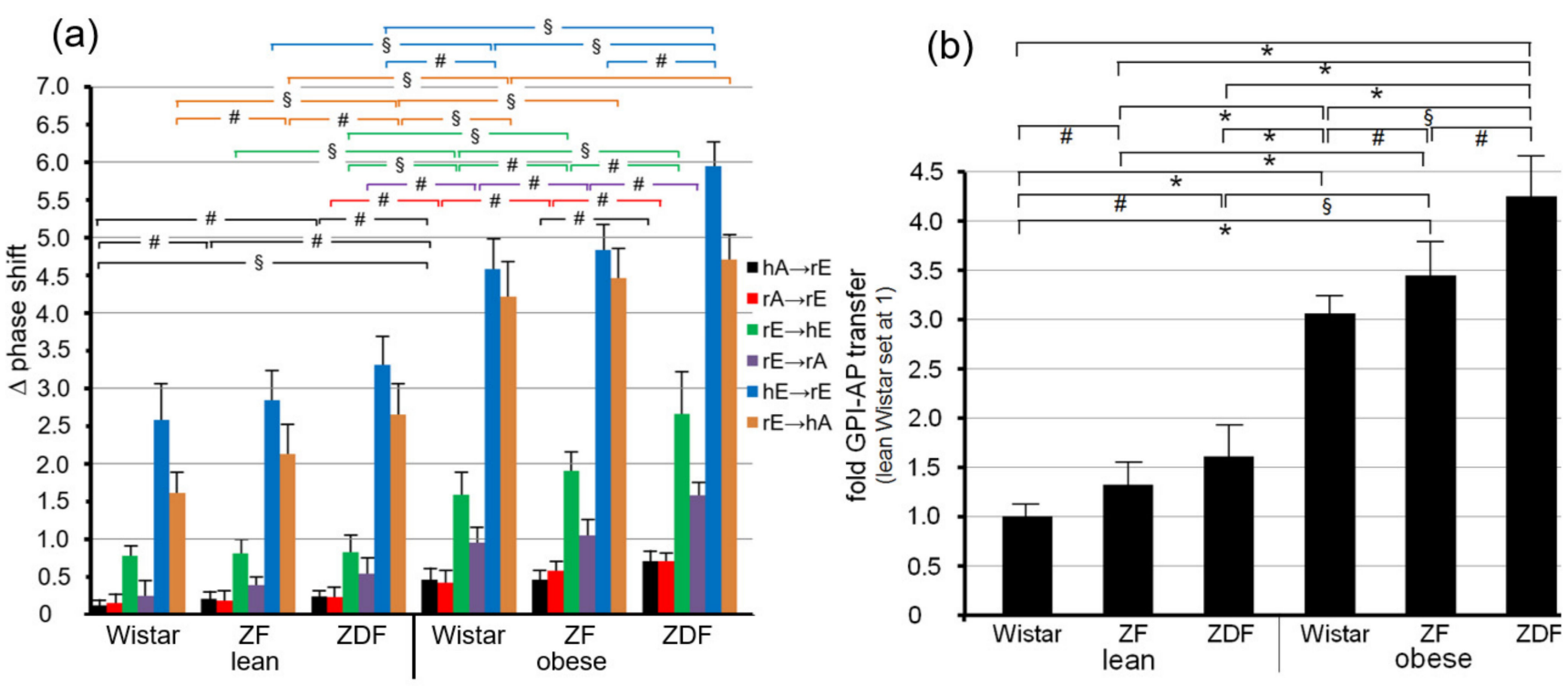

Figure 7. Comparative quantitative evaluation of the six rat groups for transfer of full-length GPI-APs from donor to acceptor PM for the various combinations (a) and the calculated means thereof (b). The experiment was performed as described for Figure 6 with measurements in quadruplicate (with distinct chips each) for each donor-acceptor PM combination. (a) $\Delta$ phase shifts as measure for GPI-AP-induced increases in phase shift are calculated as described for Figure 6 and given as means \pm SD for each combination with statistical significance $\left(\$ p \leq 0.02,{ }^{\#} p \leq 0.05\right.$; only between rat groups displaying relatively small differences for reasons of clarity). (b) Fold GPI-AP transfer was calculated relative to control (acceptor PM only, Figure 6) for each of the six rat groups upon calculation of the means for the donor-acceptor PM combinations for each rat group and normalization of lean Wistar rats (set at 1 ) as means \pm SD with statistical significance ( $p \leq 0.01,{ }^{\circledR} p \leq 0.02,{ }^{*} p \leq 0.05$ between all rat groups).

\subsection{Transfer of Full-Length GPI-APs between Rat PM at Various Combinations Is Impaired by Serum Proteins, among Them GPLD1}

For mimicking of the conditions for the transfer of GPI-APs in vivo, in particular with regard to the milieu surrounding the donor and acceptor tissues and blood cells, by the SAW chip-based sensing system, the buffer present during the incubation of donor and acceptor PM (at 1200-4800 s) was supplemented with serum (Figure 1c). As expected, two-step ionic (at 400-600 s) and then covalent capture (at 600-800 s) of human adipocyte acceptor PM followed by capping of reactive groups (at 800-1000 s) and then removal of $\mathrm{Ca}^{2+}$ (at 1000-1200 s) resulted in pronounced mass loading onto the chip surface (Figure 8a; see Figure 2 for explanation). Injection of diluted serum from lean Wistar rats together with human erythrocyte donor PM (at 1200-4800 s) led to considerably diminished transfer of AChE and CD59 (red line) compared to the absence of serum (blue line). The use of serum depleted of proteins by PEG precipitation (orange line) or heat treatment (pink line) or proteinase $\mathrm{K}$ digestion (green line) or of serum supplemented with synthetic phosphoinositolglycan41 (PIG, brown line), which resembles the structure of the GPI anchor core glycan [61], impaired the serum-induced reduction in GPI-AP transfer at varying degrees. Apparently, rat serum contains proteins which interfere with transfer of GPI-APs, in part by interaction with the core glycan of their GPI anchor, which is competed for by synthetic PIG. The specificity of serum inhibition of transfer was confirmed by the missing effect on the transmembrane proteins, Band-3 and Glycophorin (Figure 8a). 
(a)

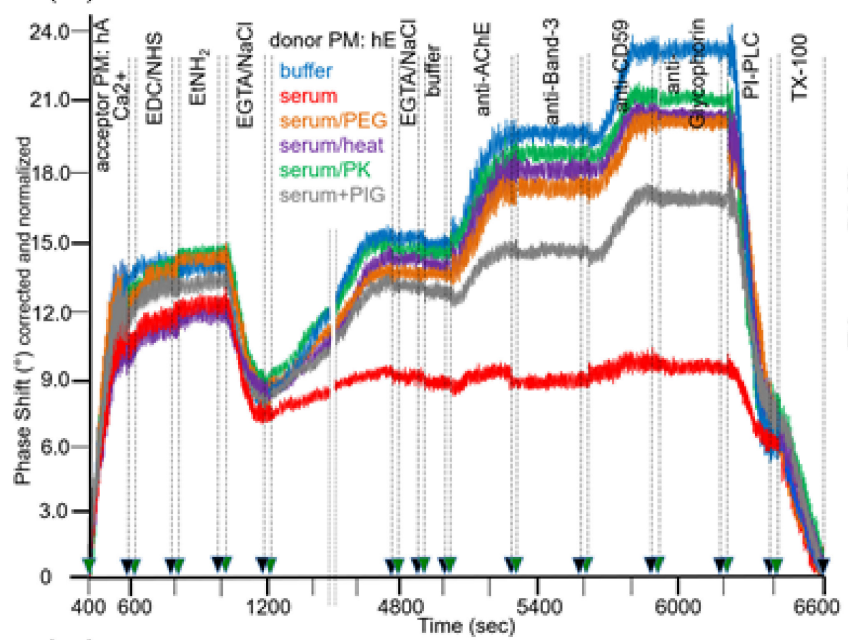

(C)

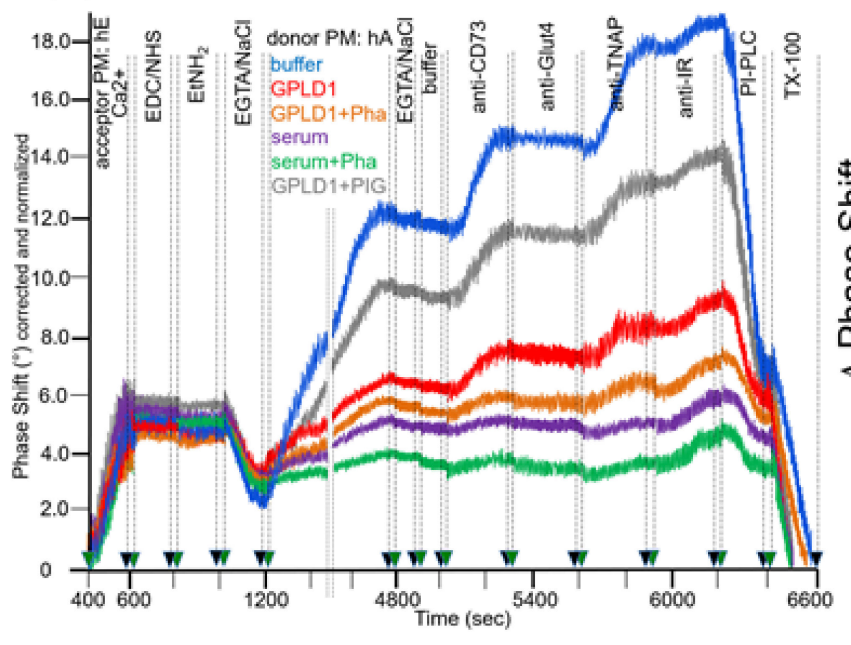

(b)
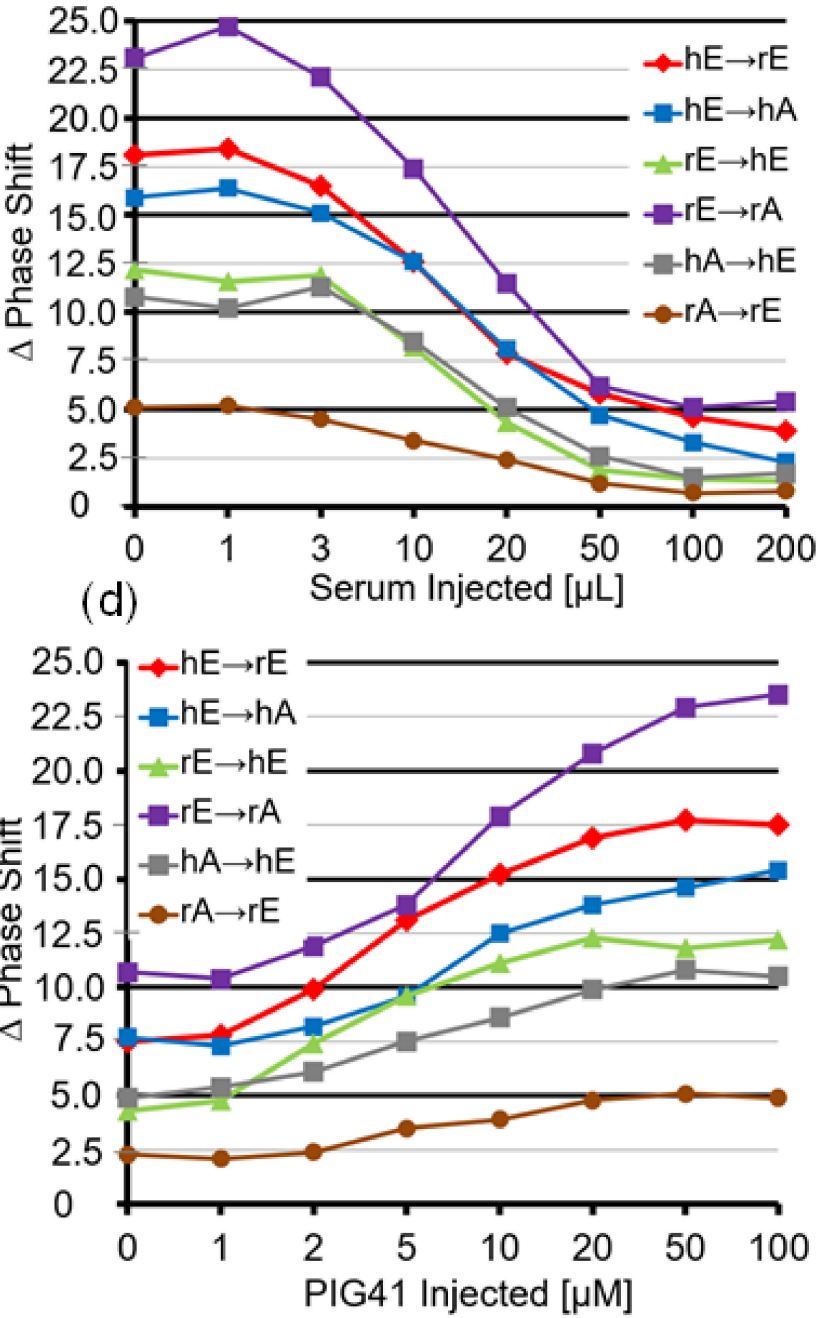

Figure 8. Effect of serum proteins and PIG on the transfer of full-length GPI-APs from donor to acceptor PM at various combinations. $400 \mu \mathrm{L}$ of human erythrocyte (a) or adipocyte (c) donor PM were injected at $1200 \mathrm{~s}$ and at a flow rate of $60 \mu \mathrm{L} / \mathrm{min}$ into chips with human adipocyte (a) and erythrocyte (c), respectively, acceptor PM captured by ionic $\left(\mathrm{Ca}^{2+}\right)$ and covalent bonds (EDC/NHS). (a,c) After blockade with $\mathrm{EtNH}_{2}$ and washing with EGTA/NaCl as described for Figure 2, $100 \mu \mathrm{L}$ of washing buffer or serum from obese rats (diluted 5-fold with buffer), which had been treated with PEG6000, heat, proteinase K (PK), or supplemented with GPLD1 (0.4 units) alone or together with $30 \mu \mathrm{M}$ PIG41 or $100 \mu \mathrm{M}$ Pha, were injected as indicated. Thereafter, the chips were incubated until $4800 \mathrm{~s}$ at $37^{\circ} \mathrm{C}$ at flow rate 0 (double hatched lines). Following injection of EGTA/ $\mathrm{NaCl}$ and then washing buffer, the protein composition of the acceptor PM was assayed by consecutive injection of antibodies against GPI-APs and transmembrane proteins, then of PI-PLC, and finally of TX-100 as indicated. The phase shift measured is given upon correction for unspecific interaction (no acceptor PM) and normalization for variable capturing efficacy. The experiment was repeated once with similar results. (b) Increasing volumes of rat serum (diluted 5-fold) or buffer or (d) $20 \mu \mathrm{L}$ of rat serum, together with increasing concentrations of PIG41 or buffer, were injected. $\Delta$ phase shifts as measure for GPI-AP transfer are calculated as described for Figure 3. The experiments were repeated two times with similar results. Mean values are given for each donor-acceptor PM combination.

Inhibition of GPI-AP transfer by serum from lean Wistar rats held true for each of the six donor-acceptor PM combinations and was dependent on the volume injected with maximal effect at 50-100 $\mu \mathrm{L}$ (Figure $8 \mathrm{~b}$ ).

As a putative candidate for a serum protein inhibiting GPI-AP transfer, GPLD1 was considered based on its interaction with and cleavage of the GPI anchor of GPI-APs [40,62,63]. Consequently, the experiment was repeated with recombinant GPLD1 instead of total serum (Figure 8c). In fact, injection of GPLD1 together with human adipocyte donor PM 
into chips with covalently captured human erythrocyte acceptor PM led to considerable lowering of transfer (at 1200-4800 s, red line) compared to buffer (blue line) which, however, was less pronounced than that provoked by total serum proteins (pink line). Interestingly, ortho-phenanthroline (Pha), which inhibits GPLD1 by chelating of divalent cations [62,63], further enhanced inhibition of GPI-AP transfer by both GPLD1 (orange line) and total serum proteins (green line). Strikingly, PIG41 partially relieved downregulation of transfer by GPLD1 (Figure 8c; brown line).

Restoration of GPLD1-blocked GPI-AP transfer by PIG41 was observed with each of the six donor-acceptor PM combinations and found to depend on the concentration with half-maximal effect at 7-10 $\mu \mathrm{M}$ (Figure $8 \mathrm{~d}$ ). Taken together, these findings strongly suggested that (i) GPLD1 represents one of the serum proteins interfering with transfer of GPI-APs and (ii) its inhibitory potency is due to interaction with the core glycan rather than lipolytic cleavage of the GPI anchor of GPI-APs (Figure 1c).

3.4. Transfer of GPI-APs between Rat PM Depends on the Assembly of GPI Anchors, Phospholipids, and Cholesterol in Non-Vesicular Structures

Previous studies have demonstrated that full-length GPI-APs reconstituted in vitro with phospholipids and cholesterol at certain composition and ratio into micelle-like complexes [32] become translocated into the outer leaflet of isolated or cellular PM under maintenance of their biological function [33]. Similar complexes have recently been identified in serum of rats and humans and their levels were found to be reduced in diabetic and obese rats and humans compared to normal ones [31]. Furthermore, in the present investigation, the translocation of AChE from micelle-like complexes into human adipocyte and erythrocyte acceptor PM was analyzed using the novel chip-based SAW sensing system. Furthermore, this system enabled the discrimination between transfer of GPI-APs from donor to acceptor PM and fusion of donor and acceptor PM (see Figure 5). Taking the available data together, it was tempting to speculate that the transfer of full-length GPI-APs from donor to acceptor PM is mediated by micelle-like complexes rather than membrane structures.

To test for the possibility that micelle-like GPI-AP complexes are generated in the chip channels in course of transfer of GPI-APs, donor PM were injected into chips with covalently captured acceptor PM at various combinations and incubated (at 1200-4800 s) in the absence (control) or presence of un- or pretreated serum proteins or $\alpha$-toxin. Then, the microfluidic chip channels were eluted, and the collected eluates were centrifuged to get rid of any membrane structures including the donor PM. The supernatants were digested with PI-PLC or left untreated for discrimination between structures harboring full-length GPI-APs and GPI-APs lipolytically released from the donor PM. After TX-114 partitioning, the detergent-enriched phases were analyzed for the presence of full-length GPI-APs and transmembrane proteins by dot blotting with corresponding antibodies (Figure 9).

Quantitative evaluation of the immune reactivity of the dots revealed considerable amounts of the GPI-APs, TNAP and CD73, in the undigested (-PI-PLC) chip eluates generated by the $\mathrm{rA} \rightarrow \mathrm{rE}$ (Figure $9 \mathrm{a}$ ), and $\mathrm{AChE}$ and CD59 by the $\mathrm{hE} \rightarrow \mathrm{rE}$ (Figure $9 \mathrm{~b}$ ) and $\mathrm{rE} \rightarrow \mathrm{rA}$ (Figure 9c) combinations in the presence of total serum proteins or blocked (by Pha) GPLD1 or $\alpha$-toxin, i.e., under conditions which have been shown to interfere with the transfer of GPI-APs (see Figure 8). For each combination, the amounts of eluted GPI-APs in the detergent-enriched phase were significantly reduced upon omission of serum proteins (control) or use of serum depleted of proteins by PEG precipitation or use of serum in combination with PIG41. The almost complete removal of GPI-AP immune reactivities from the detergent-enriched phase upon digestion with PI-PLC for all combinations demonstrated the generation of full-length GPI-APs equipped with the complete GPI anchor in the chip channels during transfer from donor to acceptor PM (Figure 9a-c). Only minute amounts of immune-reactive transmembrane proteins Glut4, IR, Band-3, and Glut1, irrespective of the donor-acceptor PM combination, were detectable in the (undigested or digested) chip eluates. 


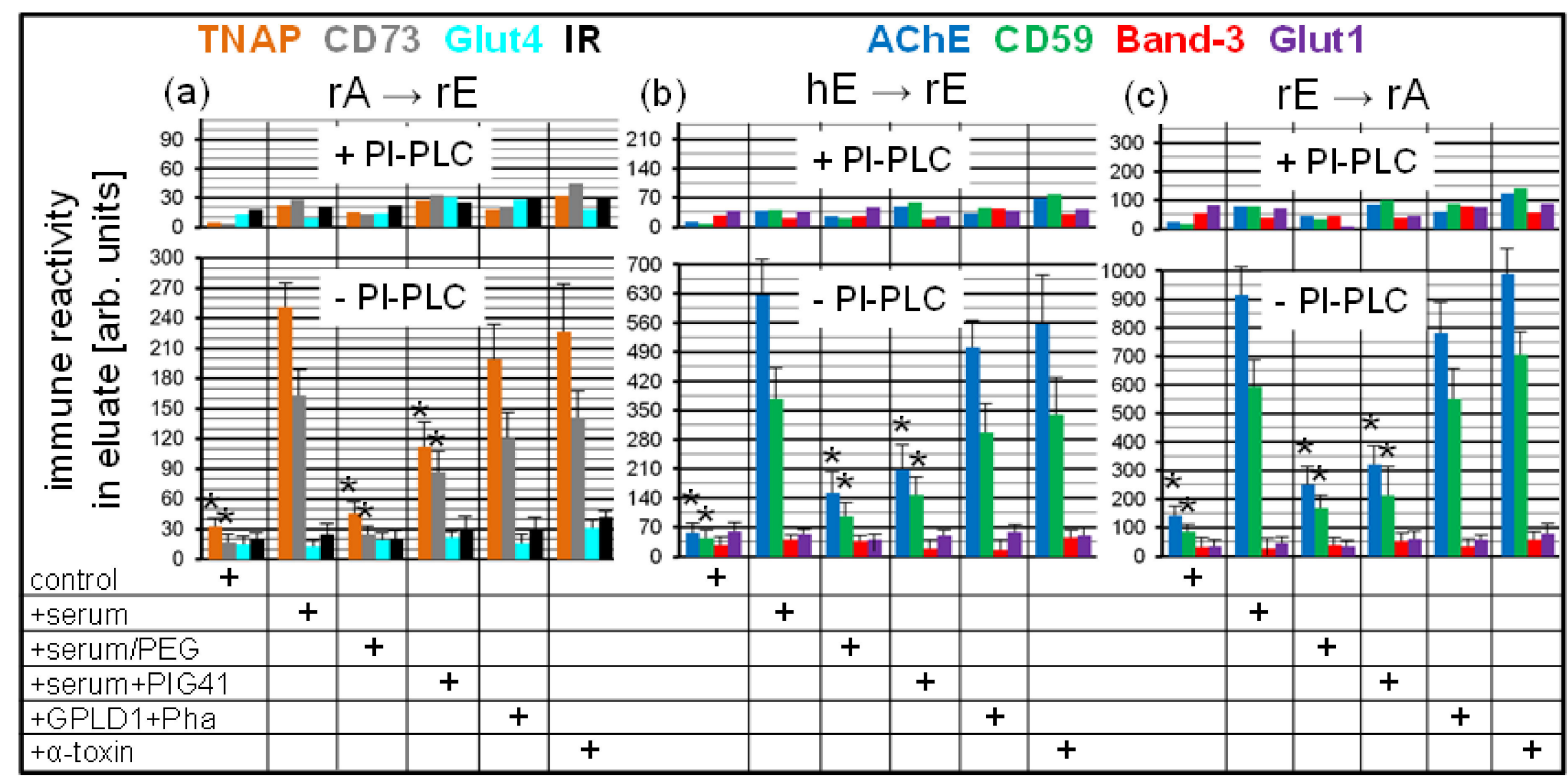

Figure 9. Analysis of the chip eluate for membrane proteins released from the donor PM upon blockade of transfer of full-length GPI-APs to acceptor PM at various combinations. Rat adipocyte (a), human erythrocyte (b), and rat erythrocyte (c) donor PM were injected at $1200 \mathrm{~s}$ and at a flow rate of $60 \mu \mathrm{L} / \mathrm{min}$ into chips with rat erythrocyte (a,b) or rat adipocyte (c) acceptor PM, respectively, consecutively captured via ionic $\left(\mathrm{Ca}^{2+}\right)$ and covalent bonds (EDC/NHS), blocked with EtNH 2 and then washed with EGTA/ $\mathrm{NaCl}$ as described for Figure 8. Thereafter, $100 \mu \mathrm{L}$ of washing buffer (control) or serum from obese rats (diluted five-fold with buffer), which had been treated with PEG6000 or left untreated, alone or together with $30 \mu \mathrm{M}$ PIG41 or GPLD1 (0.4 units) together with $100 \mu \mathrm{M}$ Pha or $\alpha$-toxin $(10 \mu \mathrm{g} / \mathrm{mL})$ were injected as indicated. Thereafter, the chips were incubated until $4800 \mathrm{~s}$ at $37^{\circ} \mathrm{C}$ at flow rate 0 . Following injection of $100 \mu \mathrm{L}$ of EGTA/NaCl at a flow rate of $60 \mu \mathrm{L} / \mathrm{min}$ and then of $400 \mu \mathrm{L}$ of washing buffer at the same flow rate, the eluate from the chip channels was collected from 4900 to $5300 \mathrm{~s}$ and then centrifuged $\left(100,000 \times g, 1 \mathrm{~h}, 4^{\circ} \mathrm{C}\right)$. The supernatants were removed, and halves incubated $\left(2 \mathrm{~h}, 30^{\circ} \mathrm{C}\right)$ in the absence (lower panels) or presence (upper panels) of PI-PLC as described in the Methods section. Following TX-114 partitioning of the incubation mixtures, the detergent-enriched phases were analyzed for the presence of GPI-APs and transmembrane proteins as indicated by dot blotting with antibodies against TNAP, CD73, AChE, CD59, Glut4, IR, Band-3 and Glut1 as described in the Methods section. "+" below the bars denotes the injection of no serum (control), +serum, PEG-treated serum (+serum/PEG), serum together with PIG41 (+serum+PIG41), GPLD1 together with Pha (+GPLD1+Pha) and $\alpha$-toxin ( $+\alpha$-toxin), respectively. The immune reactivities (arb. units) are given as means $\pm \mathrm{SD}$ (four incubations and elutions each with distinct chips) for each eluted protein (with dot blotting in triplicate) upon normalization by subtraction of unspecific signals generated in the absence of antibody ( $p \leq 0.01$ vs. untreated serum alone).

Together, the data are explained best by specific assembly of full-length GPI-APs into non-membrane structures in the chips in course of blockade of transfer by serum proteins, such as GPLD1, or $\alpha$-toxin. The blockade was presumably caused by their binding to the GPI anchors and apparently prerequisite for the accumulation of full-length GPI-APs in the chip channels at amounts, which were detected by dot blotting. It is tempting to speculate that full-length GPI-APs in non-membrane structures (which cannot be spun down by centrifugation at $100,000 \times g$ ) are also generated in the course of (unblocked) transfer following release from the donor PM, however for a short period only, due to rapid translocation into acceptor PM.

Next, the nature of the non-membrane structures apparently harboring the full-length GPI-APs, was characterized (Figure 10). For this, donor PM were injected into $\mathrm{TiO}_{2}$ chips with covalently captured acceptor PM at various combinations and then incubated under conditions of maximal blockade of GPI-AP transfer (see Figure 8c), i.e., in the presence of serum from obese ZDF rats and Pha. Then, the eluates of the chip channels were collected and centrifuged to get rid of any membrane structures, including the donor PM. Portions of the supernatants were treated with TX-100 or left untreated and thereafter incubated with $\alpha$-toxin coupled to Sepharose beads. After centrifugation, the collected beads were 
extracted with SDS (Laemmli buffer) and then analyzed by dot blotting with antibodies against GPI-APs, transmembrane proteins, and peripheral membrane proteins (annexinV). In addition, portions of the SDS extracts were determined for cholesterol contents. Both annexin- $\mathrm{V}$ and cholesterol have recently been demonstrated to be constituents of micelle-like GPI-AP complexes in rat und human serum [33].

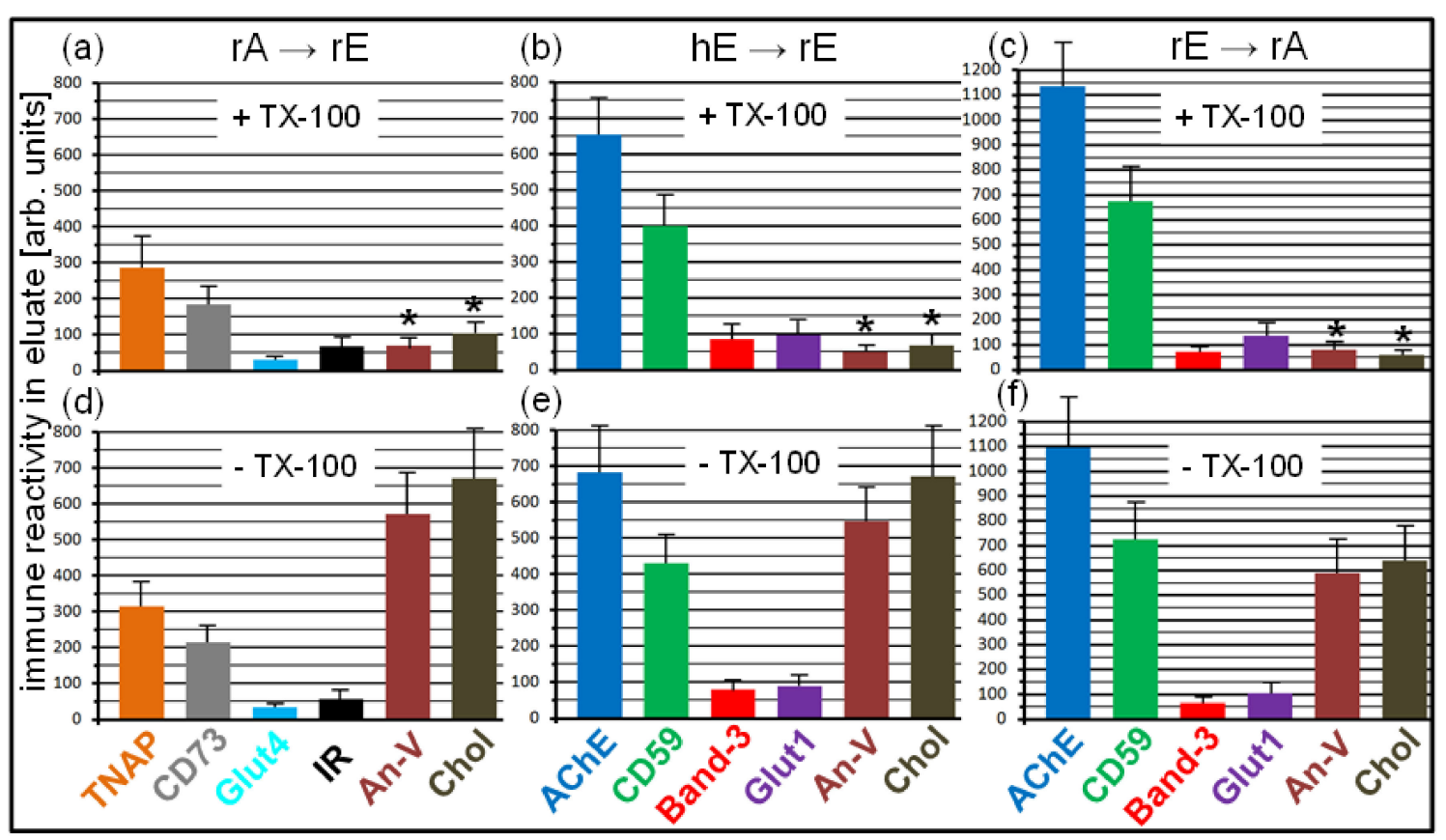

Figure 10. Analysis of the chip eluate for micelle-like GPI-AP complexes released from the donor PM upon blocked transfer of full-length GPI-APs to acceptor PM at various combinations. Rat adipocyte (a,d), human erythrocyte (b,e), and rat erythrocyte $(\mathbf{c}, \mathbf{f})$ donor PM were injected into chips with rat erythrocyte $(\mathbf{a}, \mathbf{b}, \mathbf{d}, \mathbf{e})$ or rat adipocyte $(\mathbf{c}, \mathbf{f})$ acceptor PM as described for Figure 9. Following injection of $100 \mu \mathrm{L}$ of serum from obese ZDF rats (diluted five-fold with buffer) together with $100 \mu \mathrm{M}$ Pha, the chips were incubated until $4800 \mathrm{~s}$ at $37^{\circ} \mathrm{C}$ at flow rate 0 . Following injection of $100 \mu \mathrm{L}$ of EGTA/NaCl at a flow rate of $60 \mu \mathrm{L} / \mathrm{min}$ and then of $400 \mu \mathrm{L}$ of washing buffer at the same flow rate, the eluate from the chip channels was collected from 4900 to $5300 \mathrm{~s}$ and then centrifuged $\left(100,000 \times g, 1 \mathrm{~h}, 4{ }^{\circ} \mathrm{C}\right)$. The supernatants were removed, and halves incubated in the absence (d-f) or presence (a-c) of TX-100 (0.1\%) for $1 \mathrm{~h}$ at $30^{\circ} \mathrm{C}$ and then with $\alpha$-toxin coupled to Sepharose beads as described in the Methods section for $20 \mathrm{~h}$ at $4{ }^{\circ} \mathrm{C}$ (head-over rotation). The mixtures were centrifuged $(10,000 \times g$, $5 \mathrm{~min}, 4^{\circ} \mathrm{C}$ ). The pellets were washed three times by suspending in washing buffer and recentrifugation. The final pellets were suspended in the same volume of two-fold Laemmli sample buffer and heated $\left(5 \mathrm{~min}, 65^{\circ} \mathrm{C}\right)$. Following centrifugation $\left(10,000 \times g, 5 \mathrm{~min}, 25^{\circ} \mathrm{C}\right)$, the supernatants were assayed for the presence of GPI-APs and transmembrane proteins by dot blotting with antibodies against TNAP, CD73, AChE, CD59, Glut4, Glut1, Band-3 and Annexin-V as described in the Methods section. Portions of the washed and Laemmli-extracted $\alpha$-toxin Sepharose beads were determined for cholesterol. The immune reactivities and cholesterol amounts (arb. units) are given as means \pm SD (four distinct transfer incubations and chip elutions each) with dot blotting in triplicate each upon normalization by subtraction of unspecific signals generated in the absence of antibody and Sepharose beads, respectively ( ${ }^{*} p \leq 0.01$ vs. incubation in the absence of TX-100).

Quantitative evaluation of the immune reactivity of the dots revealed considerable amounts of the GPI-APs TNAP and CD73 or AChE and CD59 in the TX-100-treated (upper panels) as well as untreated (lower panels) chip eluates generated by the $\mathrm{rA} \rightarrow \mathrm{rE}$ (Figure 10a,d) and hE $\rightarrow$ rE (Figure 10b,e) as well as rE $\rightarrow$ rA (Figure 10c,f) combinations, respectively, in the presence of total serum proteins, including blocked GPLD1. In contrast, only minute amounts of the transmembrane proteins Glut4, IR, Band-3, and Glut1 were detectable, irrespective of the combination and treatment of the eluate with or without TX-100. Strikingly, annexin-V and cholesterol were detected in untreated eluates of each combination at considerable amounts (Figure 10d-f) but were significantly diminished upon treatment with TX-100 (Figure 10a-c). These data strongly suggested that in course 
of blockade of GPI-AP transfer, full-length GPI-APs accumulate in the chip channels which are embedded together with the phospholipid-binding protein annexin- $\mathrm{V}$ and cholesterol in detergent-sensitive non-membrane structures. It is tempting to speculate that those structures are similar to micelle-like GPI-AP complexes constituted by phospholipids, lysophospholipids, and cholesterol at certain ratios as previously described [30,33] and mediate the transfer of GPI-APs from donor to acceptor PM in the chip in the absence of serum proteins.

3.5. Control of Transfer of GPI-APs between Rat PM at Various Combinations by Serum Proteins Depends on the Metabolic State of the Rats

The above observation (see Figure 8) demonstrated that rat serum proteins, among them GPLD1, interfere with the transfer of GPI-APs from donor to acceptor PM. Previous findings revealed differential interaction of GPI-APs with serum proteins from rats of varying metabolic phenotype [32]. Together, this raised the possibility of inhibition of GPI-AP transfer by serum proteins in relation to the metabolic state of the rats, which was tested by the final set of experiments (Figures 11 and 12).

(a)

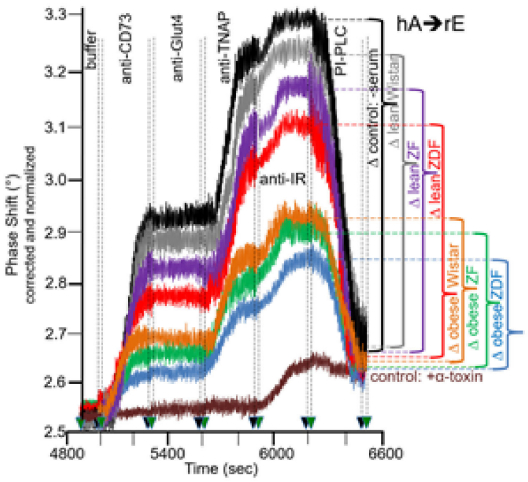

(b)

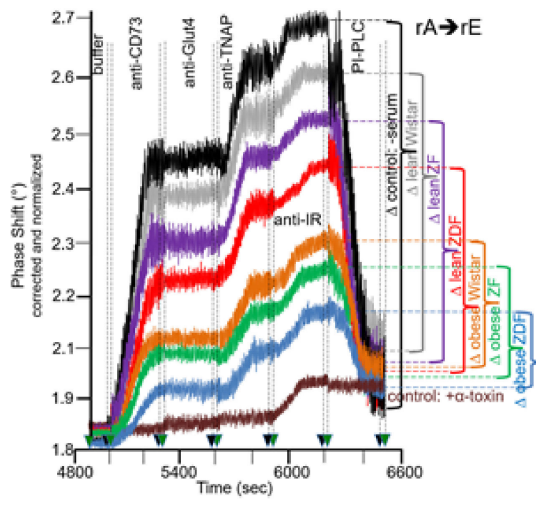

(c)

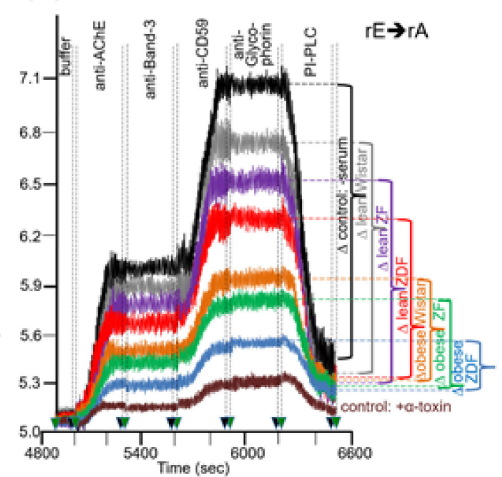

(d)

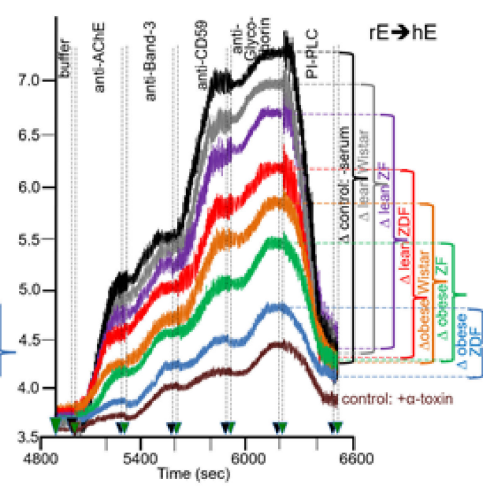

(e)

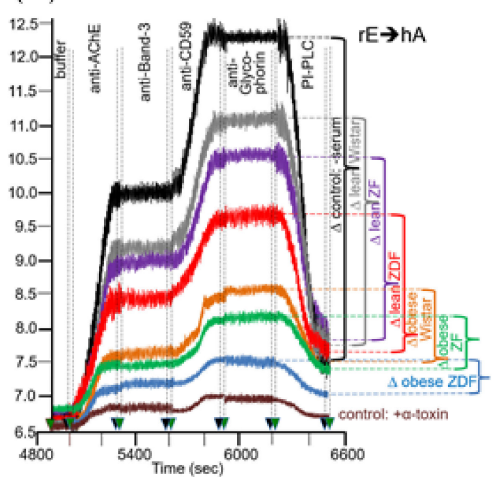

(f)

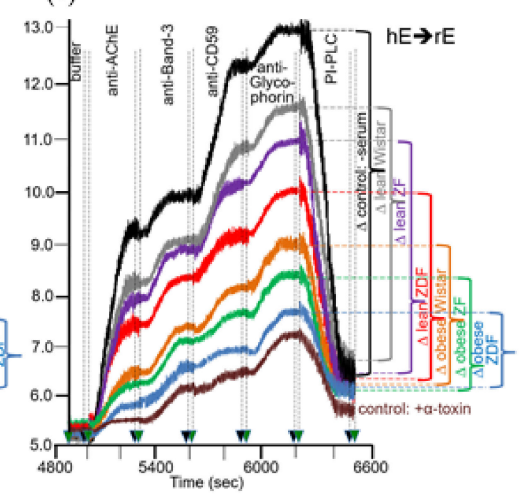

Figure 11. Determination of the effect of serum proteins from the six rat groups on the transfer of full-length GPI-APs from donor to acceptor PM at various combinations. The experiment was performed as described for Figure 6 with injection of $400 \mu \mathrm{L}$ of donor PM (800-1200 s) at a flow rate of $60 \mu \mathrm{L} / \mathrm{min}$ and subsequent incubation (until $4800 \mathrm{~s}, 60 \mathrm{~min}, 37^{\circ} \mathrm{C}$ ) of the donor-acceptor PM combinations ((a), hA $\rightarrow \mathrm{rE}$; (b), $\mathrm{rA} \rightarrow \mathrm{rE}$; (c), $\mathrm{rE} \rightarrow \mathrm{rA} ;(\mathbf{d}), \mathrm{rE} \rightarrow \mathrm{hE} ;(\mathbf{e}), \mathrm{rE} \rightarrow \mathrm{hA} ;(\mathbf{f}), \mathrm{hE} \rightarrow \mathrm{rE})$ in the absence (control: -serum) or presence of $100 \mu \mathrm{L}$ serum (diluted five-fold) from the six rat groups or in the presence of $10 \mu \mathrm{g} / \mathrm{mL} \alpha$-toxin (control: $+\alpha$-toxin) as indicated (donor PM $\rightarrow$ acceptor PM). At variance with Figure 6 , the rat (r) donor and acceptor PM were derived from adipocytes (A) and erythrocytes (E) which had been isolated from obese ZDF rats. Phase shifts are shown only between start of buffer injection (4800 s) and termination of PI-PLC injection (6600 s). $\Delta$ phase shifts as measure for GPI-AP transfer are calculated as described for Figure 3. 
(a)
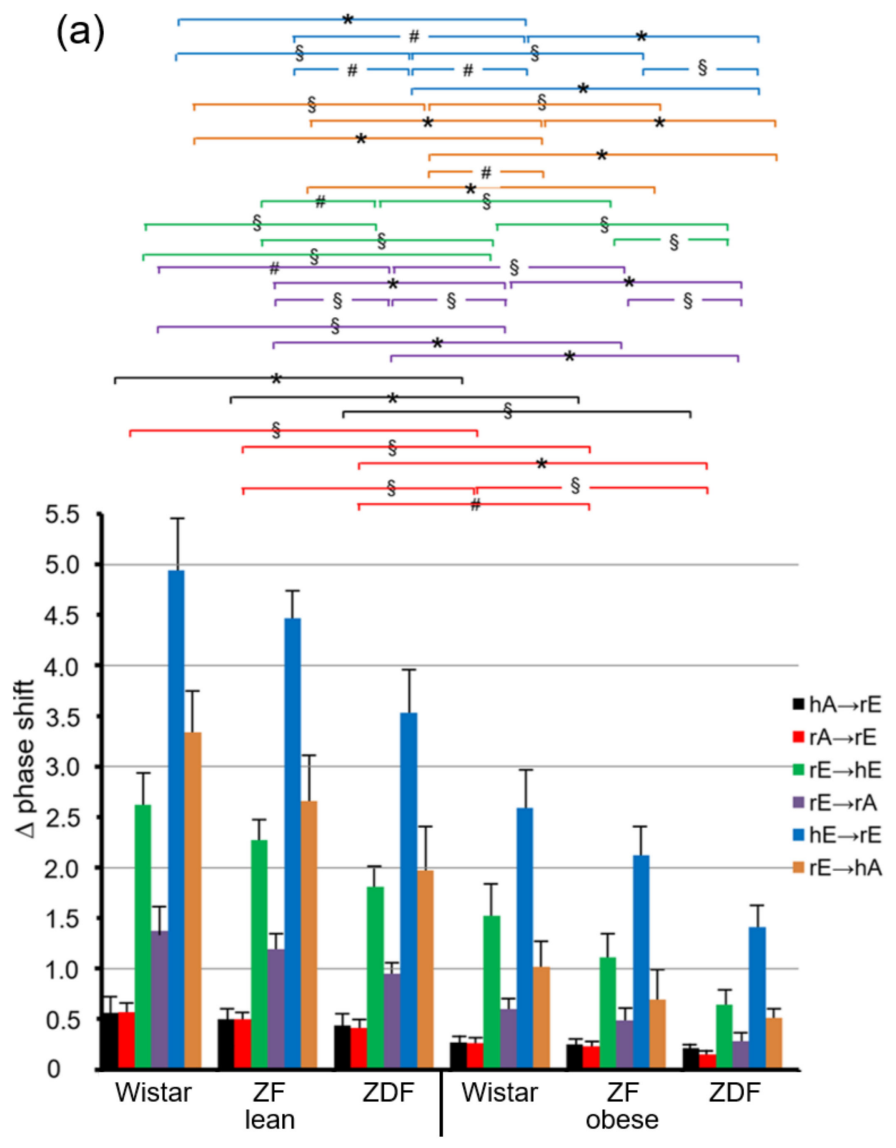

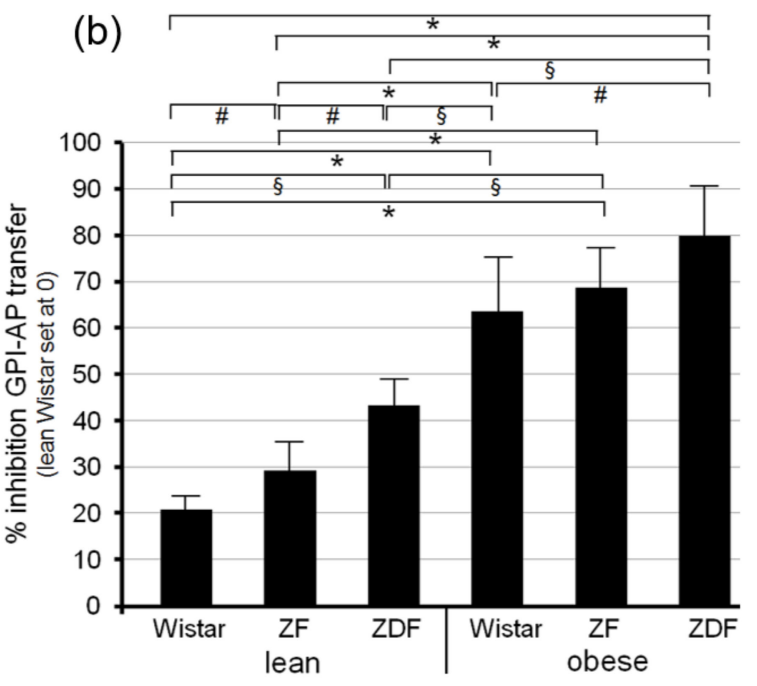

Figure 12. Comparative quantitative evaluation for the six rat groups of the inhibition of transfer of full-length GPI-APs from donor to acceptor PM at the various combinations (a) and the calculated means thereof (b). The experiment was performed as described for Figure 11 with measurements repeated six times for each donor-acceptor PM combination (different incubations with distinct chips each). (a) $\Delta$ phase shifts as measure for GPI-AP-induced increases in phase shift are calculated as described for Figure 7 and given as means \pm SD for each combination with statistical significance $(* p \leq 0.01$, $\S p \leq 0.02,{ }^{\#} p \leq 0.05$ ) indicated only for rat groups displaying relatively small differences (for reasons of clarity). (b) \% inhibition of GPI-AP transfer was calculated relative to control (-serum, Figure 11) for each of the six donor-acceptor PM combinations and each of the six rat groups upon normalization of lean Wistar rats (set at 0 ) as means \pm SD with statistical significance $\left({ }^{*} p \leq 0.01,{ }^{\S} p \leq 0.02,{ }^{*} p \leq 0.05\right)$ indicated between all rat groups.

Lowering of GPI-AP transfer by serum proteins was monitored for each of the six rat groups using the above six donor-acceptor PM combinations (Figure 11). Transfer of adipocyte CD73 and TNAP (Figure 11a,b), as well as erythrocyte AChE and CD59 (Figure 11c-f), were lowest for obese ZDF rats. This presumably reflected the most pronounced blockade of GPI-AP transfer, which was almost as potent as that provoked by $\alpha$-toxin (control for maximal inhibition). For obese ZF and Wistar rats and lean ZDF and ZF rats, intermediary levels of GPI-AP transfer in this ranking order of declining potency were measured, compatible with its intermediary blockade. Lean Wistar rats displayed highest transfer and thus the least potent blockade. Importantly, for each of the six donor-acceptor PM combinations incubated with serum from each of the six rat groups, no transfer of adipocyte Glut4 and IR (Figure 11a,b) as well as erythrocyte Band-3 and Glycophorin (Figure 11c-f) was detected. Moreover, for each combination and serum incubation, final injection of PI-PLC (at 6200-6500 s) resulted in decrease of GPI-AP transfer (at 6200 s) by 50 to $85 \%$. This reemphasized the efficacy of the transfer for GPI-APs compared to transmembrane proteins.

Quantitative evaluation revealed drastic differences in the transfer of total GPI-APs in the presence of serum proteins between the various donor-acceptor PM combinations with identical ranking for each rat group with decreasing efficacy in that order (Figure 11): $\mathrm{hE} \rightarrow \mathrm{rE}>\mathrm{rE} \rightarrow \mathrm{hA}>\mathrm{rE} \rightarrow \mathrm{hE}>\mathrm{rE} \rightarrow \mathrm{rA}>\mathrm{hA} \rightarrow \mathrm{rE}>\mathrm{rA} \rightarrow \mathrm{rE}$. These data confirmed 
the above finding (see Figure 7) that the transfer efficacy is determined by both donor and acceptor PM.

Most importantly, significant differences in GPI-AP transfer became apparent between the six rat sera, which were independent of the donor-acceptor PM combination (Figure 12a). Consequently, maximal differentiation power was obtained by summing-up the phase shift differences measured for all six donor-acceptor PM combinations for each of the six rat groups and calculating the \% inhibition of GPI-AP transfer (Figure 12b). This resulted in significant differences between the six rat groups with increasing transfer inhibition in that ranking order: lean Wistar $<\mathrm{ZF}<\mathrm{ZDF}<$ obese Wistar $<\mathrm{ZF}<\mathrm{ZDF}$.

The differential inhibition of GPI-AP transfer by serum proteins from rats of different metabolic phenotype may be explained by subtle differences in the steady-state and kinetic parameters of their binding to the GPI anchor of GPI-APs, such as affinity and $k_{\text {on }}$ - and $\mathrm{k}_{\text {off }}$-rates. Those could be rate-limiting for the relief of serum proteins from binding to GPI-APs, and thus for their subsequent translocation into the PM of tissue and blood cells in vivo.

\section{Discussion}

\subsection{Cell-Free Analysis of the Intercellular Transfer of GPI-APs}

The major advantage of studying cellular processes with cell-free assays, in general, relies on the use of defined molecular components and experimental conditions as well as on their straightforward manipulation with the aim to identify the optimal configuration, which may also be relevant in vivo. In particular, cell-free assaying of the intercellular transfer of GPI-APs with the aid of a microfluidic chip-based SAW sensor, as introduced in the present study, enables the variation of the donor and acceptor PM derived from relevant tissue and blood cells, such as adipocytes and erythrocytes, at six different combinations as well as of the extracellular milieu, such as serum proteins, among them GPLD1. For this, acceptor PM covalently captured by the $\mathrm{TiO}_{2}$ chip surface (Figures $1 \mathrm{a}$ and 2) were incubated with injected donor PM within the chip channels. After removal of the donor PM, the acceptor PM were assayed for the presence of GPI-APs and transmembrane proteins putatively transferred from the donor PM by injection of relevant antibodies (Figure 1b). Mass loading onto the chip surface accomplished (to a lower extent) by the transferred proteins per se and (to a higher extent) by bound antibodies (Figure 3) rather than $\left(\mathrm{Ca}^{2+}\right.$ mediated) fusion of donor and acceptor PM (which was distinguished from transfer by kinetic and biochemical criteria; Figures 4 and 5) led to right-ward shifts of the phase (phase shift increases) of the SAW which (as summation signal) reflected the transfer of proteins from donor to acceptor PM.

The data generated with the chip-based SAW sensing demonstrated that (i) rat and human adipocyte and erythrocyte PM can serve as both donor and acceptor for the transfer of GPI-APs (Figures 3 and 6), (ii) transmembrane proteins do not undergo transfer to any detectable extent (Figures 3 and 6), thus confirming previous findings [19-22], (iii) transfer efficacies differ between rat and human adipocyte and erythrocyte PM being highest between erythrocytes (Table 1), (iv) both donor and acceptor PM determine transfer efficacy (Figures 3 and 6), compatible with release of GPI-APs from donor PM as well as their translocation into acceptor PM being of comparable importance for transfer, (v) transfer of GPI-APs is affected by the incubation conditions (Figure 4) and the milieu surrounding the donor and acceptor PM with serum proteins, downregulating its efficacy (Figure 8), (vi) interaction of the core glycan of the anchor of GPI-APs with serum proteins, such as GPLD1 (in particular in the inhibited state) or $\alpha$-toxin, causes lowering of transfer efficacy (Figures 8 and 9), suggesting that this action mode mediates (part of) the inhibitory effect of serum proteins and (vii) transfer involves the incorporation of full-length, but not of anchor-less GPI-APs or transmembrane proteins, together with annexin-V and cholesterol into micelle-like complexes (Figures 9 and 10) rather than into membrane-/vesicle-like or lipoprotein-like structures (Figure 2e,f). 


\subsection{The (Patho)Physiological Relevance of the Intercellular Transfer of GPI-APs}

In addition to the elucidation of the molecular components involved in and the biochemical conditions supporting the transfer of GPI-APs between cells of neighboring or distant tissue depots or compartments, the cell-free assay was helpful to obtain initial hints for the elucidation of the cellular function and (patho)physiological role of GPI-AP transfer in vivo, according to the following considerations:

The demonstrated transfer of full-length GPI-APs between adipocyte and erythrocyte PM, as well as between erythrocyte PM in both directions in vitro (Table 1; the transfer between adipocytes, could not be assayed due to non-availability of species-specific antibodies and similar levels of AChE as well as TNAP expression in rat and human adipocytes). This suggests operation in vivo of GPI-AP transfer between cells of different types, such as adipocytes, endothelial cells, and macrophages of the same adipose tissue depot via a paracrine route, or adipose tissue cells and blood cells via an endocrine route as well as between cells of the same type, such as erythrocytes, via an endocrine route. Given the well-documented advantages and disadvantages of GPI anchorage of ectoproteins, such as maintenance of the biological function of the protein moiety [20,64-69] and membrane disturbance and lytic effects of the GPI moiety [32], respectively, it is tempting to speculate about GPI-AP transfer as a two-sided sword in the control of cell surface expression: Wanted within a tissue depot for the sake of compensation for insufficient expression at neighboring cells and unwanted between different tissue depots or blood compartment.

The decision between the putatively wanted functional or physiological paracrine transfer route and the unwanted non-functional/physiological endocrine route, made by a given GPI-AP, may be determined by the local arrangement of putative donor and acceptor cells within a tissue depot. In addition, limited accessibility of the interstitial spaces for inhibitory serum proteins and long distance between different tissue depots, as well as the presence of serum proteins, such as GPLD1, in the blood compartment may contribute to facilitation and impairment of transfer, respectively, i.e., to paracrine vs. endocrine routing of GPI-APs.

Proteins and factors have been identified which trigger down- or upregulation of transfer and apparently either interact with the core glycan of the GPI anchor, such as GPLD1 and bacterial $\alpha$-toxin or interfere with this interaction, such as synthetic PIG, respectively (Figures 8 and 9). This argues that intercellular transfer of GPI-APs is a regulated rather than spontaneous process as has already been suggested previously [70].

\subsection{Metabolic Diseases and the Intercellular Transfer of GPI-APs}

Strikingly, efficacy of transfer in the absence of serum proteins (Figures 6 and 7) and inhibition of transfer by serum proteins (Figures 11 and 12) were found to depend on the metabolic state of the rats providing the donor/acceptor PM and serum samples, respectively. Both turned out to be highest for hyperglycemia/hyperinsulinemia (obese diabetic ZDF rats), lowest for normoglycemia/normoinsulinemia (lean Wistar rats), and intermediary for normoglycemia/hyperinsulinemia depending on the plasma insulin level (Table 2) with the following ranking order of declining efficacy/inhibition: Obese ZF rats $>$ obese Wistar $>$ lean ZDF $>$ lean ZF (Figures $7 b$ and $12 b$ ).

The apparent link between transfer efficacy and transfer inhibition may be explained as follows: 1. Specific alterations of the biophysical and biochemical properties of the PM in response to elevated blood glucose and plasma insulin favor release of GPI-APs from PM of tissue and blood cells, such as adipocytes and erythrocytes, and/or their translocation into PM and thus stimulate "overall" transfer. 2. Stimulation of transfer is paralleled by upregulation of expression of serum proteins, such as GPLD1, which prevent translocation of GPI-APs into PM, presumably by interaction with the core glycan of the GPI anchor. 3. The known deleterious effects of full-length GPI-APs and GPI anchors on the integrity of phospholipid bilayers of cultured cells [32] necessitate tight control of the transfer efficacy of GPI-APs, e.g., during hyperglycemic/hyperinsulinemic state, to ensure physiological function and viability of the acceptor cells. These explanations reinforce the 
value of a cell-free assay based on defined components (donor and acceptor PM, absence or presence of serum proteins) since in vivo the apparent counterregulation of stimulation and inhibition of transfer of GPI-APs by the obese/diabetic state would have resulted in steady-state level of transfer and thereby masked the role of the metabolic genotype and feeding state in transfer. The possibility of operation in vivo of intercellular transfer of GPI-APs, e.g., from adipocytes to erythrocytes, and of its mechanistic coupling to the metabolic state justifies future investigations for delineation of cause or consequence as well as of the potential for novel approaches for the prediction or cure of metabolic diseases, such as obesity and diabetes.

With regard to the apparent correlation of the efficacy of transfer of specific GPI-APs, i.e., of TNAP, CD73, AChE, CD55, and CD59, between adipocyte and erythrocyte PM and the metabolic state of the rats (diabetic/obese vs. healthy) as revealed in the present study, only CD73 has been linked to the regulation of glucose and lipid metabolism so far. The 5'-nucleotidase activity of CD73 converts extracellular AMP to adenosine [71,72], which is known to block lipolysis and contribute to diabetic insulin resistance via signaling through adenosine $\mathrm{A}_{2 \mathrm{~B}}$ receptors [73]. In agreement, CD73-derived extracellular adenosine manages to control body fat homeostasis since deletion of CD73 has been reported to foster dyslipidemia and intramyocellular lipid accumulation in muscle of mice [74]. In particular, CD73 KO mice gained significantly less body weight and displayed lowered number and size of white adipocytes as well as increased serum free fatty acid and triglyceride levels compared to wildtype mice. This phenotype was accompanied by elevated blood glucose and serum insulin levels and impaired insulin signaling in skeletal muscle of CD73 KO mice, as reflected in decreased insulin-induced Akt phosphorylation. Insulin secretion and the level of insulin-degrading enzyme remained unaltered [74].

Interestingly, CD73 harboring the complete GPI anchor was reported to be released from cultured and primary adipocytes in microvesicles in response to metabolically relevant stress factors, such as high levels of palmitate, reactive oxygen species, and anti-diabetic drugs [75-78]. Furthermore, the level of CD73 in plasma was shown to be correlated with insulin sensitivity in diabetic mice and human probands [79-82].

In addition to CD73, only a few other GPI-APs have been linked so far to glucose and lipid metabolism, among them glycolipid-anchored cAMP-binding ectoprotein (Gce1), T-cadherin, and glypican-4 (Gpc4). Gce1, which binds and cleaves cyclic adenosine monophosphate (cAMP) through phosphodiesterase activity, has first been identified at the outer leaflet of PM of yeast [83] and then rat adipocytes [38]. Gce1 cooperates with CD73 in the degradation of cAMP via AMP to adenosine [84]. Both are thought to coordinate the inverse regulation of lipid degradation and synthesis at the surface of intracellular lipid droplets between small and large adipocytes [85,86].

T-cadherin acts as a GPI-anchored cell surface coreceptor [87] for the hexameric and high-molecular-weight species of adiponectin [88]. This adipokine is exclusively secreted by differentiated adipocytes [89] and is downregulated in the serum of obese and diabetic rodents and humans [90]. Since those adiponectin species have been demonstrated to activate NF-kB [91], T-cadherin expressed in endothelial and smooth muscle cells has been linked to the anti-inflammatory response of adiponectin in course of metabolic syndrome and endothelial dysfunction [92]. It remains to be investigated whether GPIanchored T-cadherin is transferred from those cells to adiponectin effector cells which display low T-cadherin expression, such as myocytes and hepatocytes. In this case, transfer may contribute to adiponectin-induced stimulation of fatty acid oxidation in muscle and glycogen synthesis in liver as well as inhibition of gluconeogenesis in liver [93].

Gpc4 is a member of the family of GPI-anchored heparan sulfate proteoglycans and supports as a coreceptor a number of growth factors, such as Wnt, fibroblast growth factors, and Hedgehog in mammals [94,95]. Gpc4 was reported to regulate insulin signaling via interaction with the insulin receptor [96]. Importantly, both membrane-associated GPIanchored and soluble anchor-less Gpc4 were able to interact with the unoccupied insulin receptor and to stimulate insulin signaling, whereas the occupied insulin receptor failed to 
interact with Gpc4. Overexpression of the native GPI-anchored Gpc4 in or incubation of the recombinant anchor-less Gpc4 with 3T3-L1 adipocytes caused upregulation of insulin signaling, whereas depletion of Gpc4 blocked insulin receptor autophosphorylation and downstream signaling [96].

Interestingly, Gpc4 was detected in serum of mice and humans, with levels being positively correlated to body fat mass and insulin resistance [96]. The expression of soluble Gpc4 in serum and its relationship to BMI and glucose tolerance could rely on its lipolytic release from the surface of donor cells. In fact, GPI-specific phospholipases C and D were demonstrated to cleave the GPI anchor of Gpc4 [97,98]. Furthermore, serum levels of GPLD1 were shown to be elevated in response to feeding a high-sucrose diet [99], but to be diminished in $o b / o b$ mice [100] as holds true for Gpc4 [96]. The strong correlation between serum Gpc4 levels and BMI in humans together with the observation that Gpc4 is released from primary adipocytes in vitro strongly argue for adipose tissue as the major source of serum Gpc4. These findings have been interpreted to indicate that Gpc4 acts as an insulinsensitizing adipokine by direct interaction with the insulin receptor and accompanying activation and downstream signaling independent of whether being presented in the GPI-anchored or soluble lipolytically cleaved version.

The data presented in this study now raise the possibility that (part of) the link between glucose/lipid metabolism and the function of certain GPI-APs previously attributed to their stable surface expression at certain cell types, such as adipocytes [74,96,101-105], or to their cleavage into a soluble anchor-less version [97-100] relies on the paracrine or endocrine transfer of their full-length versions from donor to acceptor/effector cells.

\subsection{Future Studies of Intercellular Transfer of GPI-APs In Vivo}

The presented findings about stimulatory and inhibitory factors of transfer of GPI-APs between PM in vitro should motivate analysis of the (patho)physiological relevance of intercellular transfer in appropriate animal models for obesity and diabetes. One option relies on the expression of green fluorescent protein (GFP) as GPI-anchored version (GPIGFP) in relevant tissues, such as adipose, liver, and muscle, in transgenic healthy, obese, and diabetic mice using tissue-specific inducible promoters. The route of GPI-GFP from expressing to non-expressing cells of the same tissue depot (paracrine route) or of different tissue depots (endocrine route) may be determined by high-resolution imaging at various time points upon induction. Moreover, this technology would enable the investigation of intercellular transfer of GPI-GFP in response to endogenous (genotypic) and/or exogenous (environmental) cues, such as ageing, nutritional state, and stress. Thereby, the possibility of control of expression of cell surface proteins is not solely determined by gene expression in the corresponding cell type but, in addition, by acquisition of GPI-APs from neighboring or distant tissue and blood cells upon transfer through direct contact or via body fluids would be addressed.

Considering physiological relevance, it may be of interest to see whether transfer of GPI-APs is confined to certain microdomains (lipid rafts) of the acceptor PM [106,107]. In nonpolarized cells, such as fibroblasts and T-cells, GPI-APs are organized in cholesterol-containing nanoclusters [108]. At variance in polarized epithelial cells, such as Madin-Darby canine kidney and intestinal cells, GPI-APs of a single species initially become targeted to small cholesterol-independent homoclusters, which subsequently coalesce into larger cholesteroldependent heteroclusters consisting of multiple GPI-APs species [109,110]. Moreover, it has been demonstrated previously that in fully polarized cells, GPI-APs are directly sorted to the apical cell surface without passing through the basolateral PM. This argues for apical vs. basolateral sorting of GPI-APs at intracellular sites prior to arrival at PM [111,112]. Thus, considering transfer of GPI-GFP to PM during cellular or animal studies, several possibilities are conceivable for the final targeting/destination of transferred GPI-GFP: Homogenous distribution over the complete PM vs. clustering in microdomains and, in addition, in polarized cells, exclusive expression at either the apical or the basolateral surface vs. uniform distribution over the complete cell surface [113]. In any case, the 
recently demonstrated impact of different carboxy-terminal GPI-attachment signals on apical vs. basolateral trafficking of GPI-APs via control of their oligomerization state [114] has to be considered for the construction of GPI-GFP passenger candidates suitable for studying intercellular GPI-AP transfer in vivo.

After successful visualization of donor and acceptor cells fostering GPI-AP transfer via the paracrine or endocrine route, the nature of GPI-APs specifically transferred in course of a given (patho)physiological state should be identified. With this information, the causal relationship between the paracrine or endocrine transfer of specific GPI-APs and a normal or disease phenotype may be studied in mice with knockout/in of the genes encoding the authentic GPI-AP/chimeric transmembrane version, which have to be constructed by exchange of the signals for GPI and transmembrane anchorage [115-117].

\subsection{Conclusions}

The cell-free chip-based sensing assay for the transfer of full-length GPI-anchored cell surface proteins between PM, introduced in the present study (for human and rat erythrocytes and adipocytes), demonstrated its dependence on the metabolic state (here obese and diabetic) of the donor organism (here rats) and its control by serum proteins (here in particular GPLD1). Upregulation of transfer by hyperglycemia and hyperinsulinemia is counterbalanced by serum proteins, which interact with the GPI anchor of the cell surface proteins within micelle-like complexes upon release from PM. This assay will be helpful for identification of the components, tissues, and (patho)physiological processes specifically involved in intercellular transfer of cell surface proteins as well as for screening for drug candidates which modulate transfer in course of dysregulation as cause for or consequence of certain (metabolic) diseases.

The available experimental body of evidence clearly indicates that intercellular transfer of GPI-APs via non-membrane structures, i.e., micelle-like GPI-AP complexes [30-33] or lipoprotein-like particles $[29,58,118-120]$, as analyzed in the present study, must be regarded as a mode of protein transfer between cells. Protein transfer has meanwhile gained acceptance as a mechanism for the regulation of the (surface) expression of a given protein in a given cell independent of the expression of the corresponding gene in that cell. Another mode is represented by extracellular vesicles which manage to transfer both membrane and soluble proteins in course of budding from donor cells and subsequent fusion with acceptor cells [1-6]. Recent studies have unequivocally demonstrated the (patho)physiological relevance of protein transfer in vivo, e.g., for the adipocyte-extracellular-vesicle-endothelium axis, which is governed by the metabolic state [121-124].

Finally, it has to be stated that intercellular transfer of GPI-APs does not represent the only path for a cell to get rid of GPI-APs, but rather is only a minor one. The others, identified during the last three decades, encompass (i) endocytosis followed by sorting to the endosomal/lysosomal compartment for recycling/degradation of unwanted/nonfunctional GPI-APs $[125,126]$, (ii) in polarized cells, transcytosis following internalization from one PM compartment, targeting of transport vesicles across the cytoplasm and their fusion with the other compartment for trafficking of GPI-APs from the apical to the basolateral cell surface vice versa $[127,128]$, (iii) shedding from the cell surface in course of lipolytic cleavage (see Introduction) for hepatic clearance or operation as signaling molecule or mediation of effects at distinct sites, (iv) release in extracellular vesicles (see Introduction) and (v) in lymphocytes trogocytosis as the extraction of GPI-APs embedded in intact PM fragments from the cell surface of antigen-presenting cells and subsequent transfer to $T$, $\mathrm{B}$ and natural killer cells [129-131]. This panel of possible fates and functions of GPI-APs upon expression at the cell surface has now to be supplemented with intercellular transfer via non-membrane structures corroborating the diversity and complexity of the biology and (patho)physiology of GPI-APs.

Supplementary Materials: The following are available online at https: / www.mdpi.com/article / 10.3390/biomedicines9101452/s1, File S1: Fundamentals of biomolecule sensing with surface acoustic waves using the samX-biosensor from SAW Inc. (Bonn, Munich, Germany). 
Author Contributions: G.A.M., design of the study, implementation of the methods, experimentation, data mining, interpretation of the results, writing (original draft), writing (final version), review and editing; M.H.T. and T.D.M., design of the study, interpretation of the results and review. All authors have read and agreed to the published version of the manuscript.

Funding: T.D.M. receives research funding by the German Research Foundation DFG-TRR296 and TRR152. M.H.T. receives research funding from the Initiative and Networking Fund of the Helmholtz Association and from the European Research Council ERC (AdG HypoFlam no. 695054) and from the Helmholtz Alliance "Aging and Metabolic Programming" (AMPro).

Institutional Review Board Statement: All experimental procedures were conducted in accordance with the German Animal Protection Law (paragraph 6) and corresponded to international animal welfare legislation and rules. The human serum samples were obtained from the participants (healthy controls) of the observational study "BioDiab" (study ID 724-15, 20 June 2017).

Informed Consent Statement: All human volunteers gave informed and written consent as approved by the respective institutional review board of the Ludwig-Maximilians-Universität München.

Data Availability Statement: The datasets generated and analyzed during the current study are available from the corresponding author (G.A.M.; guenter.mueller@helmholtz-muenchen.de) on reasonable request and will be provided as the original SAW data files together with the appropriate SAW software for data visualization and processing, if required, under consideration of the relevant conditions for licensing of FitMaster ${ }^{\circledR}$, SensMaster®and SequenceMaster ${ }^{\circledR}$.

Conflicts of Interest: No conflicts of interest, financial or otherwise, are declared by G.A.M. and T.D.M. M.H.T. is a member of the scientific advisory board of ERX Pharmaceuticals (Cambridge, MA, USA) and was member of the Research Cluster Advisory Panel (ReCAP) and of the scientific advisory board of the Novo Nordisk Foundation. He received funding for his research projects by Novo Nordisk and Sanofi Pharma Germany. He was a consultant for Bionorica SE, Menarini Ricerche S.p.A. and Bayer Pharma AG. As CEO of Helmholtz Zentrum München, M.H.T. has been responsible for collaboration with a multitude of companies and academic institutions, worldwide, including but not limited to Boehringer Ingelheim, Eli Lilly, Novo Nordisk, Medigene, Arbormed, and BioSyngen. He is responsible for commercial technology transfer activities of Helmholtz Center Munich, including diabetes-related patent portfolios, e.g., WO/2016/188932 A2 or WO/2017/194499 A1. M.H.T. confirms that to the best of his knowledge, none of the above funding sources were involved in the preparation of this paper. This declaration acknowledges that this paper adheres to the principles for transparent reporting and scientific rigor of preclinical research recommended by funding agencies, publishers, and other organizations engaged with supporting research.

\section{References}

1. Van Niel, G.; D’Angelo, G.; Raposo, G. Shedding light on the cell biology of extracellular vesicles. Nat. Rev. Mol. Cell Biol. 2018, 19, 213-228. [CrossRef]

2. Rome, S.; Blandin, A.; Le Lay, S. Adipocyte-derived extracellular vesicles: State of the art. Int. J. Mol. Sci. 2021, 22, 1788. [CrossRef]

3. Müller, G. Microvesicles/exosomes as potential novel biomarkers of metabolic diseases. Diabetes Metab. Syndr. Obes. 2012, 5, 247-282. [CrossRef] [PubMed]

4. $\quad$ Durcin, M.; Fleury, A.; Taillebois, E.; Hilairet, G.; Krupova, Z.; Henry, C.; Truchet, S.; Trötzmüller, M.; Köfeler, H.; Mabilleau, G.; et al. Characterization of adipocyte-derived extracellular vesicle subtypes identified distinct protein and lipid signatures for large and small extracellular vesicles. J. Extracell. Vesicles 2017, 6, 1305677. [CrossRef] [PubMed]

5. Haraszti, R.A.; Didiot, M.-C.; Sapp, E.; Leszyk, J.; Shaffer, S.A.; Rockwell, H.E.; Gao, F.; Narain, N.R.; DiFiglia, M.; Kiebish, M.A.; et al. High-resolution proteomic and lipidemic analysis of exosomes and microvesicles from different cell sources. J. Extracell. Vesicles 2016, 5, 32570. [CrossRef]

6. Lakhter, A.J.; Sims, E.K. Emerging roles for extracellular vesicles in diabetes and related metabolic disorders. Mol. Endocrinol. 2015, 29, 1535-1548. [CrossRef]

7. Eisenhaber, B.; Bork, P.; Eisenhaber, B. Post-translational GPI lipid anchor modification of proteins in kingdoms of life: Analysis of protein sequence data from complete genomes. Protein Eng. 2001, 14, 17-25. [CrossRef]

8. Ferguson, M.A.J.; Haldar, K.; Cross, G.A.M. Trypanosoma brucei variant surface glycoprotein has a sn-1,2-dimyristyl glycerol membrane anchor at its COOH terminus. J. Biol. Chem. 1985, 260, 4963-4968. [CrossRef]

9. Haldar, K.; Ferguson, M.A.J.; Cross, G.A.M. Acylation of a Plasmodium falciparum merozoite surface antigen via sn-1,2-diacyl glycerol. J. Biol. Chem. 1985, 260, 4969-4974. [CrossRef]

10. Kinoshita, T.; Fujita, M. Biosynthesis of GPI-anchored proteins: Special emphasis on GPI lipid remodeling. J. Lipid Res. 2016, 57, 6-24. [CrossRef] 
11. Orlean, P.; Menon, A.K. GPI anchoring of protein in yeast and mammalian cells, or: How we learned to stop worrying and love glycophospholipids. J. Lipid Res. 2007, 48, 993-1011.

12. Kinoshita, T.; Fujita, M.; Maeda, Y. Biosynthesis, remodelling and functions of mammalian GPI-anchored proteins: Recent progress. J. Biochem. 2008, 144, 287-294. [CrossRef]

13. Muniz, M.; Riezman, H. Trafficking of glycosylphosphatidylinositol anchored proteins from the endoplasmic reticulum to the cell surface. J. Lipid Res. 2016, 57, 352-360. [CrossRef]

14. Rieu, J.-P.; Ronzon, F.; Place, C.; Dekkiche, F.; Cross, B.; Roux, B. Insertion of GPI-anchored alkaline phosphatase into supported membranes: A combined AFM and fluorescence microscopy study. Acta Biochim. Pol. 2004, 51, 189-197. [CrossRef]

15. Cross, B.; Ronzon, F.; Roux, B.; Rieu, J.-P. Measurement of the anchorage force between GPI-anchored alkaline phosphatase and supported membranes by AFM force spectroscopy. Langmuir 2005, 21, 5149-5153. [CrossRef] [PubMed]

16. Caseli, L.; Masui, D.C.; Furriel, R.P.M.; Leone, F.A.; Zaniquelli, M.E.D.; Orbulescu, J.; Leblanc, R.M. Rat osseous plate alkaline phosphatase as Langmuir monolayer-An infrared study at the air-water interface. J. Colloid Interface Sci. 2008, 320, 476-482. [CrossRef] [PubMed]

17. Kouzayha, A.; Besson, F. GPI-alkaline phosphatase insertion into phosphatidylcholine monolayers: Phase behavior and morphology changes. Biochem. Biophys. Res. Commun. 2005, 333, 1315-1321. [CrossRef]

18. Ronzon, F.; Rieu, J.-P.; Chauvet, J.-P.; Roux, B. A thermodynamic study of GPI-anchored and soluble form of alkaline phosphatase films at the air-water interface. J. Colloid Interface Sci. 2006, 301, 493-502. [CrossRef] [PubMed]

19. Bouma, S.R.; Drislane, F.W.; Huestis, W.H. Selective extraction of membrane-bound proteins by phospholipid vesicles. Circulation 1977, 104, 2649-2652.

20. Medof, M.E.; Kinoshita, T.; Nussenzweig, V. Inhibition of complement activation on the surface of cells after incorporation of decay-accelerating factor (DAF) into their membranes. J. Exp. Med. 1984, 160, 1558-1578. [CrossRef]

21. Premkumar, D.R.D.; Fukuoka, Y.; Sevlever, D.; Brunschwig, E.; Rosenberry, T.L.; Tykocinski, M.L.; Medof, M.E. Properties of exogenously added GPI-anchored proteins following their incorporation into cells. J. Cell. Biochem. 2001, 82, 234-245. [CrossRef]

22. Suzuki, K.; Okumura, Y. Mechanism of selective release of membrane proteins from human erythrocytes in the presence of liposomes. Arch. Biochem. Biophys. 2000, 379, 344-352. [CrossRef]

23. Nakamura, M.; Tsujii, K.; Katsuragi, Y.; Kurihara, K.; Sunamoto, J. Taste receptor proteins directly extracted by liposome from intact epithelium of bullfrog tongue. Biochem. Biophys. Res. Commun. 1994, 201, 415-422. [CrossRef] [PubMed]

24. Okumura, Y.; Ishitobi, M.; Sobel, M.; Akiyoshi, K.; Sunamoto, J. Transfer of membrane proteins from human platelet to liposomal fraction by interaction with liposomes containing an articifical boundary lipid. Biochem. Biophys. Acta 1994, 1194, 335-340. [CrossRef]

25. Kogure, K.; Nakamura, C.; Okuda, O.; Hayashi, K.; Ueno, M. Effect of dicetylphosphate or stearic acid on spontaneous transfer of protein from influenza virus-infected cells to dimyristoylphosphatidylcholine liposomes. Biochim. Biophys. Acta 1997, 1329, 174-182. [CrossRef]

26. Zalman, L.S.; Wood, L.M.; Frank, M.M.; Müller-Eberhard, H.J. Deficiency of the homologous restriction factor in paroxysmal nocturnal hemoglobinuria. J. Exp. Med. 1987, 165, 572-577. [CrossRef]

27. Wilcox, L.A.; Ezzel, J.L.; Bernshaw, N.J.; Parker, C.J. Molecular basis of the enhanced susceptibility of the erythrocytes of paroxysmal nocturnal hemoglobinuria to hemolysis in acidified serum. Blood 1991, 78, 820-829. [CrossRef] [PubMed]

28. Van den Berg, C.W.; Cinek, T.; Hallett, M.B.; Horejsi, V.; Morgan, B.P. Exogenous glycosyl phosphatidylinositol-anchored CD59 associates with kinases in membrane clusters on U937 cells and becomes Ca(2+)-signaling competent. J. Cell Biol. 1995, 131, 669-677. [CrossRef]

29. Müller, G.A. Membrane insertion and intercellular transfer of glycosylphosphatidylinositol-anchored proteins: Potential therapeutic applications. Arch. Physiol. Biochem. 2020, 126, 139-156. [CrossRef]

30. Müller, G.A.; Herling, A.W.; Stemmer, K.; Lechner, A.; Tschöp, M.H. Chip-based sensing for release of unprocessed cell surface proteins in vitro and in serum and its (patho)physiological relevance. Am. J. Physiol. Endocrinol. Metab. 2019, 317, E212-E233. [CrossRef]

31. Müller, G.A.; Ussar, S.; Tschöp, M.H.; Müller, T.D. Age-dependent membrane release and degradation of full-length glycosylphosphatidylinositol-anchored proteins in rats. Mech. Ageing Dev. 2020, 190, 111307. [CrossRef]

32. Müller, G.A.; Lechner, A.; Tschöp, M.H.; Müller, T.D. Interaction of full-length glycosylphosphatidylinositol-anchored proteins with serum proteins and their translocation to cells in vitro depend on the (pre-)diabetic state in rats and humans. Biomedicines 2021, 9, 277. [CrossRef]

33. Müller, G.A.; Tschöp, M.H.; Müller, T.D. Upregulated phospholipase D activity toward glycosylphosphatidylinositol-anchored proteins in micelle-like serum complexes in metabolically deranged rats and humans. Am. J. Physiol. Endocrinol. Metab. 2020, 318, E462-E479. [CrossRef]

34. Harasymiak-Krzyzanowska, I.; Niedojadlo, A.; Karwat, J.; Kotula, L.; Gil-Kulik, P.; Sawiuk, M.; Kocki, J. Adipose tissue-derived stem cells show considerable promise for regenerative medicine applications. Cell. Mol. Biol. Lett. 2013, 18, 479-493. [CrossRef]

35. Bertheuil, N.; Chaput, B.; Menard, C.; Varin, A.; Laloze, J.; Watier, E.; Tarte, K. Adipose mesenchymal stromal cells: Definition, immunomodulatory properties, mechanical isolation and interest for plastic surgery. Ann. Chir. Plast. Esthet. 2019, 64, 1-10. [CrossRef] [PubMed] 
36. Sekler, I.; Lo, R.S.; Kopito, R.R. A conserved glutamate is responsible for ion selectivity and pH dependence of the mammalian anion exchangers AE1 and AE2. J. Biol. Chem. 1995, 270, 28751-28758. [CrossRef] [PubMed]

37. Kiechle, F.L.; Jarett, L.; Kotagal, N.; Popp, D.A. Partial purification from rat adipocyte plasma membranes of a chemical mediator which stimulates the action of insulin on pyruvate dehydrogenase. J. Biol. Chem. 1981, 256, 2945-2951. [CrossRef]

38. Müller, G.; Wetekam, E.; Jung, C.; Bandlow, W. Membrane association of lipoprotein lipase and a cAMP-binding ectoprotein in rat adipocytes. Biochemistry 1994, 33, 12149-12159. [CrossRef] [PubMed]

39. Andrä, J.; Böhling, A.; Gronewold, T.M.A.; Schlecht, U.; Perpeet, M.; Gutsmann, T. Surface acoustic wave biosensor as a tool to study the interaction of antimicrobial peptides with phospholipid and lipopolysaccharide model membranes. Langmuir 2008, 24, 9148-9153. [CrossRef] [PubMed]

40. Huang, K.-S.; Li, S.; Fung, W.-J.C.; Hulmes, J.D.; Reik, L.; Pan, Y.-C.E.; Low, M.G. Purification and characterization of glycosylphosphatidylinositol-specific phospholipase D. J. Biol. Chem. 1990, 265, 17738-17745. [CrossRef]

41. Rigaud, J.L.; Levy, D.; Mosser, G.; Lambert, O. Detergent removal by non-polar polystyrene beads-Applications to membrane protein reconstitution and two-dimensional crystallization. Eur. Biophys. J. 1998, 27, 305-319. [CrossRef]

42. Rigaud, J.L.; Mosser, G.; Lacapere, J.J.; Olofsson, A.; Levy, D.; Ranck, J.L. Bio-Beads: An efficient strategy for two-dimensional crystallization of membrane proteins. J. Struct. Biol. 1997, 118, 226-235. [CrossRef]

43. Morandat, S.; Bortolato, M.; Roux, B. Cholesterol-dependent insertion of glycosylphosphatidyl-anchored enzyme. Biochim. Biophys. Acta 2002, 1564, 473-478. [CrossRef]

44. Bordier, C. Phase separation of integral membrane proteins in Triton X-114 solution. J. Biol. Chem. 1981, 256, 1604-1607. [CrossRef]

45. Gronewold, T.M.A.; Glass, S.; Quandt, E.; Famulok, M. Monitoring complex formation in the blood-coagulation cascade using aptamer-coated SAW sensors. Biosens. Bioelectron. 2005, 20, 2044-2052. [CrossRef] [PubMed]

46. Walter, E.L.; Roberts, W.L.; Rosenberry, T.L.; Ratnoff, W.D.; Medof, M.E. Structural basis for variations in the sensitivity of human decay accelerating factor to phosphatidylinositol-specific phospholipase C cleavage. J. Immunol. 1990, 144, $1030-1036$.

47. Schröter, S.; Derr, P.; Conradt, H.S.; Nimtz, M.; Hale, G.; Kirchhoff, C. Male-specific modification of human CD52. J. Biol. Chem. 1999, 274, 29862-29873. [CrossRef] [PubMed]

48. Wong, Y.W.; Low, M.G. Phospholipase resistance of the glycosyl-phosphatidylinositol membrane anchor on human alkaline phosphatase. Clin. Chem. 1992, 38, 2517-2525. [CrossRef] [PubMed]

49. Raghupathy, R.; Anilkumar, A.A.; Polley, A.; Singh, P.P.; Yadav, M.; Johnson, C.; Suryawanshi, S.; Saikam, V.; Sawant, S.D.; Panda, A.; et al. Transbilayer lipid interactions mediate nanoclustering of lipid-anchored proteins. Cell 2015, 161, 581-594. [CrossRef]

50. Levental, I.; Levental, K.; Heberle, F. Lipid rafts: Controversies resolved, mysteries remain. Trends Cell Biol. 2020, 30, 341-353. [CrossRef] [PubMed]

51. Seong, J.; Wang, Y.; Kinoshita, T.; Maeda, Y. Implications of lipid moiety in oligomerization and immunoreactivities of GPIanchored proteins. J. Lipid Res. 2013, 54, 1077-1091. [CrossRef]

52. Wadehra, M.; Goodglick, L.; Braun, J. The tetraspan protein EMP2 modulates the surface expression of caveolins and glycosylphosphatidyl inositol-linked proteins. Mol. Biol. Cell 2004, 15, 2073-2083. [CrossRef]

53. Väkevä, A.; Jauhiainen, M.; Ehnholm, C.; Lehto, T.; Meri, S. High-density lipoproteins can act a carriers of glycophosphoinositol lipid-anchored CD59 in human plasma. Immunology 1994, 82, 28-33.

54. Gordon, V.M.; Nelson, K.L.; Buckley, J.T.; Stevens, V.L.; Tweten, R.K.; Elwood, P.C.; Leppla, S.H. Clostridium septicum alpha toxin uses glycosylphosphatidylinositol-anchored protein receptors. J. Biol. Chem. 1999, 274, 27274-27280. [CrossRef] [PubMed]

55. Dolezal, S.; Hester, S.; Kirby, P.S.; Nairn, A.; Pierce, M.; Abbott, K.L. Elevated levels of glycosylphosphatidylinositol (GPI) anchored proteins in plasma from human cancers detected by C. septicum alpha toxin. Cancer Biomark. 2014, 14, 55-62. [CrossRef]

56. Giovanni, J.D.; Iborra, C.; Maulet, Y.; Leveque, C.; El Far, O.; Seagar, M. Calcium-dependent regulation of SNARE-mediated membrane fusion of calmodulin. J. Biol. Chem. 2010, 285, 23665-23675. [CrossRef]

57. Burgoyne, R.; Clague, M.J. Calcium and calmodulin in membrane fusion. Biochim. Biophys. Acta 2003, 1641, 137-143. [CrossRef]

58. Müller, G.A. The release of glycosylphosphatidylinositol-anchored proteins from the cell surface. Arch. Biochem. Biophys. 2018, 656, 1-18. [CrossRef]

59. Rooney, I.A.; Heuser, J.E.; Atkinson, J.P. GPI-anchored complement regulatory proteins in seminal plasma. An analysis of their physical condition and the mechanisms of their binding to exogenous cells. J. Clin. Investig. 1996, 97, 1675-1686. [CrossRef] [PubMed]

60. Rabesandratana, H.; Toutant, J.P.; Reggio, H.; Vidal, M. Decay-accelerating factor (CD55) and membrane inhibitor of reactive lysis (CD59) are released within exosomes during In vitro maturation of reticulocytes. Blood 1998, 91, 2573-2580. [CrossRef]

61. Frick, W.; Bauer, A.; Bauer, J.; Wied, S.; Müller, G. Structure-activity relationship of synthetic phosphoinositolglycans mimicking metabolic insulin action. Biochemistry 1998, 37, 13421-13436. [CrossRef] [PubMed]

62. Stieger, S.; Diem, S.; Jakob, A.; Brodbeck, U. Enzymatic properties of phosphatidylinositol-glycan-specific phospholipase C from rat liver and phosphatidylinositol-glycan-specific phospholipase D from rat serum. Eur. J. Biochem. 1991, 197, 67-73. [CrossRef]

63. Li, J.-I.; Hollfelder, K.; Huang, K.-S.; Low, M.G. Structural features of GPI-specific phospholipase D revealed by proteolytic fragmentation and $\mathrm{Ca}^{2+}$ binding studies. J. Biol. Chem. 1994, 269, 28963-28971. [CrossRef]

64. Nagarajan, S.; Anderson, M.; Ahmed, S.N.; Sell, K.W.; Selvaraj, P. Purification and optimization of functional reconstitution on the surface of leukemic cell lines of GPI-anchored Fc gamma receptor III. J. Immunol. Methods 1995, 184, 241-251. [CrossRef] 
65. Zhang, F.; Schmidt, W.G.; Hou, Y.; Williams, A.F.; Jacobson, K. Spontaneous incorporation of the glycosyl-phosphatidylinositollinked protein Thy-1 into cell membranes. Proc. Natl. Acad. Sci. USA 1992, 89, 5231-5235. [CrossRef] [PubMed]

66. Ilangumaran, S.; Arni, S.; Poincelet, M.; Theler, J.M.; Brennan, P.J.; Nasir-ud-Din; Hoessli, D.C. Integration of mycobacterial lipoarabinomannans into glycosylphosphatidylinositol-rich domains of lymphomonocytic cell plasma membranes. J. Immunol. 1995, 155, 1334-1342. [PubMed]

67. Walter, E.I.; Ratnoff, W.D.; Long, K.E.; Kazura, J.W.; Medof, M.E. Effect of glycoinositolphospholipid anchor lipid groups on functional properties of decay-accelerating factor proteins in cells. J. Biol. Chem. 1992, 267, 1245-1252. [CrossRef]

68. Nosjean, O.; Briolay, A.; Roux, B. Mammalian GPI proteins: Sorting, membrane residence and functions. Biochim. Biophys. Acta 1997, 1331, 153-186. [CrossRef]

69. Müller, G.A. Glycosylphosphatidylinositol-Anchored Proteins and Their Release from Cells_From Phenomenon to Meaning, 1st ed.; Nova Science Publishers Inc.: New York, NY, USA, 2018; pp. 39-91.

70. Suzuki, K.; Okumura, Y. GPI-linked proteins do not transfer spontaneously from erythrocytes to liposomes. New aspects of reorganization of the cell membrane. Biochemistry 2000, 39, 9477-9485. [CrossRef]

71. Goding, J.W.; Grobben, B.; Slegers, H. Physiological and pathophysiological functions of the ecto-nucleotide pyrophosphatase/phosphodiesterase family. Biochim. Biophys. Acta 2003, 1638, 1-19. [CrossRef]

72. Zimmermann, H.; Zebisch, M.; Sträter, N. Cellular function and molecular structure of ecto-nucleotidases. Purinergic Signal. 2012, 8, 437-502. [CrossRef] [PubMed]

73. Figler, R.A.; Wang, G.; Srinivasan, S.; Young Jung, D.; Zhang, Z.; Pankow, J.S.; Ravid, K.; Fredholm, B.; Hedrick, C.C.; Rich, S.S.; et al. Links between insulin reistance, adenosine A2B receptors, and inflammatory markers in mice and humans. Diabetes 2011, 60, 669-679. [CrossRef] [PubMed]

74. Burghoff, S.; Flögel, U.; Bongardt, S.; Burkart, V.; Sell, H.; Tucci, S.; Ikels, K.; Eberhard, D.; Kern, M.; Klöting, N.; et al. Deletion of CD73 promotes dyslipidemia and intramyocellular lipid accumulation in muscle of mice. Arch. Physiol. Biochem. 2013, 119, 39-51. [CrossRef] [PubMed]

75. Müller, G.; Wied, S.; Over, S.; Frick, W. Inhibition of lipolysis by palmitate, $\mathrm{H}_{2} \mathrm{O}_{2}$ and the sulfonylurea drug, glimepiride, in rat adipocytes depends on cAMP degradation by lipid droplets. Biochemistry 2008, 47, 1259-1273. [CrossRef] [PubMed]

76. Müller, G.; Jung, C.; Straub, J.; Wied, S.; Kramer, W. Induced release of membrane vesicles and exosomes from rat adipocytes containing lipid droplets, lipid raft and glycosylphosphatidylinositol-anchored proteins. Cell. Signal. 2009, 21, 324-338. [CrossRef] [PubMed]

77. Müller, G.; Jung, C.; Wied, S.; Biemer-Daub, G.; Frick, W. Transfer oft he glycosylphosphatidylinositol-anchored 5'-nucleotidase CD73 from adiposomes into rat adipocytes stimulates lipid synthesis. Br. J. Pharmacol. 2010, 160, 878-891. [CrossRef]

78. Müller, G.; Wied, S.; Dearey, E.A.; Biemer-Daub, G. Glycosylphosphatidylinositol-anchored proteins coordinate lipolysis inhibition between large and small adipocytes. Metabolism 2011, 60, 1021-1037. [CrossRef]

79. Lunkes, D.I.; Lunkes, D.S.; Morsch, V.M.; Mazzanti, C.M.; Morsch, A.L.; Miron, V.R.; Schetinger, M.R. NTPDase and 5'nucelotidase activities in rats with alloxan-induced diabetes. Diabetes Res. Clin. Pract. 2004, 65, 1-6. [CrossRef] [PubMed]

80. Guzman-Flores, J.M.; Cortez-Espinosa, N.; Cortes-Garcia, J.D.; Vargas-Morales, J.M.; Catano-Canizalez, Y.G.; Rodriguez-Rivera, J.G.; Portales-Perez, D.P. Expression of CD73 and A2A receptors in cells from subjects with obesity and type 2 diabetes mellitus. Immunobiology 2015, 220, 976-984. [CrossRef]

81. Oyarzun, C.; Salinas, C.; Gomez, D.; Jaramillo, K.; Perez, G.; Alarcon, S.; Podesta, L.; Flores, C.; Quezada, C.; San Martin, R. Increased levels of adenosine and ecto $5^{\prime}$-nucleotidase (CD73) activity precede renal alterations in experimental diabetic rats. Biochem. Biophys. Res. Commun. 2015, 468, 354-359. [CrossRef]

82. Antonioli, L.; Blandizzi, C.; Csoka, B.; Pacher, P.; Hasko, G. Adenosine signalling in diabetes mellitus-Pathophysiology and therapeutic considerations. Nat. Rev. Endocrinol. 2015, 11, 228-241. [CrossRef]

83. Müller, G.; Schubert, K.; Fiedler, F.; Bandlow, W. The cAMP-binding ectoprotein from Saccharomyces cerevisiae is membraneanchored by glycosylphosphatdylinositol. J. Biol. Chem. 1992, 267, 25337-25346. [CrossRef]

84. Müller, G.; Jung, C.; Wied, S. Translocation of glycosylphosphatidylinositol-anchored proteins from plasma membrane microdomains to lipid droplets in rat adipocytes is induced by palmitate, $\mathrm{H}_{2} \mathrm{O}_{2}$ and the sulfonylurea drug, glimepiride. Mol. Pharmacol. 2008, 73, 1513-1529. [CrossRef]

85. Müller, G. Control of lipid storage and cell size between adipocytes by vesicle-associated glycosylphosphatidylinositol-anchored proteins. Arch. Physiol. Biochem. 2010, 117, 23-43. [CrossRef] [PubMed]

86. Müller, G.; Wied, S.; Jung, C.; Straub, J. Coordinated regulation of esterification and lipolysis by palmitate, $\mathrm{H}_{2} \mathrm{O}_{2}$ and the anti-diabetic sulfonylurea drug, glimepiride, in rat adipocytes. Eur. J. Pharmacol. 2008, 597, 6-18. [CrossRef]

87. Ranscht, B.; Dours-Zimmermann, M.T. T-cadherin, a novel cadherin cell adhesion molecule in the nervous system lacks the conserved cytoplasmic region. Neuron 1991, 7, 391-402. [CrossRef]

88. Hug, C.; Wang, J.; Ahmad, N.S.; Bogan, J.S.; Tsao, T.-S.; Lodish, H.F. T-cadherin is a receptor for hexameric and high-molecularweight forms of Acrp30/adiponectin. Proc. Natl. Acad. Sci. USA 2004, 101, 10308-10313. [CrossRef] [PubMed]

89. Scherer, P.E.; Williams, S.; Fogliano, M.; Baldini, G.; Lodish, H.F. A novel serum protein similar to C1q, produced exclusively in adipocytes. J. Biol. Chem. 1995, 270, 26746-26749. [CrossRef] 
90. Hara, K.; Boutin, P.; Mori, Y.; Tobe, K.; Dina, C.; Yasuda, K.; Yamauchi, T.; Otabe, S.; Okada, T.; Eto, K.; et al. Genetic variation in the gene encoding adiponectin is associated with an increased risk of type 2 diabetes in the Japanese population. Diabetes 2002, 51, 536-540. [CrossRef]

91. Tsao, T.S.; Murrey, H.E.; Hug, C.; Lee, D.H.; Lodish, H.F. Oligomerization state-dependent activation of NF-kappa B signaling pathway by adipocyte complement-related protein of $30 \mathrm{kDa}$ (Acrp30). J. Biol. Chem. 2002, 277, 29359-29362. [CrossRef]

92. Ouchi, N.; Ohishi, M.; Kihara, S.; Funahashi, T.; Nakamura, T.; Nagaretani, H.; Kumada, M.; Ohashi, K.; Okamoto, Y.; Nishizawa, H.; et al. Association of hypoadiponectinemia with impaired vasoreactivity. Hypertension 2003, 42, 231-234. [CrossRef]

93. Yamauchi, T.; Kamon, J.; Minokoshi, Y.; Ito, Y.; Waki, H.; Uchida, S.; Yamashita, S.; Noda, M.; Kita, S.; Ueki, K.; et al. Adiponectin stimulates glucose utilization and fatty-acid oxidation by activating AMP-activated protein kinase. Nat. Med. 2002, 8, 1288-1295. [CrossRef]

94. Filmus, J.; Capurro, M.; Rast, J. Glypicans. Genome Biol. 2008, 9, 224-229. [CrossRef] [PubMed]

95. Fico, A.; Maina, F.; Dono, R. Fine-tuning of cell signaling by glypicans. Cell. Mol. Life Sci. 2011, 68, 923-929. [CrossRef] [PubMed]

96. Ussar, S.; Bezy, O.; Blüher, M.; Kahn, C.R. Glypican-4 enhances insulin signaling via interaction with the insulin receptor and serves as a novel adipokine. Diabetes 2012, 61, 2289-2298. [CrossRef]

97. Brunner, G.; Metzm, C.N.; Nguyen, H.; Gabrilove, J.; Patel, S.R.; Davitz, M.A.; Rifkin, D.B.; Wilson, E.L. An endogenous glycosylphosphatidylinositol-specific phospholipase D releases basic fibroblast growth factor-heparan sulfate proteoglycan complexes from human bone marrow cultures. Blood 1994, 83, 2115-2125. [CrossRef]

98. Traister, A.; Shi, W.; Filmus, J. Mammalian Notum induces the release of glypicans and other GPI-anchored proteins from the cell surface. Biochem. J. 2007, 410, 503-511. [CrossRef] [PubMed]

99. Kurtz, T.A.; Fineberg, N.S.; Considine, R.V.; Deeg, M.A. Insulin resistance is associated with increased serum levels of glycosylphosphatidylinositol-specific phospholipase D. Metabolism 2004, 53, 138-139. [CrossRef]

100. Bowen, R.F.; Raikwar, N.S.; Olson, L.K.; Deeg, M.A. Glucose and insulin regulate glycosylphosphatidylinositol-specific phospholipase D expression in islet beta cells. Metabolism 2001, 50, 1489-1492. [CrossRef]

101. Koszalka, P.; Öküyaman, B.; Huo, Y.; Zernecke, A.; Flögel, U.; Braun, N.; Bucheiser, A.; Decking, U.K.M.; Smith, M.L.; Sevigny, J.; et al. Targeted disruption of $c d 73 /$ ecto5"-nucleotidase alters thromboregulation and augments vascular inflammatory response. Circ. Res. 2004, 95, 814-821. [CrossRef]

102. Xu, X.; Fassett, J.; Hu, X.; Zhu, G.; Lu, Z.; Li, Y.; Schnermann, J.; Bache, R.J.; Chen, Y. Ecto-5'-nucleotidase deficiency exacerbates pressure-overload-induced left ventricular hypertrophy and dysfunction. Hypertension 2008, 51, 1557-1564. [CrossRef]

103. Wang, L.; Fan, J.; Chen, S.; Zhang, Y.; Curiel, T.J.; Zhang, B. Graft-versus-host disease is enhanced by selective CD73 blockade in mice. PLoS ONE 2013, 8, e58397. [CrossRef] [PubMed]

104. Niemelä, J.; Ifergan, I.; Yegutkin, G.G.; Jalkanen, S.; Prat, A.; Airas, L. IFN-ß regulates CD73 and adenosine expression at the blood-brain barrier. Eur. J. Imunol. 2008, 38, 2718-2726. [CrossRef]

105. Tak, E.; Ridyard, D.; Kim, J.H.; Zimmerman, M.; Werner, T.; Wang, X.X.; Shabeka, U.; Seo, S.W.; Christians, U.; Klawitter, J.; et al CD73-dependent generation of adenosine and endothelial Adora2b signaling attenuate diabetic nephropathy. J. Am. Soc. Nephrol. 2014, 25, 547-563. [CrossRef]

106. Varma, R.; Mayor, S. GPI-anchored proteins are organized in submicron domains at the cell surface. Nature 1998, 394, 798-801. [CrossRef]

107. Saha, S.; Anilkumar, A.A.; Mayor, S. GPI-anchored protein organization and dynamics at the cell surface. J. Lipid Res. 2016, 57, 159-175. [CrossRef] [PubMed]

108. Goswami, D.; Gowrishankar, K.; Bilgrami, S.; Ghosh, S.; Raghupathy, R.; Chadda, R.; Vishwakarma, R.; Rao, M.; Mayor, S. Nanoclusters of GPI-anchored proteins are formed by cortical actin-driven activity. Cell 2008, 135, 1085-1097. [CrossRef] [PubMed]

109. Paladino, S.; Lebreton, S.; Tivodar, S.; Formiggini, F.; Ossato, G.; Gratton, E.; Tramier, M.; Coppey-Moisan, M.; Zurzolo, C. Golgi sorting regulates organization and activity of GPI proteins at apical membranes. Nat. Chem. Biol. 2014, 10, 350-357. [CrossRef]

110. Paladino, S.; Lebreton, S.; Lelek, M.; Riccio, P.; De Nicola, S.; Zimmer, C.; Zurzolo, C. GPI-anchored proteins are confined in subdiffraction clusters at the apical surface of polarized epithelial cells. Biochem. J. 2017, 474, 4075-4090. [CrossRef] [PubMed]

111. Koller, E.; Ranscht, B. Differential targeting of T- and N-cadherin in polarized epithelial cells. J. Biol. Chem. 1996, 271, 30061-30067. [CrossRef]

112. Paladino, S.; Pocard, T.; Catino, M.A.; Zurzolo, C. GPI-anchored proteins are directly targeted to the apical surface in fully polarized MDCK cells. J. Cell Biol. 2006, 172, 1023-1034. [CrossRef]

113. Gowrishankar, K.; Ghosh, S.; Saha, S.; Rumamol, C.; Mayor, S.; Rao, M. Active remodeling of cortical actin regulates spatiotemporal organization of cell surface molecules. Cell 2012, 149, 1353-1367. [CrossRef]

114. Paladino, S.; Lebreton, S.; Tivodar, S.; Campana, V.; Tempre, R.; Zurzolo, C. Different GPI-attachment signals affect the oligomerisation of GPI-anchored proteins and their apical sorting. J. Cell Sci. 2008, 121, 4001-4007. [CrossRef]

115. Keller, G.A.; Siegel, M.W.; Caras, I.W. Endocytosis of glycophospholipid-anchored and transmembrane forms of CD4 by different endocytic pathways. EMBO J. 1994, 11, 863-874. [CrossRef]

116. Kodukula, K.; Gerber, L.D.; Amthauer, R.; Brink, L.; Udenfriend, S. Biosynthesis of glycosylphosphatidylinositol (GPI)-anchored membrane proteins in intact cells: Specific amino acid requirements adjacent to the site of cleavage and GPI attachment. J. Cell Biol. 1993, 120, 657-664. [CrossRef] [PubMed] 
117. Medof, M.E.; Nagarajan, S.; Tykocinski, M.L. Cell-surface engineering with GPI-anchored proteins. FASEB J. 1996, 10, 574-586. [CrossRef] [PubMed]

118. Mahmood, A.; Engle, M.J.; Alpers, D.H. Secreted intestinal surfactant-like particles interact with cell membranes and extracellular matrix proteins. J. Physiol. 2002, 542, 237-244. [CrossRef]

119. Eaton, S. Release and trafficking of lipid-linked morphogens. Curr. Opin. Genet. Dev. 2006, 16, 17-22. [CrossRef]

120. Ilangumaran, S.; Robinson, P.J.; Hoessli, D.C. Transfer of exogenous glycosylphosphatidylinositol (GPI)-linked molecules to plasma membranes. Trends Cell Biol. 1996, 6, 163-167. [CrossRef]

121. Wadey, R.M.; Connolly, K.D.; Mathew, D.; Walters, G.; Rees, D.A.; James, P.E. Inflammatory adipocyte-derived extracellular vesicles promote leukocyte attachment to vascular endothelial cells. Atherosclerosis 2019, 283, 19-27. [CrossRef]

122. Sabaratnam, R.; Svenningsen, P. Adipocyte-endothelium crosstalk in obesity. Front. Endocrinol. 2021, 12, 681290. [CrossRef]

123. Kita, S.; Maeda, N.; Shimomura, I. Interorgan communication by exosomes, adipose tissue, and adiponectin in metabolic syndrome. J. Clin. Investig. 2019, 129, 4041-4049. [CrossRef]

124. Crewe, C.; Joffin, N.; Rutkowski, J.M.; Kim, M.; Zhang, F.; Towler, D.A.; Gordillo, R.; Scherer, P.E. An endothelial to adipocyte extracellular vesicle axis governed by metabolic state. Cell 2018, 175, 695-708. [CrossRef]

125. Fivaz, M.; Vilbois, F.; Thurnheer, S.; Pasquali, C.; Abrami, L.; Bickel, P.E.; Parton, R.G.; van der Goot, F.G. Differential sorting and fate of endocytosed GPI-anchored proteins. EMBO J. 2002, 21, 3989-4000. [CrossRef]

126. Cai, B.; Caplan, S.; Naslavsky, N. cPLA2 $\alpha$ and EHD1 interact and regulate the vesiculation of cholesterol-rich, GPI-anchored, protein-containing endosomes. Mol. Biol. Cell 2012, 23, 1874-1888. [CrossRef]

127. Polishchuk, R.; Di Pentima, A.; Lippincott-Schwartz, J. Delivery of raft-associated, GPI-anchored proteins to the apical surface of polarized MDCK cells by a transcytotic pathway. Nat. Cell Biol. 2004, 6, 297-307. [CrossRef]

128. Sabharanjak, S.; Sharma, P.; Parton, R.G.; Mayor, S. GPI-anchored proteins are delivered to recycling endosomes via a distinct cdc42-regulated, clathrin-independent pinocytic pathway. Dev. Cell 2002, 2, 411-423. [CrossRef]

129. Hudrisier, D.; Joly, E. Plasma membrane nibbling: All lymphocytes do it, but why? ELSO Gaz. 2002, 9, 1-5.

130. Stinchcombe, J.C.; Bossi, G.; Booth, S.; Griffiths, G.M. The immunological synapse of CTL contains a secretory domain and membrane bridges. Immunity 2001, 15, 751-761. [CrossRef]

131. Charpentier, J.C.; King, P.D. Mechanisms and functions of endocytosis in T cells. Cell Commun. Signal. 2021, 19, 92. [CrossRef] 